Leitlinien

Z Rheumatol $2020 \cdot 79$ (Suppl 3):S67-S95 https://doi.org/10.1007/s00393-020-00893-1

(c) Deutsche Gesellschaft für Rheumatologie e.V. Published by Springer Medizin Verlag $\mathrm{GmbH}$. All rights reserved 2020

J. H. Schirmer' $\cdot$ P. M. Aries ${ }^{2} \cdot$ K. Balzer ${ }^{3}$ P. Berlit ${ }^{4}$ T. A. Bley ${ }^{5} \cdot$ F. Buttgereit ${ }^{6} \cdot$ M. Czihal ${ }^{7} \cdot$ C. Dechant ${ }^{8} \cdot$ C. Dejaco ${ }^{9} \cdot$ U. Garske ${ }^{10} \cdot$ J. Henes $^{11} \cdot$ J. U. Holle ${ }^{12} \cdot$ K. Holl-

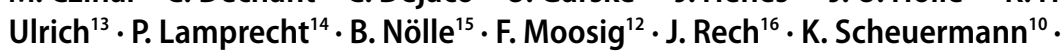
M. Schmalzing ${ }^{17} \cdot$ W. A. Schmidt ${ }^{18} \cdot$ M. Schneider ${ }^{19} \cdot$ H. Schulze-Koops ${ }^{8}$.

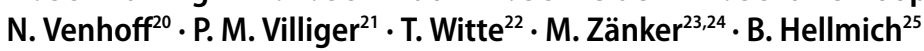

${ }^{1}$ Klinik für Innere Medizin I, Sektion Rheumatologie, Exzellenzzentrum Entzündungsmedizin, Universitätsklinikum Schleswig-Holstein, Campus Kiel, Kiel, Deutschland; ${ }^{2}$ Rheumatologie im Struenseehaus, Hamburg, Deutschland; ${ }^{3}$ Abteilung für Gefäß- und Endovaskulärchirurgie, St. Marien Hospital, GFO Kliniken Bonn, Bonn, Deutschland; ${ }^{4}$ Deutsche Gesellschaft für Neurologie, Berlin, Deutschland; ${ }^{5}$ Institut für Diagnostische und Interventionelle Radiologie, Universitätsklinikum Würzburg, Würzburg, Deutschland; ${ }^{6}$ Medizinische Klinik mit Schwerpunkt Rheumatologie und Klinische Immunologie (CCM), Charité Universitätsmedizin Berlin, Berlin, Deutschland; ${ }^{7}$ Sektion Angiologie Gefäßzentrum, Medizinische Klinik und Poliklinik IV, Klinikum der Universität München, München, Deutschland; ${ }^{8}$ Sektion Rheumatologie und klinische Immunologie, Medizinische Klinik und Poliklinik IV, Klinikum der Universität München, München, Deutschland; ${ }^{9}$ Klinische Abteilung für Rheumatologie und Immunologie, Medizinische Universität Graz, Landesweiter Dienst für Rheumatologie, Südtiroler Sanitätsbetrieb, Graz, Österreich; ${ }^{10}$ Deutsche Rheuma-Liga Bundesverband e. V., Bonn, Deutschland;

${ }^{11}$ Medizinische Klinik II, Rheumatologie, Universitätsklinikum Tübingen, Tübingen, Deutschland; ${ }^{12}$ Rheumazentrum Schleswig-Holstein Mitte, Neumünster, Deutschland; ${ }^{13}$ Pathologie - Hamburg, Labor Lademannbogen MVZ, Hamburg, Deutschland; ${ }^{14} \mathrm{Klinik}$ für Rheumatologie und klinische Immunologie, Universität zu Lübeck, Lübeck, Deutschland; ${ }^{15}$ Klinik für Ophthalmologie, Universitätsklinikum SchleswigHolstein, Campus Kiel, Kiel, Deutschland; ${ }^{16}$ Medizinische Klinik 3, Rheumatologie und Immunologie, Universitätsklinikum Erlangen, Erlangen, Deutschland; ${ }^{17}$ Medizinische Klinik II, Rheumatologie/Klinische Immunologie, Universitätsklinikum Würzburg, Würzburg, Deutschland; ${ }^{18}$ Rheumatologie und klinische Immunologie, Immanuel Krankenhaus Berlin-Buch, Berlin, Deutschland; ${ }^{99}$ Poliklinik und Funktionsbereich für Rheumatologie, Universitätsklinikum Düsseldorf, Düsseldorf, Deutschland; ${ }^{20}$ Klinik für Rheumatologie und klinische Immunologie, Vaskulitis-Zentrum Freiburg, Department Innere Medizin,

Universitätsklinikum Freiburg, Medizinische Fakultät, Albert-Ludwigs-Universität Freiburg, Freiburg, Deutschland; ${ }^{21}$ Universitätsklinik für Rheumatologie, Immunologie und Allergologie, Inselspital, Bern, Schweiz; ${ }^{22}$ Klinik für Immunologie und Rheumatologie, Medizinische Hochschule Hannover, Hannover, Deutschland; ${ }^{23}$ Abteilung für Innere Medizin, Immanuel Klinikum Bernau Herzzentrum Brandenburg, Bernau, Deutschland; ${ }^{24}$ Medizinische Hochschule Brandenburg, Neuruppin, Deutschland; ${ }^{25}$ Klinik für Innere Medizin, Rheumatologie und Immunologie, Vaskulitiszentrum Süd, Medius Klinik, Kirchheim unter Teck, Deutschland

\title{
S2k-Leitlinie: Management der Großgefäßvaskulitiden
}

\section{Begründung für die Erstellung der Leitlinie}

Die rasche Diagnostik und Therapie der Großgefäßvaskulitiden (GGV) sind von großer Wichtigkeit, da es durch Gefäßverschlüsse und Aneurysmen zu schwerwiegenden Komplikationen kommen kann (z. B. Erblindung, zerebrale oder Extremitätenischämie) [131, 224]. Trotz einer Standardtherapie mit Glukokortikoiden (GC) kommt es bei einem erheblichen Teil der Betroffenen zu Rezidiven der Erkrankung, und bei Subgruppen ist die Mortalität erhöht [50, 96, 131]. Darüber hinaus verursachen GC häufig Komorbiditäten [209, 270].
Wachsende Erkenntnisse zu Diagnostik (insbesondere bildgebende Verfahren) und Therapie der GGV ermöglichen inzwischen differenziertere und effektivere Therapiestrategien unter Verwendung GC-sparender Substanzen einschließlich Biologika. Akutsprechstunden sichern eine rasche Diagnostik und Therapie und reduzieren damit das Auftreten eines akuten Visusverlustes als Komplikation der Riesenzellarteriitis (RZA) $[68,206]$.

Abgesehen von einer S1-Leitlinie zur zerebralen Vaskulitis [23], in der auch GGV berücksichtigt werden, sind bis dato keine evidenzbasierten Leitlinien für GGV in deutscher Sprache verfügbar. 


\section{Zusatzmaterial online}

Die Online-Version dieses Beitrags (https:// doi.org/10.1007/s00393-020-00893-1) enthält weitere Inhalte zur Leitlinie. Zusatzmaterial:

- Kurzfassung der Leitlinie, publiziert in der Zeitschrift für Rheumatologie, Heft 9/2020; https://doi.org/10.1007/s00393-02000894-0;

- Leitlinienreport.

Beitrag und Zusatzmaterial stehen Ihnen auf www.springermedizin.de zur Verfügung. Bitte geben Sie dort den Beitragstitel in die Suche ein, das Zusatzmaterial finden Sie beim Beitrag unter „Ergänzende Inhalte“.

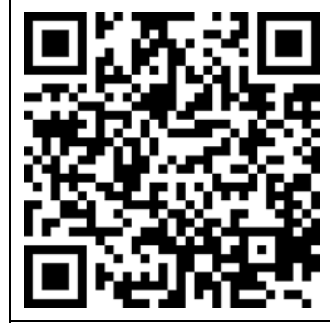

Die vorliegende Leitlinie thematisiert das Management der GGV umfassend und verfolgt dafür einen interdisziplinären Ansatz unter Einbezug zahlreicher am Management der GGV beteiligter Fachdisziplinen.

Die Leitlinie wurde unter Berücksichtigung anderer $\mathrm{zu}$ diesem Thema publizierter Leitlinien wie den aktualisierten Empfehlungen der European League Against Rheumatism (EULAR) zum Management der GGV [102] und den EULAR-Empfehlungen zur Bildgebung bei GGV in der klinischen Praxis erstellt [63]. Obwohl die Polymyalgia rheumatica (PMR) ein häufiges Symptom der RZA darstellt, wird das Management der isolierten (nicht mit einer RZA assoziierten) PMR nicht in dieser Leitlinie behandelt. Hierzu verweisen wir auf die nationalen und internationalen Leitlinien zur Behandlung der PMR $[40,64]$.

\section{Definition}

GGV sind Systemerkrankungen, die sich durch eine Entzündung hauptsächlich der großen arteriellen Gefäße manifestieren [122], d. h. im Bereich der Aorta und der von ihr abgehenden Arterien. $\mathrm{Zu}$ den GGV zählen die RZA
Infobox AWMF - Registernummer: 060-007

Klassifikation: S2k

https://www.awmf.org/leitlinien/detail/ll/ 060-007.html

Besonderer Hinweis:

Die Medizin unterliegt einem fortwährenden Entwicklungsprozess, sodass alle Angaben, insbesondere zu therapeutischen Verfahren, immer nur dem Wissenstand zur Zeit der Drucklegung der Leitlinie entsprechen können. Hinsichtlich der angegebenen Empfehlungen zur Therapie wurde die größtmögliche Sorgfalt beachtet.

Die Benutzer selbst bleiben verantwortlich für jede diagnostische und therapeutische Applikation, Medikation und Dosierung.

und die Takayasu-Arteriitis (TAK). Ihre Definitionen gemäß der Chapel HillKonsensuskonferenz sind in - Tab. 1 dargestellt.

Eine Vielzahl weiterer Erkrankungen kann mit einer Vaskulitis der großen Gefäße einhergehen. Hier sind z. B. die idiopathische Aortitis, inflammatorische Aortenaneurysmen (z.B. im Rahmen einer idiopathischen oder IgG4-assoziierten Periaortitis), Morbus Behçet oder das Cogan-Syndrom zu nennen [76, 122, 135]. Eine sichere Abgrenzung z. B. einer idiopathischen Aortitis von einer TAK oder einer extrakraniellen RZA ist nicht immer möglich. Es ist nicht Ziel dieser Leitlinie, über die Behandlung von RZA und TAK hinaus gesonderte Therapieempfehlungen für die Diagnostik und Behandlung dieser weiteren Erkrankungen mit Vaskulitis der großen Gefäße abzugeben. Deren medikamentöse Therapie erfolgt in der Regel nach aktuellen Empfehlungen der Therapie der korrespondierenden Systemerkrankung [38, 97].

\section{Epidemiologie}

Die RZA betrifft häufiger Frauen als Männer im Alter von $\geq 50$ Jahren. In Europa ist sie in dieser Altersgruppe die häufigste idiopathische Vaskulitis [90, 103]. Daten aus einer vergleichbaren Bevölkerung (Olmsted County, Minnesota, USA) zeigen ein Lebenszeitrisiko, an einer RZA zu erkranken, für Frauen von ca. $1 \%$ und für Männer von ca. 0,5\% [55].
An der im Vergleich zur RZA im europäischen Raum selteneren TAK (Inzidenz ca. 1 pro Million Einwohner) erkranken überwiegend junge Frauen ( $<50$ Jahre, oft im Alter zwischen 20 und 30 Jahren). Der Einfluss unterschiedlicher Umweltfaktoren und prädisponierender genetischer Faktoren in der Pathogenese beider Erkrankungen wird in den weltweit regional differierenden Inzidenz- und Prävalenzzahlen erkennbar. Die TAK ist in Japan häufiger als in Europa und den USA, wohingegen die RZA in Japan seltener ist verglichen mit Europa und den USA [19, 203, 266].

\section{Adressaten und Ziele der Leitlinie}

Diese Leitlinie richtet sich an alle in der Diagnostik und Behandlung der GGV (und häufig assoziierter Komplikationen und Begleiterkrankungen) beteiligten Personengruppen wie ärztliches und Pflegepersonal und soll als Informationsquelle und Leitfaden in der stationären und ambulanten Versorgung an GGV Erkrankter dienen. Zielgruppe sind einerseits Behandelnde in der Rheumatologie und anderen an der Erstellung der Leitlinie mitwirkenden Disziplinen, die an der spezialfachärztlichen Versorgung von GGV beteiligt sind, darunter die Angiologie, Gefäßchirurgie, innere Medizin, Neurologie, Ophthalmologie, Pathologie und Radiologie. Andererseits dient die Leitlinie zur Information für andere Fachdisziplinen (u.a. Nuklearmedizin, Labormedizin, physikalische und rehabilitative Medizin) und die hausärztliche und allgemeine Versorgung (u.a. Allgemeinmedizin, Geriatrie; z. B. zur Früherkennung, Zuweisung und Frühdiagnostik).

Die Leitlinie soll, basierend auf der verfügbaren Evidenz, als Entscheidungshilfe bei der Diagnose, Therapie und Langzeitbetreuung an GGV Erkrankter dienen. Die Leitlinie gilt für alle Erwachsenen mit dem Verdacht oder Nachweis einer RZA oder TAK. 
Tab. 1 Revidierte Definitionen von RZA und TAK nach der Chapel Hill-Konsensuskonferenz (CHCC) von 2012 [122]

\begin{tabular}{ll} 
Name & Definition \\
\hline $\begin{array}{l}\text { Großgefäß- } \\
\text { vaskulitis } \\
\text { (GGV) }\end{array}$ & $\begin{array}{l}\text { Vaskulitis, welche die großen Arterien häufiger betrifft als andere Vaskulitiden. } \\
\text { Große Arterien sind die Aorta und ihre großen Äste. Arterien jeder Größe können } \\
\text { betroffen sein. }\end{array}$ \\
$\begin{array}{l}\text { Riesenzell- } \\
\text { arteriitis } \\
\text { (RZA) }\end{array}$ & $\begin{array}{l}\text { Arteriitis, häufig granulomatös, meist die Aorta und/oder ihre großen Äste be- } \\
\text { treffend, mit einer Prädilektion für die Äste der Karotiden und Vertebralarterien. } \\
\text { Betrifft häufig die Temporalarterie. Beginn meistens bei Patient(inn)en, die älter } \\
\text { als } 50 \text { Jahre sind und häufig assoziiert mit Polymyalgia rheumatica. }\end{array}$ \\
$\begin{array}{l}\text { Takayasu- } \\
\text { Arteriitis } \\
\text { (TAK) }\end{array}$ & $\begin{array}{l}\text { Arteriitis, häufig granulomatös, hauptsächlich die Aorta und/oder ihre großen } \\
\text { Äste betreffend. Beginn meistens bei Patient(inn)en, die jünger als } 50 \text { Jahre sind. }\end{array}$
\end{tabular}

\section{Methodik}

\section{Systematik und beteiligte Fachgesellschaften}

Die Erstellung der Leitlinie folgt der Systematik der Arbeitsgemeinschaft der wissenschaftlichen medizinischen Fachgesellschaften (AWMF, https://www. awmf.org/leitlinien/awmf-regelwerk. html) durch eine strukturierte Erarbeitung von Fragestellungen und Konsensfindung auf dem Boden der verfügbaren Literatur. Das methodische Vorgehen ist im Leitlinienreport $\mathrm{zu}$ dieser Leitlinie ausführlich beschrieben.

Die Erstellung wurde unter Federführung der Deutschen Gesellschaft für Rheumatologie (DGRh) und unter Beteiligung von Experten aus für die Thematik relevanten Fachgesellschaften realisiert. Beteiligt sind neben der DGRh der Berufsverband Deutscher Pathologen e.V., die Deutsche Gesellschaft für Angiologie - Gesellschaft für Gefäßmedizin e. V. (DGA), Deutsche Gesellschaft für Gefäßchirurgie und Gefäßmedizin - Gesellschaft für operative, endovaskuläre und präventive Gefäßmedizin e.V. (DGG), Deutsche Gesellschaft für Innere Medizin (DGIM), Deutsche Gesellschaft für Neurologie (DGN), Deutsche Gesellschaft für Pathologie (DGP), Deutsche Ophthalmologische Gesellschaft (DOG), Deutsche Röntgengesellschaft e. V. (DRG), Österreichische Gesellschaft für Rheumatologie und Rehabilitation (ÖGR), Schweizerische Gesellschaft für Rheumatologie (SGR) sowie 2 Patientenvertreterinnen der Deutschen RheumaLiga Bundesverband e.V.. Die Deutsche Gesellschaft für Allgemeinmedizin und Familienmedizin (DEGAM) wurde ebenfalls zur Teilnahme am Leitlinienprojekt eingeladen, war jedoch aus Kapazitätsgründen nicht in der Lage, ein Mitglied für die Leitlinienkommission $\mathrm{zu}$ entsenden.

\section{Übergeordnete Prinzipien}

\section{Übergeordnetes Prinzip A (starker Konsens)}

Die Versorgung der an Großgefäßvaskulitiden Erkrankten soll auf einer gemeinsamen Entscheidung zwischen den Erkrankten und Behandelnden unter Berücksichtigung von Wirksamkeit, Sicherheit und Wirtschaftlichkeit beruhen.

\section{Übergeordnetes Prinzip B (starker Konsens)}

An Großgefäßvaskulitiden Erkrankte sollten Zugang zu Informationen über ihre Erkrankung, insbesondere zu den Auswirkungen der Großgefäßvaskulitiden, ihren wichtigsten Warnsymptomen und ihrer Behandlung (einschließlich behandlungsbedingter Komplikationen) erhalten sowie auf die Möglichkeit zur Teilnahme an Selbsthilfegruppen aufmerksam gemacht werden.

An GGV Erkrankte profitieren von einer konsequenten Schulung hinsichtlich der Symptome ihrer Erkrankung und im Umgang mit den verordneten Therapien. Die Entscheidung über diagnostische und therapeutische Maßnahmen wird gemeinsam mit den Betroffenen im Sinne eines „shared decision making“ getroffen. Bei älteren an GGV Erkrankten, bei denen demenzielle Entwicklung und Gebrechlichkeit relevante Komorbiditäten darstellen, ist es besonders bedeutsam, mit Einverständnis der Betroffenen Angehörige in Schulung und Therapiekonzept mit einzubeziehen.

\section{Übergeordnetes Prinzip C (starker Konsens)}

Ziele der Behandlung sind die Verhinderung akuter und später Komplikationen durch die Großgefäßvaskulitiden bzw. durch die Toxizität der medikamentösen Therapie, die Reduktion der Mortalität sowie der Erhalt und die Verbesserung der Lebensqualität an Großgefäßvaskulitiden Erkrankter.

Außer der plötzlichen Erblindung als bedeutsamster Frühkomplikation bei RZA kann es durch die GGV zu multiplen weiteren entzündlich bedingten Komplikationen der Gefäße kommen, hierunter insbesondere zerebrale und Extremitätenischämien, und als wichtige Spätkomplikation Aneurysmen mit der Gefahr von Dissektionen und Ruptur (hier besteht z.B. bei einer Subgruppe der RZA eine erhöhte Mortalität) [131, 224]. Gleichermaßen besteht ein hohes Risiko insbesondere für GC-assoziierte Komplikationen und Infektionen unter immunsuppressiver Therapie [44, 209].

Mehrere Studien kommen zu dem Ergebnis, dass die Lebensqualität an GGV Erkrankter in physischen und psychischen Bereichen signifikant reduziert ist verglichen mit gleichaltrigen Gesunden, aber auch mit diversen Gleichaltrigen mit anderen chronischen Erkrankungen (z.B. Diabetes mellitus, koronare Herzerkrankung) [2, 202, 277]. Die Lebensqualität wird aus Sicht der Betroffenen durch die Angst vor Visusverlust und anderen ischämischen Komplikationen sowie vor Nebenwirkungen der GC-Therapie bestimmt. Sie gleicht sich gesunden Kontrollen an, wenn eine anhaltende Remission unter niedrig dosierten oder ausgeschlichenen GC erreicht werden kann [124]. 


\section{Übergeordnetes Prinzip D (starker Konsens)}

\section{An Großgefäßvaskulitiden Erkrankte sollen auf durch die Behandlung beein- flusste (einschließlich kardiovaskulärer) Komorbiditäten untersucht werden. Um das kardiovaskuläre Risiko und behand- lungsbedingte Komplikationen zu ver- ringern, sollten Lebensstilberatung und Maßnahmen der Prävention und me- dikamentösen Prophylaxe angeboten werden.}

Bei GGV bestehen häufig Komorbiditäten. Einige davon können durch eine GC-Therapie aggraviert oder induziert werden. $\mathrm{Zu}$ den häufigsten GC-assoziierten Komplikationen gehören die Entstehung oder Aggravierung bereits bestehender Infektionserkrankungen, kardiovaskuläre Ereignisse, arterielle Hypertonie, Diabetes mellitus, Osteoporose, Gewichtszunahme, Glaukom, Katarakt und Nebennierenrindeninsuffizienz [39, 71, 121, 209, 255]. Bei Beginn einer GCTherapie wird deren Vorhandensein oder ein anzunehmendes Risiko für ihre Entwicklung üblicherweise mit erhoben und in das Therapiekonzept einbezogen (z. B. früher Beginn einer GC-einsparenden Therapie). Informationen über Vermeidung therapiebedingter Komorbiditäten sind integraler Bestandteil von Schulungen für an GGV Erkrankte [104].

\section{Infektionen und Impfungen}

Das Risiko von schwerwiegenden Infektionen ist insbesondere bei an RZA Erkrankten unter höheren GC-Dosen erhöht und mit einer erhöhten Mortalität assoziiert [234, 270, 271]. Für Empfehlungen zur Aktualisierung des Impfstatus verweisen wir auf die internationalen Empfehlungen der EULAR für entzündlich rheumatische Erkrankungen und die jeweils aktualisierten Empfehlungen der national zuständigen Institutionen (unter immunsuppressiver Therapie können Besonderheiten wie mögliche Kontraindikationen für Lebendimpfstoffe zu beachten sein) [16]. Vor Beginn immunsuppressiver Therapien ist der Ausschluss der jeweils substanzspezifischen Kontraindikatio- nen oder besonders $\mathrm{zu}$ beachtender Komorbiditäten in der klinischen Routine etabliert (z.B. Niereninsuffizienz bei MTX und der Ausschluss von chronischen Virushepatitiden und latenter Tuberkulose vor Biologikatherapien). Bei Vorliegen relevanter Komorbiditäten können spezifische Maßnahmen oder die Auswahl einer anderen immunsuppressiven Therapie notwendig werden (u. a. Antibiotikaprophylaxen z. B. mit Isoniazid bei latenter Tuberkulose) [72, 268]. Personen unter medikamentöser Immunsuppression werden üblicherweise in der Routineversorgung hinsichtlich des Auftretens von therapieassoziierten Infektionen klinisch und mittels Laborkontrollen überwacht und im Falle des Auftretens einer Infektion ggf. frühzeitig antiinfektiv behandelt [66]. Trotz relevanter Risikofaktoren (hohes Alter, GCTherapie) finden sich in der Literatur nur wenige Berichte von Pneumocystisjirovecii-Pneumonien bei an GGV Erkrankten. Die in 2 retrospektiven Fallserien berichteten Fälle traten bei höherer GC-Dosis $(>30 \mathrm{mg} / \mathrm{Tag})$ und niedriger Lymphozytenzahl auf und waren mit erhöhter Mortalität assoziiert [21, 133]. Es liegen positive Erfahrungen zum Einsatz medikamentöser Chemoprophylaxen bei z.B. Granulomatose mit Polyangiitis (Wegener) vor [49, 205]. Der Nutzen einer medikamentösen Chemoprophylaxe (z. B. Trimethoprim/Sulfamethoxazol $960 \mathrm{mg}$ 3-mal wöchentlich) ist für die GGV bisher nicht untersucht, sodass derzeit keine Empfehlung für oder gegen einen Einsatz einer PJP-Prophylaxe bei den GGV ausgesprochen werden kann.

\section{Kardiovaskuläres Risiko-} management und Diabetes mellitus

Kardiovaskuläre Ereignisse sind bei einer Subgruppe (Beteiligung der Aorta) von Betroffenen mit RZA mitursächlich für eine erhöhte Mortalität [75, 131, 261]. GC-Therapien können das Risiko kardiovaskulärer Ereignisse erhöhen (insbesondere wenn bereits ein kardiovaskuläres Risikoprofil vorhanden ist) und zu einer Verschlechterung eines Diabetes mellitus führen, weshalb Diagnostik und Thera- pie kardiovaskulärer Risikofaktoren inklusive eines Diabetes mellitus Teil eines supportiven Therapiekonzeptes bei GGV sind [211, 255].

\section{Osteoporose}

Zur Prävention, Diagnostik und Therapie der Osteoporose wird auf die Leitlinie des Dachverbandes Osteologie (DVO) verwiesen, insbesondere auf Maßnahmen zur Prophylaxe von Osteoporose und Frakturen (z.B. Empfehlungen zu körperlicher Aktivität und Sturzprophylaxe sowie Prüfung der Medikation und zu Lebensstil und Ernährung inklusive Indikationen zur ausreichenden Versorgung mit Kalzium und Vitamin D, Gewichtsoptimierung, Nikotinverzicht), zur Diagnostik (abhängig von Alter und klinischem Gesamtkontext inklusive systemischer GC-Therapie, Prüfung der Indikationsstellung einer osteologischen Basisdiagnostik inklusive einer Knochendichtemessung) und $\mathrm{zu}$ medikamentöser Therapie [59].

\section{Weitere Glukokortikoid-assoziierte Komorbiditäten}

Zum Umgang mit diversen weiteren GCassoziierten Komorbiditäten (z. B. Glaukom, Katarakt u. v. m.) verweisen wir auf die Empfehlungen der EULAR [71, 255].

\section{Spezifische Empfehlungen}

\section{Zeitpunkt von Diagnosestellung und Therapiebeginn}

\section{Empfehlung 1a (starker Konsens)}

Bei Verdacht auf eine Riesenzellarteriitis sollte umgehend eine Vorstellung bei einem auf die interdisziplinäre Diagnostik und Therapie von Großgefäßvaskulitiden spezialisierten Team erfolgen. Auch bei Verdacht auf eine Takayasu-Arteriitis sollten Diagnostik und Therapie durch ein spezialisiertes Team erfolgen, bei drohender ischämischer Komplikation ebenfalls umgehend. 
Tab. 2 Typische Symptome und Befunde der RZA und TAK (modifiziert, orientiert an [102])

\section{Riesenzellarteriitis}

Alter (bei Erstmanifestation) $\geq 50$ Jahre

Erhöhte serologische Entzündungsparameter (CRP/BSG)

Neu aufgetretene anhaltende Cephalgien, oft temporal

Veränderungen der Temporalarterien (Schwellung, Verhärtung, abgeschwächter Puls, Druckschmerzhaftigkeit)

B-Symptomatik (Fieber, Gewichtsverlust, Nachtschweiß)

Polymyalgia rheumatica (insbesondere auf GC-Standarddosen refraktäre Polymyalgie)

Transiente oder permanente Sehstörungen (Amaurosis fugax, Diplopie, akuter Visusverlust bis zur ein- oder beidseitigen Erblindung)

Kieferclaudicatio

Berührungsempfindlichkeit der Kopfhaut (z. B. Kämmschmerzen)

Claudicatio der Extremitäten, insbesondere obere Extremitäten

Pulsverlust/Blutdruckseitendifferenz der oberen Extremitäten

Selten

Kopfhaut- und Zungennekrosen

Symptome einer zerebralen Ischämie, insbesondere hintere Strombahn

Symptome sonstiger Organischämien (Myokard, Niere, Darm)

Symptome einer Aortendissektion bzw. -ruptur als Erstmanifestation

\section{Empfehlung $\mathbf{1 b}$ (starker Konsens)}

Bei begründetem Verdacht auf eine Riesenzellarteriitis soll umgehend eine Glukokortikoidtherapie begonnen werden. Nicht sofort zur Verfügung stehende Diagnostik soll den Beginn einer Glukokortikoidtherapie bei Verdacht auf Riesenzellarteriitis nicht verzögern. Bestätigt sich der Verdacht auf das Vorliegen einer Riesenzellarteriitis nach abgeschlossener sorgfältiger Abklärung nicht, soll die begonnene Glukokortikoidtherapie unter Überwachung rasch beendet werden.

Bei neu aufgetretener RZA besteht ein erhebliches Risiko einer plötzlichen Erblindung, die meist durch eine anteriore ischämische Optikusneuropathie
Takayasu-Arteriitis

Alter (bei Erstmanifestation) $<50$ Jahre

Erhöhte serologische Entzündungsparameter (CRP/BSG)

B-Symptomatik (Fieber, Gewichtsverlust, Nachtschweiß)

Neu aufgetretene Symptome oder Verschlechterung von Symptomen einer Extremitätenminderperfusion (Claudicatio intermittens, Subclavian-steal-Syndrom) insbesondere der oberen Extremität

Pulsverlust/Blutdruckseitendifferenz der oberen Extremitäten

Karotidynie

Symptome einer zerebralen oder okulären Ischämie

Symptome sonstiger Organischämien (Myokard, Niere, Darm), insbesondere renovaskuläre Hypertonie

(AION) verursacht ist. Dieses kann durch eine sofortige GC-Therapie deutlich gesenkt werden [110]. Ein persistierender Visusverlust (Visusreduktion, Gesichtsfeldausfall oder vollständige Erblindung; ein- oder beidseitig) tritt auch heutzutage noch bei einem nicht unerheblichen Anteil der Fälle von RZA auf. Der Anteil permanenter Visusverluste bei der RZA reicht in den größeren Studien von ca. 6 bis $37 \%$ (in einer Studie ca. $8 \%$ vollständige ein- oder beidseitige Erblindung) [78, $88,110,206,224,276]$. Die unterschiedliche Prävalenz lässt sich möglicherweise durch die unterschiedlichen Kollektive in den Studien erklären (z. B. rheumatologische vs. ophthalmologische Kohorten, unterschiedliche verwendete Einschlusskriterien, unterschiedliche Definitionen permanenter visueller Symptome von Vi- susverschlechterung bis zur vollständigen Erblindung). Zu persistierendem Visusverlust bis zur Erblindung kommt es in aller Regel vor der Therapieeinleitung, während es nach Therapiebeginn mit GC nur noch selten zu einem frühen, akuten und persistierenden Visusverlust kommt $[88,110,224]$. Der Verdacht auf das Neuauftreten einer RZA erfordert daher eine umgehende Diagnostik und Therapie (typische Symptome in - Tab.2). Es konnte belegt werden, dass die Einrichtung sog. Fast-Track-Sprechstunden, in denen bei Verdacht auf RZA binnen $24 \mathrm{~h}$ eine fachspezifische Abklärung inklusive Ultraschalldiagnostik zumindest der Temporal- und Axillararterien erfolgt und die Therapie entsprechend früher eingeleitet wird, das Risiko einer Erblindung ebenso wie die notwendige Dauer einer stationären Behandlung signifikant reduzieren kann $[68,206]$. Die Empfehlung zur Diagnostik und Therapie durch in der Versorgung von GGV erfahrene interdisziplinäre Teams begründet sich dadurch, dass diesen alle erforderlichen diagnostischen Methoden einschließlich der unten genannten bildgebenden Verfahren in der Regel zeitnah zur Verfügung stehen und sie über ausreichende Expertise im Einsatz dieser Methoden und in der Versorgung von GGV verfügen.

In der täglichen Praxis kann sich die Zuweisung bei hochgradigem Verdacht auf eine RZA zu einem der oben beschriebenen Teams aus diversen Gründen verzögern. Kann keine umgehende Vorstellung des Patienten zur Diagnostik realisiert werden, ist bei begründetem Verdacht auf eine RZA (z. B. typische klinische Konstellation in Verbindung mit einer Erhöhung von BSG/CRP) dennoch eine sofortige Behandlung mit GC notwendig, um das Risiko einer Erblindung zu minimieren. Insbesondere bei Visusstörungen (und RZA-Verdacht) ist ein unmittelbarer Beginn der Therapie unabhängig vom Zeitraum bis zur diagnostischen Sicherung notwendig (s. Empfehlungen $3 \mathrm{a}$ und $\mathrm{d}$ ). Unter einer solchen präemptiven GC-Therapie sinkt die Sensitivität der diagnostischen Verfahren rasch ab $[98,159]$. Dies erfordert, dass diese diagnostischen Verfahren nach Einleitung einer GC-Therapie schnellst- 
Tab. 3 Auswahl klinischer Untersuchungen, die GGV-typische Befunde erfassen können

\section{Riesenzellarteriitis}

Palpation der Temporalarterienpulse und Prüfung der Druckschmerzhaftigkeit der Temporalarterien und ggf. der Fazial- und Okzipitalarterien

Prüfung der peripheren Pulse der oberen Extremitäten (Aa. brachiales, radiales, ulnares)

Auskultation von Strömungsgeräuschen über Herz, Karotiden, Aa. subclaviae, axillares

Bei Claudicatio intermittens Prüfung der Pulse der unteren Extremitäten und Auskultation von Strömungsgeräuschen der Aa. femorales

Blutdruckmessung an beiden Armen (Prüfung einer Seitendifferenz)

Prüfung einer Druck- und Bewegungsschmerzhaftigkeit der proximalen Extremitätenmuskeln und Beweglichkeit in Schulter- und Hüftgelenken (Symptome einer Polymyalgia rheumatica)

möglich durchgeführt werden (s. Empfehlung 2b).

Die Mehrzahl der Symptome einer TAK ist nicht spezifisch (•Tab. 2). Bei begründetem Verdacht auf das Vorliegen einer TAK sind eine zeitnahe Abklärung und Therapie bei einem auf GGV spezialisierten Team einschließlich der Bildgebung großer Gefäße ebenfalls indiziert. Für die TAK fehlen Studien für ein FastTrack-Verfahren. Die Dringlichkeit ergibt sich bei TAK aus der klinischen Konstellation: Eine sofortige Überweisung ist bei Symptomen oder Befunden, die auf ein erhöhtes Risiko für akute bzw. kritische ischämische Komplikationen hinweisen, angezeigt.

\section{Diagnostik}

\section{Empfehlung 2a (starker Konsens)}

Die Basisdiagnostik bei Verdacht auf eine Großgefäßvaskulitis soll eine gezielte Anamnese und eine gründliche klinische Untersuchung insbesondere der arteriellen Gefäße einschließen. Zudem soll eine Labordiagnostik einschließlich C-reaktiven Proteins und Blutsenkungsgeschwindigkeit erfolgen.

\section{Takayasu-Arteriitis}

Prüfung der Pulse der Karotiden sowie der oberen und unteren Extremitäten (Aa. brachiales, radiales, ulnares; Aa. femorales, popliteae, tibialis posteriores, dorsalis pedis)

Auskultation von Strömungsgeräuschen über Herz, Karotiden, Aa. subclaviae, axillares, Aorta abdominalis, Aa. femorales

Blutdruckmessung an beiden Armen (Prüfung einer Seitendifferenz)

Knöchel-Arm-Index
Empfehlung 2b (starker Konsens)

Die klinische Verdachtsdiagnose einer Großgefäßvaskulitis soll zeitnah durch bildgebende Verfahren oder histopathologisch gesichert werden. Insbesondere, wenn bereits eine Glukokortikoidtherapie begonnen wurde (z. B. bei begründetem Verdacht auf Riesenzellarteriitis), sollte die Diagnostik wegen unter Therapie abnehmender Sensitivität rasch vervollständigt werden.

\section{Empfehlung 2c (starker Konsens)}

Grundsätzlich sollten bei der Auswahl der diagnostischen Verfahren die klinische Fragestellung (z. B. zu untersuchendes Gefäßareal) sowie standortspezifische Faktoren wie Verfügbarkeit und Untersuchererfahrung berücksichtigt werden.

\section{Empfehlung 2d (starker Konsens)}

Bei unklaren oder negativen Befunden in Bildgebung oder Histologie und fortbestehendem klinischem Verdacht sollte ein weiteres diagnostisches Verfahren eingesetzt werden.

Es sind keine allgemein konsentierten Diagnosekriterien zur Sicherung der GGV verfügbar. Die Klassifikationskriterien des American College of Rheu- matology (ACR) von 1990 wurden nicht als diagnostisches Instrument entworfen und können eine GGV weder sicher beweisen noch ausschließen [12, 117]. Insbesondere die nicht selten vorkommende extrakranielle RZA wird von den ACR-Kriterien nicht adäquat erfasst [27, 186]. Eine Reevaluation der ACR-Kriterien an der Studienpopulation der „Diagnosis and Classification of Vasculitis Study“ (DCVAS) zeigte, dass die Sensitivität der ACR-Kriterien für die heute klinisch als RZA und TAK diagnostizierten Fälle niedriger ist als initial berichtet [237]. Für die TAK werden häufig die von Ishikawa vorgeschlagenen Diagnosekriterien verwendet bzw. deren modifizierte Version nach Sharma et al. [119, 243]. Die revidierten Kriterien der Chapel Hill-Konsensuskonferenz von 2012 beinhalten eine nomenklatorische Gliederung, die spezifisch definierte Erkrankungsprozesse benennt und beschreibt (- Tab. 1). Die CHCC stellt den nomenklatorischen und definitorischen Konsens für die Gruppe der Vaskulitiden dar, auf dessen Grundlage die Entwicklung von Klassifikationskriterien und diagnostischen Kriterien in Studien verfolgt wird (z.B. DCVAS-Studie) [122]. Weder für die RZA noch für die TAK steht ein trennscharfer diagnostischer Biomarker zur Verfügung. Daher muss die Diagnose anhand einer Zusammenschau von Anamnese, körperlicher Untersuchung, Labor, bildgebender Verfahren und ggf. Histopathologie gestellt werden. Der übliche Ort einer bioptischen Sicherung bei RZA ist die A. temporalis superficialis, die Diagnose einer GGV wird jedoch in einzelnen Fällen auch aus (z.B. bei gefäßchirurgischen Eingriffen gewonnenen) Proben anderer Gefäßregionen gestellt.

\section{Klinische Untersuchung}

Bei Verdacht auf GGV kann (über die Anamnese und internistische Basisuntersuchung hinaus) eine gründliche Untersuchung der arteriellen Gefäße zusätzliche Hinweise auf eine Erkrankung der großen Gefäße liefern (• Tab. 3)

\section{Labor}

Spezifische Laborparameter zur Diagnostik von GGV sind nicht verfügbar. 
In der Regel sind die unspezifischen Entzündungsparameter bei Diagnosestellung erhöht, wobei CRP und BSG gemäß einer großen retrospektiven Studie eine vergleichbare Sensitivität und Spezifität zeigten [129]. In dieser Studie wiesen $4 \%$ der mittels TAB gesicherten Fälle von unbehandelter RZA weder eine erhöhte BSG, noch ein erhöhtes CRP bei Erstdiagnose auf [129]. Beim Auftreten von Rezidiven (evtl. unter immunsuppressiver Therapie) sind BSG und CRP häufig (aber nicht grundsätzlich) ebenfalls erhöht nachweisbar, die Werte sind in der Regel jedoch niedriger als bei Erstmanifestation [9]. Unter einer Therapie mit Tocilizumab (TCZ) ist $\mathrm{zu}$ beachten, dass hierunter in der Regel eine vollständige Suppression der CRP-Synthese und eine Normalisierung der BSG vorliegen, der Verlauf der serologischen Entzündungsparameter also zur Verlaufskontrolle einer GGV nicht mehr herangezogen werden kann [253, 254]. Dies zu berücksichtigen kann bei der Auswahl der verwendeten Medikation relevant sein, wenn eine klinische Konstellation vorliegt, in der die serologischen Entzündungsparameter von besonderem Interesse für die Durchführung von Verlaufskontrollen sind (z.B. RZA ohne begleitende Polymyalgie oder Kopfschmerzsymptome, RZA und begleitendes nichtentzündliches Kopfschmerzsyndrom, durch Begleiterkrankungen wie Demenz schwer anamnestizierbare an GGV Erkrankte etc.).

\section{Diagnostische Sicherung}

Zur diagnostischen Sicherung sind bei der RZA und TAK verschiedene bildgebende Verfahren geeignet. Bei der RZA mit prädominant kranieller Beteiligung ist die Temporalarterienbiopsie (TAB) eine geeignete Alternative. Die stetige Weiterentwicklung diagnostischer Techniken ermöglicht zunehmend den Verzicht auf invasive diagnostische Verfahren zur Diagnosesicherung (z.B. Sicherung der RZA mittels Sonographie oder Schnittbildgebung anstelle von TAB, Sicherung der TAK mittels Sonographie oder Schnittbildgebung) [63, 159, 200, 215]. Sowohl die Anwendung bildgebender Verfahren, die histopa- thologische Befundung als auch die operative Gewinnung eines repräsentativen Temporalarterienbiopsates setzen Erfahrung und Training in der Methodik voraus [63, 159]. Die konventionelle Angiographie ist zur reinen Diagnostik einer GGV heute obsolet und wird nur noch im Rahmen von Interventionen eingesetzt $[63,95]$.

$\mathrm{Da}$ es nach Beginn einer GC-Therapie $\mathrm{zu}$ einer raschen Reduktion der Sensitivität der diagnostischen Methoden kommt (z.B. Sonographie nach 1, TAB nach 3 Tagen), ist die schnelle Durchführung der diagnostischen Maßnahmen nach Beginn einer präemptiven GC-Therapie (wie bei Verdacht auf RZA indiziert) notwendig [159]. Auch wenn die Durchführung innerhalb von 1 bis 3 Tagen nicht gelingt, ist eine schnellstmögliche Diagnostik mittels Bildgebung oder Biopsie sinnvoll, es muss dann die verringerte Sensitivität der Methoden berücksichtigt werden. Einzelne Verfahren können auch über einen langen Zeitraum noch diagnostische Befunde erbringen, und ihre Durchführung kann auch unter länger laufender Therapie noch sinnvoll sein. Dies betrifft z.B. den Nachweis charakteristischer morphologischer Veränderungen der großen Gefäße in der Schnittbildgebung oder lange persistierende histopathologische Befunde (s. auch Abschnitt „Histopathologie“).

Eine negative Bildgebung (oder Biopsie) schließt eine GGV nicht sicher aus. Da keines der zur Verfügung stehenden Verfahren eine $100 \%$ ige Sensitivität aufweist, erfordern negative Ergebnisse eine Betrachtung im klinischen Gesamtkontext und bei fortbestehendem Verdacht die Kombination mehrerer diagnostischer Verfahren [18, 159, 215]. Wenn z. B. ein hoher klinischer Verdacht auf eine RZA besteht und ein positiver Bildgebungstest vorliegt, wird die Diagnose einer RZA üblicherweise ohne zusätzliche Tests (TAB oder weitere Bildgebung) gestellt [63]. Bei geringer klinischer Wahrscheinlichkeit und negativem Bildgebungsergebnis wird die Diagnose einer RZA meist als unwahrscheinlich angesehen [63]. In allen anderen Situationen sind zusätzliche Verfahren (weitere
Bildgebung oder Biopsie) zur Abklärung erforderlich.

\section{Bildgebende Verfahren}

Empfehlung 2e (starker Konsens)

Bei Verdacht auf eine prädominant kranielle Riesenzellarteriitis sollte die Ultraschalluntersuchung der Arteriae temporales und axillares die bildgebende Modalität der ersten Wahl darstellen. Alternativ kann die hochauflösende MRT eingesetzt werden. Bei Verdacht auf eine prädominant extrakranielle Beteiligung sollte die MRT/MR-Angiographie, PET-CT oder CT eingesetzt werden.

Empfehlung 2f (starker Konsens)

Zur Beurteilung einer zusätzlichen aortalen Beteiligung bei prädominant kranieller Riesenzellarteriitis kann die MRT, CT oder PET-CT eingesetzt werden.

Empfehlung 2g (starker Konsens)

Bei Verdacht auf Takayasu-Arteriitis sollte die MR-Angiographie als Methode der ersten Wahl eingesetzt werden. Alternativ kann eine PET/PET-CT, Sonographie oder CT-Angiographie durchgeführt werden.

Im Jahr 2018 wurden detaillierte Empfehlungen der EULAR zum Einsatz bildgebender Verfahren bei GGV publiziert [63].

Ultraschall. Die Ultraschalluntersuchung der Aa. temporales und axillares wird als erstes bildgebendes Verfahren bei Verdacht auf eine prädominant kranielle RZA empfohlen. Ein nicht komprimierbares "Halo“-Zeichen ist der Ultraschallbefund, der eine RZA mit kranieller Manifestation mit hoher diagnostischer Sicherheit anzeigt $[14,15,48]$. In spezialisierten Zentren unter Einsatz moderner Gerätetechnik sind Sensitivität und Spezifität des Ultraschalls für die Diagnosestellung der RZA hoch, mit berichteter Sensitivität von mehr als $80 \%$ und Spezifität von mehr als $90 \%[14,67,70,128]$. Bei 
Kombination von passender Klinik und Sonographie verbessern sich Sensitivität und Spezifität, sodass die TAB nur in nicht eindeutigen Situationen nötig ist [159]. Die Reproduzierbarkeit der Ergebnisse von Pathologen und Ultraschalluntersuchern bei der Beurteilung von Biopsaten bzw. Ultraschallvideos ist vergleichbar [159]. Erfahrene Sonographeure erzielen eine hohe Reliabilität [229].

In vielen Fällen ist auch die Detektion extrakranieller Veränderungen der RZA mittels Sonographie möglich, typischerweise im Bereich der Aa. axillares $[85,236]$. Die thorakale Aorta und die proximalen Anteile ihrer großen Abgänge sowie die intrakraniellen Gefäße sind der Sonographie zur Sicherung von Wandveränderungen bei Vaskulitis hingegen nur eingeschränkt zugängig. Die Sensitivität der Bildgebung wird durch eine begonnene GC-Therapie rasch reduziert. Sie sank nach Ergebnissen der TABUL-Studie für die Sonographie um ca. ein Drittel bereits nach 1 Tag GCTherapie [159].

Bei der TAK lassen sich in mehr als $80 \%$ der Fälle charakteristische sonographische Veränderungen der supraaortalen Arterien mit konzentrischer Wandverdickung (Macaroni-Zeichen) finden, am häufigsten in der A. carotis communis $[162,218]$. Darüber hinaus kann der Befall weiterer häufig befallener Gefäßsegmente, etwa der abdominellen Aorta und der Nierenarterien, sonographisch beurteilt werden. Systematische Studien zur diagnostischen Güte der Sonographie in der Diagnostik der TAK liegen nicht vor.

MRT. Eine hochauflösende Magnetresonanztomographie (MRT) der oberflächlichen Schädelarterien kann als Alternative zur farbkodierten Duplexsonographie für die RZA-Diagnostik verwendet werden, wenn der Ultraschall nicht verfügbar oder nicht schlüssig ist (Sensitivität 78\%, Spezifität $90 \%$ in einer deutschen Multicenterstudie) [63, 137]. Diese Untersuchungsmethode ist bei 1,5 und 3 Tesla (T) mit gleicher Auflösung möglich, allerdings kann mit 3-T-Scannern aufgrund der höheren Signalausbeute eine bessere Bildqualität erreicht werden. Auch die Sensitivität der MRT der Temporalarterien für die Diagnose der kraniellen RZA nimmt unter GCTherapie ab (Reduktion der Sensitivität nach mehr als 1 Tag GC-Therapie um ca. ein Viertel) [98]. Kombiniert mit einer MR-Angiographie können zusätzlich zu den oberflächlichen Schädelarterien auch die großen extrakraniellen Gefäße einschließlich der thorakalen Aorta bezüglich Strukturveränderungen (Wandverdickung, Stenosen und Verschlüsse, Aneurysmen) sowie Kontrastmittelaufnahme der Gefäßwand in einer umfassenden MR-Untersuchung ohne erneute Kontrastmittelgabe beurteilt werden.

Bei der TAK wird - aufgrund des meist jungen Alters der Erkrankten und der im Verlauf häufig notwendigen wiederholten Bildgebungen bei rezidivierendem oder mit morphologischen Veränderungen der Gefäße einhergehendem Verlauf - die MRT als Instrument ohne Strahlenexposition häufig eingesetzt [63, 274].

PET, PET-CT, PET-MRT und CT-Angiographie. Bisher wurde die Positronenemissionstomographie(PET)-Computertomographie (CT) mit ${ }^{18}$ F-Fluordeoxyglucose $\left(\left[{ }^{18} \mathrm{~F}\right] \mathrm{FDG}\right)$ primär für den Nachweis einer extrakraniellen RZA angewendet [63]. In 2 kürzlich publizierten Studien konnte unter Einsatz moderner hochauflösender PETScanner eine Vaskulitis auch an der A. temporalis, maxillaris und vertebralis nachgewiesen werden [196, 226]. Auch mittels CT-Angiographie können im Einzelfall Hinweise auf das Vorliegen einer kraniellen RZA mit Beteiligung der Temporalarterien erhoben werden [54].

Die Darstellung entzündlicher Veränderungen der Wand der großen intrathorakalen Gefäße als auch von (entzündlich bedingten) Stenosierungen und Aneurysmen ist mittels kontrastmittelgestützter CT-Angiographie oder $\left[{ }^{18} \mathrm{~F}\right] \mathrm{FDG}$ PET-CT möglich [27, 34, 63, 146, 260]. Eine konzentrische Wandverdickung der thorakalen Aorta von $>2,2 \mathrm{~mm}$ weist auf das Vorliegen einer RZA hin [24].

Bis dato erfolgte die $\left[{ }^{18} \mathrm{~F}\right] \mathrm{FDG}-$ PET/PET-CT-Diagnostik bei Verdacht auf GGV ohne allgemein akzeptierte methodische Standards [212]. Kürzlich wurde jedoch ein Konsensusstatement zur standardisierten Befunderhebung in der $\left[{ }^{18} \mathrm{~F}\right]$ FDG-PET-CT-Diagnostik bei GGV und/oder PMR publiziert. Für die klinische Routine wird dort die visuelle, semiquantitative Beurteilung der vaskulären Radiotracer-Anreicherung gegenüber der hepatischen Anreicherung empfohlen [247]. Metaanalysen von FallKontroll-Studien berechneten Sensitivitäten von 80 bis $90 \%$ und Spezifitäten von 89 bis $98 \%$ für die Diagnostik der GGV [247]. Da die Sensitivität der $\left[{ }^{18} \mathrm{~F}\right] \mathrm{FDG}-$ PET-CT bei der RZA nach einer über 10 Tage durchgeführten hoch dosierten GC-Therapie deutlich sinkt, aber nach einer Therapie von 3 Tagen noch erhalten ist [195], ist die $\left[{ }^{18} \mathrm{~F}\right] \mathrm{FDG}$-PETCT-Diagnostik analog zu den anderen diagnostischen Verfahren in dieser Indikation möglichst innerhalb von 3 Tagen nach Beginn einer GC-Therapie sinnvoll. Bei der TAK war in einer Metaanalyse die Sensitivität der $\left[{ }^{18} \mathrm{~F}\right]$ FDG-PETCT vergleichbar mit der bei der RZA, während die Spezifität geringer zu sein schien. Die $\left[{ }^{18} \mathrm{~F}\right]$ FDG-PET ist daher gut zur primären Diagnosestellung bzw. zum Ausschluss einer TAK geeignet. Der Einsatz der $\left[{ }^{18} \mathrm{~F}\right]$ FDG-PET oder $\left[{ }^{18} \mathrm{~F}\right]$ FDGPET-CT als diagnostisches Instrument der ersten Wahl wird limitiert über die Verfügbarkeit und die heterogene Kostenerstattung in Deutschland (in der Indikation Großgefäßvaskulitiden wird sie zum Zeitpunkt der Fertigstellung dieser Leitlinie nicht generell, aber z. B. im Rahmen der ambulanten spezialärztlichen Versorgung in der Rheumatologie als Leistung der gesetzlichen Krankenversicherung oder nach individueller Beantragung einer Kostenübernahme erstattet). Die Strahlenexposition eines $\left[{ }^{18} \mathrm{~F}\right]$ FDG-PET mit Low-dose-CT liegt bei modernen PET-CT-Scannern bei ca. 3-4 Millisievert (mSv), bei älteren Systemen bei etwa $7 \mathrm{mSv}$. Hierbei stammt die wesentliche Strahlenexposition aus der diagnostischen CT-Komponente. Die Strahlenexposition ist bei allen Untersuchungen (insbesondere bei Follow-upUntersuchungen) stets zu berücksichtigen, deren Indikation sorgfältig zu stellen ist [247]. Ein Vorteil der $\left[{ }^{18} \mathrm{~F}\right]$ FDG-PET$\mathrm{CT}$ ist die Detektion weiterer möglicher 
Differenzialdiagnosen wie Malignome oder anderer entzündlicher Prozesse, z. B. wenn der Verdacht auf eine GGV aufgrund einer Konstellation mit Fieber, Gewichtsverlust und/oder Nachtschweiß (sog. B-Symptomatik) ungeklärter Ursache geäußert worden ist.

Eine prinzipielle Alternative zur $\left[{ }^{18} \mathrm{~F}\right]$ FDG-PET-CT mit niedrigerer Strahlenexposition wäre die $\left[{ }^{18} \mathrm{~F}\right] \mathrm{FDG}-\mathrm{PET}$ MRT. Die Datenlage zur $\left[{ }^{18} \mathrm{~F}\right]$ FDGPET-MRT in der Vaskulitisdiagnostik ist allerdings begrenzt, und $\left[{ }^{18} \mathrm{~F}\right] \mathrm{FDG}$ PET-MRT-Geräte sind nur in wenigen Einrichtungen verfügbar [73, 147].

\section{Screening auf Großgefäßbeteiligung} bei prädominant kranieller Riesenzellarteriitis. Bei Diagnose einer prädominant extrakraniellen RZA (z.B. sonographisch oder mittels Biopsie) ist eine ergänzende Beurteilung einer Mitbeteiligung der großen extrakraniellen Gefäße, z.B. mittels MRT, CT oder $\left[{ }^{18} \mathrm{~F}\right] \mathrm{FDG}-$ PET-CT möglich. Die Subgruppe der RZA mit aortaler Beteiligung hat ein erhöhtes Risiko für das Auftreten von Aortenaneurysmen, diese gehen mit einer erhöhten Mortalität durch kardiovaskuläre Komplikationen inklusive Dissektionen einher und können Anlass für wiederholte Kontrollen und ggf. gefäßchirurgische Interventionen sein [26, 77, 131]. Bisher lassen sich aus den verfügbaren Quellen weder optimale Zeitpunkte eines Screenings auf Großgefäßbeteiligung/Aneurysmen (s. auch „Bildgebende Verlaufskontrollen nach Diagnosestellung und Therapiebeginn“) ableiten, noch resultieren aus ihnen grundsätzliche Änderungen der medikamentösen Therapiekonzepte (außer bei Verdacht auf durch persistierende Entzündung bedingte progrediente Aortendilatation), sodass die Indikationsstellung zum ergänzenden Screening auf Großgefäßbeteiligung bei Diagnosestellung individuell abzuwägen ist (vgl. auch Kapitel „Verlaufskontrollen“ und „Versorgung vaskulärer Komplikationen").

Bildgebende Verlaufskontrollen nach Diagnosestellung und Therapiebeginn. Wenn der Verdacht auf ein Rezidiv einer GGV besteht, ist die Bildgebung bei manchen Fällen hilfreich, um dieses zu bestätigen oder auszuschließen [63].

Aussagekräftige Daten zum Stellenwert der Ultraschalldiagnostik in der Abklärung des Rezidivverdachts bei den GGV liegen nicht vor. In jüngster Zeit wurden Arbeiten publiziert, die bei TAK und Beteiligung der Karotiden eine positive Korrelation zwischen Anreicherung der verdickten Gefäßwand in der Kontrastmittelsonographie und klinischer Aktivität wie auch metabolischer Aktivität in der $\left[{ }^{18} \mathrm{~F}\right]$ FDG-PET-CT zeigten mit einer Sensitivität bzw. Spezifität der Kontrastmittelsonographie zwischen 70 und $100 \%$ bzw. 80 und $100 \%$ im Vergleich zur klinischen Krankheitsaktivität [83, 116, 157]. Welchen Stellenwert die Kontrastmittelsonographie in der Abklärung des Rezidivverdachts bei TAK erlangen kann, muss in weiteren Studien evaluiert werden.

In einer prospektiven Kohortenstudie zeigte sich bei jeweils mehr als $60 \%$ der Fälle von GGV in klinischer Remission eine vaskuläre Inflammation in der Bildgebung mit sowohl $\left[{ }^{18} \mathrm{~F}\right]$ FDG-PETCT als auch MRT [216]. In einer weiteren prospektiven Kohortenstudie fand sich bei $58 \%$ der Fälle von GGV in klinischer Remission in der $\left[{ }^{18} \mathrm{~F}\right]$ FDG-PETCT noch eine aktive arterielle Inflammation. Bei diesen Fällen war das Risiko zukünftiger Rezidive erheblich erhöht [92].

Derzeit ist noch unklar, ob die anhaltende Aufnahme des Radiotracers in die Gefäßwand ([18 F]FDG-PET-CT) bzw. murale Kontrastmittelanreicherung und Wandverdickung (MRT) trotz klinischer Remission Ausdruck eines unspezifischen Remodelings oder einer fortbestehenden subklinischen Aktivität der GGV ist. Angesichts der gegenwärtig unklaren Relevanz dieser Befunde wird in den EULAR-Empfehlungen zur Bildgebung bei GGV bei klinischer und laborchemischer Remission keine routinemäßige Bildgebung empfohlen, individuell kann die Schnittbildgebung aber zur Mitbeurteilung der Krankheitsaktivität erwogen werden, z. B. bei GGV mit aortaler Beteiligung unter TCZ-Therapie (humorale Entzündungsparameter nicht verwertbar), bereits eingetretenem aortalem Strukturschaden, bzw. vor geplanten
Gefäßeingriffen [63]. In einer vergleichenden prospektiven Untersuchung bei Patienten mit RZA und extrakranieller Beteiligung sowie Patienten mit TAK eignete sich die MRT besser zur Beurteilung von Krankheitsausdehnung und Anatomie (Stenose/Aneurysmen) während die $\left[{ }^{18} \mathrm{~F}\right]$ FDG-PET besser zur Aktivitätsbeurteilung geeignet war [216]. Trotz dieses Vorteils der $\left[{ }^{18} \mathrm{~F}\right]$ FDG-PET-CT in der Beurteilung der entzündlichen Aktivität macht die mit der Methode verbundene Strahlenexposition insbesondere in der Verlaufsbeobachtung eine sorgfältige Indikationsstellung erforderlich [63].

Ultraschall, insbesondere aber MRT und CT-Angiographie eignen sich zur Verlaufsbeobachtung von strukturellen Schäden, insbesondere zum Monitoring von Stenosen, Okklusionen und/ oder Aneurysmen [63]. Die Häufigkeit des Screenings sowie die bildgebende Methode werden bei Fehlen belastbarer Daten zu den Intervallen individuell festgelegt [63]. Dabei muss berücksichtigt werden, dass gemäß populationsbasierter Untersuchungen das Risiko aortaler Spätkomplikationen ca. 5 Jahre nach Diagnose einer RZA ansteigt [161] und dass bestimmte Risikofaktoren mit einem erhöhten Risiko aortaler Dilatation einhergehen (z. B. weibliches Geschlecht, jüngeres Alter bei Diagnose, extrakranielle vaskuläre Symptome, Nachweis einer aortalen Beteiligung) [32].

\section{Histopathologie}

Empfehlung 2h (starker Konsens)

Bei Verdacht auf eine kranielle Riesenzellarteriitis soll eine Temporalarterienbiopsie erfolgen, wenn eine aussagekräftige Bildgebung nicht zur Verfügung steht. Die Probenlänge einer Temporalarterienbiopsie sollte mindestens $1 \mathrm{~cm}$ betragen.

Die Sensitivität und Spezifität der histopathologischen Untersuchung im Vergleich $\mathrm{zu}$ bildgebenden Untersuchungsverfahren in der Diagnostik der RZA und TAK sind abhängig von den klinischen Eingangskriterien des untersuchten Kollektivs und der aus diesen Kriterien resultierenden Prätest-Wahr- 
scheinlichkeit. Methodisch fehlt zudem ein "Goldstandard“, an dem bildgebende und andere Untersuchungsverfahren validiert werden können $[63,194]$.

Bei begründetem klinischem Verdacht und negativen bzw. nicht eindeutigen Befunden der Bildgebung, oder wenn eine aussagekräftige Bildgebung nicht zur Verfügung steht, wird die TAB zur histologischen Diagnosesicherung einer kraniellen RZA eingesetzt [63].

$\mathrm{Da}$ die RZA häufig einen diskontinuierlichen Befall der Gefäße aufweist (sog. „skip lesions“), ist die Sensitivität der TAB abhängig von einer ausreichenden Probenlänge des Gefäßes. Diese sollte daher mindestens $1 \mathrm{~cm}$ betragen [278]. Eine vorherige Markierung der Lokalisation mit den sonographisch ausgeprägtesten Veränderungen verbesserte die Sensitivität der TAB in mehreren Studien nicht, darunter auch eine prospektive randomisierte Studie [84, 225]. Eine bilaterale TAB erhöht die diagnostische Wahrscheinlichkeit einer RZA nur gering (und ist daher in der klinischen Praxis nicht üblich) $[30,194]$.

Bei der TAK sowie beim extrakraniellen Typ der RZA $[36,62]$ ist die bioptische Verifizierung nicht Teil der Primärdiagnostik, jedoch ist bei ggf. erforderlichen gefäßchirurgischen bzw. kardiochirurgischen Eingriffen die histologische Untersuchung von Gefäß- oder Klappenbiopsaten grundsätzlich sinnvoll (vgl. Empfehlung 9). Eine Beteiligung intraparenchymaler Arterien innerer Organe im Rahmen einer systemischen RZA wird meist als Zufallsbefund bioptisch diagnostiziert [107].

Der Einfluss einer bereits begonnenen GC-Therapie auf das histologische Untersuchungsergebnis wurde bei der RZA in verschiedenen Studien untersucht. Eine große retrospektive Fallserie zeigte, dass bei einem Teil der Betroffenen 2 Wochen nach Beginn einer GC-Therapie noch der histologische Nachweis einer RZA erbracht werden kann [3]. In einer anderen Studie gelang bei $80 \%$ der Untersuchten ein positiver histologischer Nachweis in einem Zeitraum von 7 bis 28 Tagen nach Beginn der GC-Therapie [120]. Interessanterweise wurden unter einer GCTherapie noch bei $50 \%$ bzw. $25 \%$ der Betroffenen mit einer RZA nach 9 bzw.
12 Monaten entzündliche Infiltrate in einer zweiten TAB nachgewiesen, obwohl klinisch eine Remission bestand [166]. Während diese Studien auf eine längere Persistenz des entzündlichen Infiltrates auch nach Beginn der immunsuppressiven Therapie deuten, sank demgegenüber in der TABUL-Studie die Sensitivität der TAB um ca. ein Drittel nach $\geq 7$ Tagen GC-Therapie. Die Einschlusskriterien der TABUL-Studie umfassten jedoch ein weites Spektrum an Symptomen [159]. Eine TAB wird daher optimalerweise innerhalb von wenigen Tagen nach Beginn der GC-Therapie durchgeführt. Gleichwohl besteht mindestens bis zu 4 Wochen nach Beginn der Therapie eine gute Aussicht auf eine positive Histologie [120, 191], nach einigen Quellen sogar deutlich darüber hinaus [166].

Die histologische Aufarbeitung von Gefäßbiopsaten bei RZA und TAK beinhaltet die Einbettung mehrerer Querschnitte des Gefäßes sowie Stufenschnitte in Hämatoxylin-Eosin-Färbung, ferner eine Elastica-van-Gieson-Färbung und in Zweifelsfällen immunhistochemische Untersuchungen zum Nachweis von Riesenzellen bzw. Makrophagen (z. B. CD68) sowie T-Lymphozyten (z. B. CD3). Die typischen histopathologischen Merkmale der RZA sind nach den ACR-Kriterien von 1990 eine Vaskulitis mit prädominant mononukleärer Zellinfiltration oder granulomatöser Entzündung, meist mit mehrkernigen Riesenzellen [117]. Prädilektionsort der Riesenzellen ist in der A. temporalis die Lamina elastica interna, deren Fasern häufig fragmentiert und von Makrophagen bzw. Riesenzellen destruiert sind [269]. Scharf umschriebene Granulome vom Sarkoidosetyp finden sich hier nicht. In der Regel liegt eine transmurale Entzündung durch T-Lymphozyten und Makrophagen vor mit Verdichtung im Bereich von Lamina elastica interna und Lamina elastica externa (bzw. am Übergang von Media und Adventitia) [42, 106], in weniger als $10 \%$ wird eine Vaskulitis der Vasa vasorum oder der periadventitialen kleinen Gefäße beschrieben, bei der Kleingefäßvaskulitiden eine Differenzialdiagnose darstellen können [220]. Die Intima der A. temporalis weist häufig eine Fibrose auf, Thromben können nicht selten auftreten. Eine Neutrophilie bzw. fibrinoide Gefäßwandnekrosen sind nicht typisches Teilbild einer RZA, treten jedoch selten auf.

Nicht immer sind alle morphologischen Diagnosekriterien erfüllt: In bis zu $50 \%$ der RZA-Fälle können Riesenzellen in der TAB fehlen [153]. Wenn das entzündliche Infiltrat im Übrigen die typische Lokalisation und Zusammensetzung aufweist, ist die Diagnose einer RZA dennoch histologisch möglich. Bei unklaren Befunden ist die Mitbeurteilung durch eine Referenzpathologie oft hilfreich.

Wenn keine entzündlichen Infiltrate nachweisbar sind (z.B. infolge einer bereits begonnenen GC-Therapie), kann keine sichere RZA-Diagnose anhand nichtentzündlicher histologischer Merkmale der Temporalarterien erfolgen (z. B. Ausdünnung der Media, Intimahyperplasie, Fragmentierung der Lamina elastica interna, Adventitiafibrose, Neoangiogenese, Kalzifikationen) [185].

Da sich das mikroskopische Bild in Aorta oder aortennahen Arterien bei RZA und TAK weitgehend gleicht [138], ist histomorphologisch alleine an Großgefäßen keine sichere Unterscheidung zwischen RZA und TAK möglich, wenngleich immunhistochemische Untersuchungen und experimentelle Daten ätiopathologisch eine unterschiedliche Genese nahelegen [46, 165, 238].

Typisch ist in den großen Gefäßen bei RZA und TAK die Ausbreitung der Entzündung entlang der Vasa vasorum und die oft herdförmige mottenfraßartige Destruktion der elastischen Fasern in allen Schichten der Media durch Makrophagen bzw. Riesenzellen teils auch mit Nekrosen [176] sowie der nachfolgende Ersatz des elastischen Fasergerüsts der Media durch zungenförmig um die Vasa vasorum einsprossendes kollagenes Bindegewebe. Aneurysmen der Aorta können auftreten, eine Intimabeteiligung der Aorta ist nicht charakteristisch [265]. Häufig kommt es zu Thromben, Stenosen oder Aneurysmen, gelegentlich zu einem Übergreifen der Fibrose bzw. Entzündung auf perivaskuläres Gewebe, z. B. Periaortitis oder Perikarditis [244].

Da die bioptische Diagnostik meist erst an gefäßchirurgischen Resektaten im 


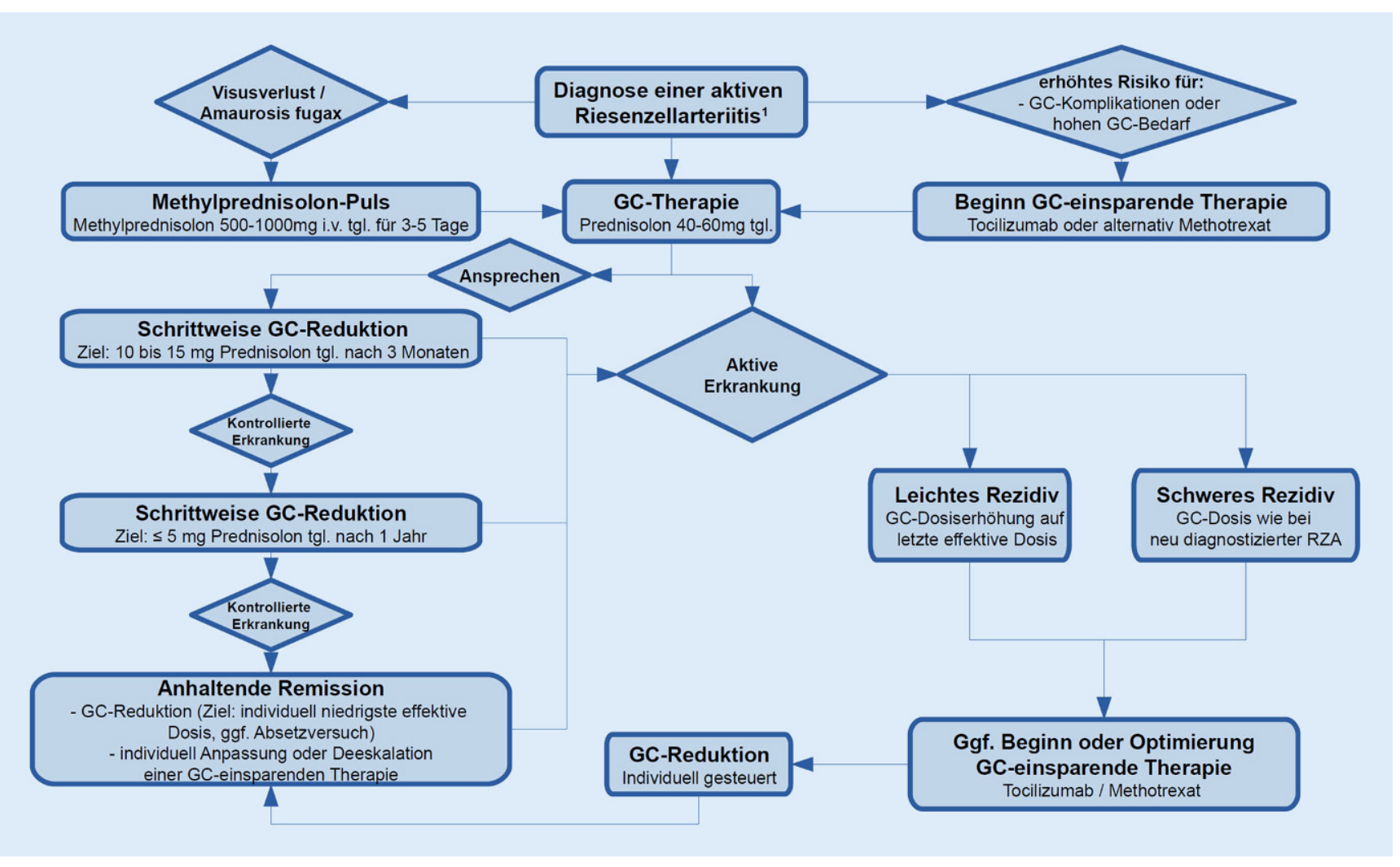

Abb. 1 ॥ Therapiealgorithmus bei Riesenzellarteriitis. Schematische Darstellung der Empfehlungen zur medikamentösen Therapie bei RZA. 'Beginn einer GC-Therapie umgehend bei begründetem Verdacht auf RZA und rasche Komplettierung der Diagnostik (vgl. Empfehlung 1b). GC Glukokortikoide, i.v. intravenös, mg Milligramm, RZA Riesenzellarteriitis, tgl. täglich

Verlauf der Erkrankung oder als Zufallsbefund erfolgt, dominieren morphologisch späte Stadien. Floride und chronische Veränderungen können synchron in einem Gefäß nachweisbar sein [17].

Obwohl einzelne Autoren Zusammenhänge zwischen dem Typ oder der Intensität der histologischen Entzündung und dem klinischen Verlauf beschreiben, lassen sich für RZA und TAK aus der verfügbaren Literatur keine direkt aus dem histologischen Bild resultierenden therapeutischen Maßnahmen ableiten $[13,28,37,45,106,127,164$, 184, 232].

Die histomorphologische Differenzialdiagnose der RZA und TAK umfasst arteriosklerotische Veränderungen, ggf. Folgen vorausgegangener angioinvasiver Eingriffe, ANCA-assoziierte Vaskulitiden, Morbus Behçet und fibromuskuläre Dysplasien, an der Aorta weiterhin auch das inflammatorische abdominale Aortenaneurysma, IgG4assoziierte Erkrankungen sowie eine in- fektiöse Aortitis (z.B. syphilitisch oder mykotisch).

\section{Glukokortikoidtherapie}

\section{Empfehlung 3a (Konsens)}

Bei Erstdiagnose einer aktiven Riesenzellarteriitis ohne Sehstörungen oder einer aktiven Takayasu-Arteriitis soll eine Glukokortikoidtherapie begonnen werden. Die Dosis sollte initial 40-60 mg Prednisolonäquivalent täglich betragen.

Therapiealgorithmus bei RZA s. - Abb. 1 und bei TAK s. - Abb. 2.

Die verfügbaren Daten zeigen, dass eine Startdosis von 40 bis 60 mg Prednisolonäquivalent in der Regel zur initialen Kontrolle einer RZA ohne ischämische Komplikationen oder einer TAK ausreichend ist [80, 141, 172]. Eine präventive Wirkung von GC in Bezug auf die ischämisch bedingten Sehstörungen kann aus retrospektiven Studien abgeleitet werden $[8,99]$. Es liegt jedoch keine Evidenz aus randomisiert kontrollierten Studien vor, aus der eine optimale GCDosis abgeleitet werden könnte.

Höhere initiale GC-Dosierungen einschließlich der i.v.-Pulsgabe von Methylprednisolon sind in mehreren Studien bei RZA ohne Sehstörungen untersucht worden. In der Zusammenschau lässt sich aus diesen Studien mit nicht einheitlichen Ergebnissen keine klare Evidenz ableiten, dass GC-Dosierungen von mehr als $60 \mathrm{mg}$ Prednisolonäquivalent täglich im Hinblick auf klinisch relevante Endpunkte wie eine Reduktion ischämischer Komplikationen der Standarddosis von 40 bis $60 \mathrm{mg}$ täglich überlegen ist, allerdings scheint ein höherer GC-Bedarf das Risiko GC-induzierter Komplikationen zu erhöhen [47, 172]. Mazlumzadeh et al. beschrieben, dass es bei an RZA Erkrankten, die im Rahmen einer randomisierten, placebokontrollierten Studie initial $15 \mathrm{mg}$ / kgKG Methylprednisolon i.v. für 3 Tage 


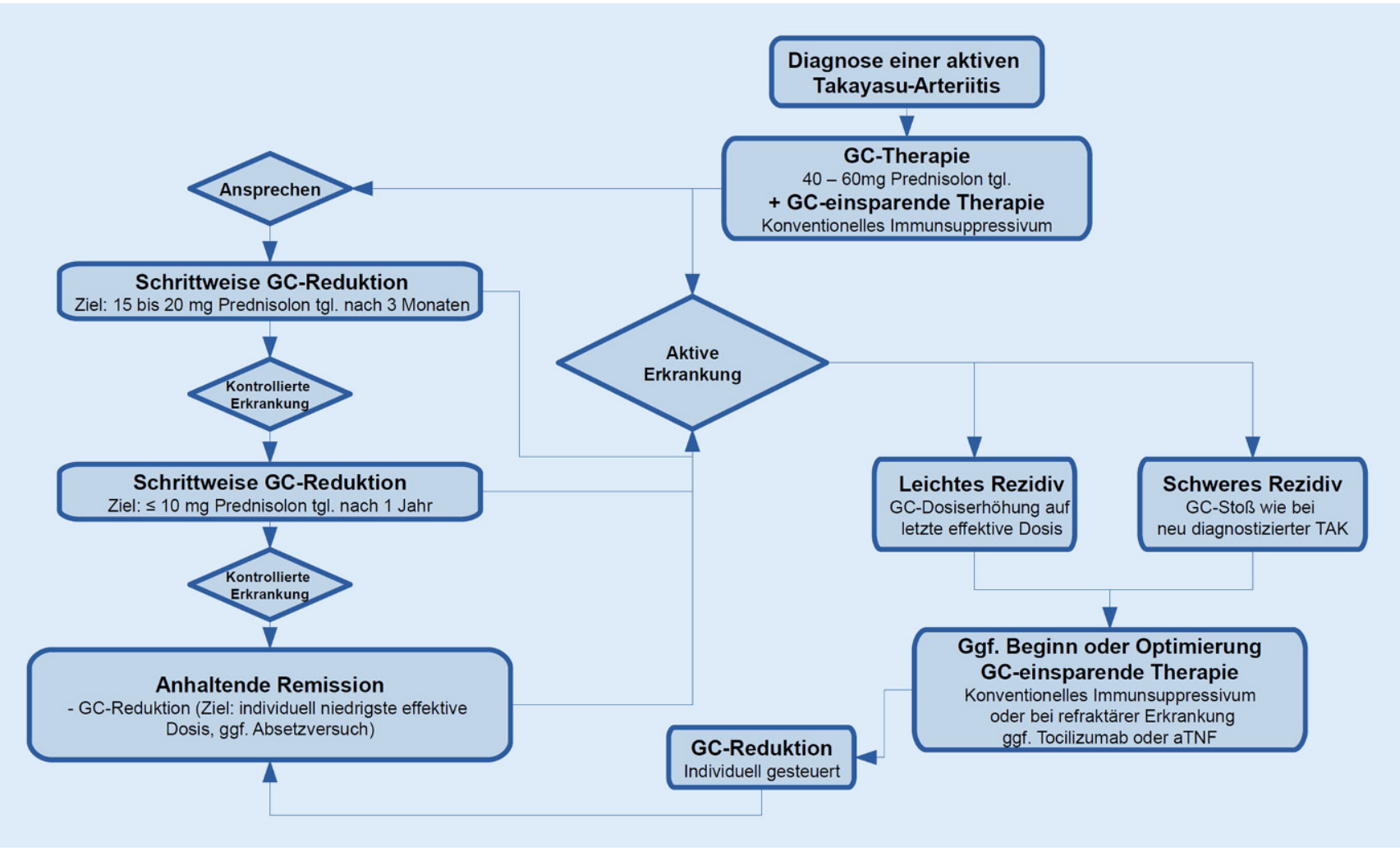

Abb. 2 ム Therapiealgorithmus bei Takayasu-Arteriitis. Schematische Darstellung der Empfehlungen zur medikamentösen Therapie bei TAK. GC Glukokortikoide, $m g$ Milligramm, TAK Takayasu-Arteriitis, tgl. täglich, aTNF Tumornekrosefaktor alpha-Antagonist

(oder Placebo) zusätzlich zu einem Prednisolon-Reduktionsschema (beginnend mit $40 \mathrm{mg}$ täglich) erhielten, in der Methylprednisolon-Pulsgruppe signifikant häufiger möglich war, Prednisolon in einen Dosisbereich $\leq 5 \mathrm{mg}$ zu reduzieren [172]. Chevalet et al. fanden dagegen in einer randomisiert kontrollierten Studie keinen Anhalt für einen langfristigen Effekt initialer Methylprednisolon-Pulse [47]. Labarca et al. beschrieben, dass initiale Prednisolon-Dosen $>40 \mathrm{mg}$ p.o. mit einer früheren Möglichkeit zur Beendigung der GC-Therapie assoziiert sind [142].

Grundsätzlich ist im Verlauf stets eine Überprüfung erforderlich, ob die verordnete medikamentöse Therapie die GGV suffizient kontrolliert; in Einzelfällen sind individuell gewählte GC-Dosen (z.B. höher bei schwer beherrschbarem Verlauf, ggf. initiale GC-Pulstherapie) und ein individuell angepasstes Reduktionsschema notwendig.

Eine kleine Studie untersuchte die Effektivität von Prednisolon mit verzöger- ter Wirkstofffreisetzung zur Erhaltungstherapie bei RZA verglichen mit unretardiertem Prednisolon. Beide Präparate schienen äquivalent wirksam zu sein [217]. GC-Therapien mit täglich alternierender Gabe führen zu einer deutlich schlechteren Kontrolle einer RZA (verglichen mit der täglichen Gabe) [118].

Aus der verfügbaren Literatur lässt sich keine eindeutige Empfehlung für unterschiedliche Behandlungsdauern oder GC-Dosen in Abhängigkeit der unterschiedlichen klinischen Subgruppen (z. B. kraniale vs. aortale Beteiligung) der RZA ableiten (sofern es nicht zu ischämischen Komplikationen gekommen ist) $[34,57,75,186,235]$.

\section{Empfehlung 3b (Konsens)}

Nach Erreichen einer Remission soll die Glukokortikoiddosis bei einer Glukokortikoidmonotherapie schrittweise reduziert werden. Es sollten etwa 10-15 mg (Riesenzellarteriitis)/15-20 mg (Takayasu-Arteriitis) Prednisolonäquivalent täglich nach 3 Monaten sowie $\leq 5 \mathrm{mg}$ (Riesenzellarteriitis)/ $\leq 10$ mg (TakayasuArteriitis) täglich nach $1 \mathrm{Jahr}$ erreicht werden.

\section{Empfehlung 3c (Konsens)}

Die Glukokortikoidreduktion sollte unter klinischen und laborchemischen Kontrollen individuell festgelegt werden. Als Ziel sollte die individuell niedrigste effektive Glukokortikoiddosierung angestrebt werden, einschließlich eines individuell gesteuerten vollständigen Ausschleichens der Glukokortikoide bei nach 1 Jahr anhaltender Remission.

Es existiert bis dato keine hochwertige Evidenz, aus der sich ein ideales GCReduktionsschema für die Therapie von GGV in der klinischen Praxis ableiten lässt.

In dieser Leitlinie werden die Definitionen der EULAR für Remission, 
Tab. 4 Definition von Aktivitätsstadien der GGV nach EULAR-Empfehlungen von 2018 [102]

\begin{tabular}{|c|c|}
\hline Aktivitätsstadium & EULAR-Konsensusdefinition \\
\hline Aktive Erkrankung & $\begin{array}{l}\text { 1. Vorhandensein typischer Anzeichen oder Symptome einer aktiven GGV } \\
\text { UND } \\
\text { 2. mindestens eines der Folgenden: } \\
\text { a. Gegenwärtige Aktivität in Bildgebung oder Biopsie } \\
\text { b. Ischämische Komplikationen, die der GGV zugeschrieben werden } \\
\text { c. Persistierend erhöhte Entzündungswerte (nach Ausschluss anderer } \\
\text { Ursachen) }\end{array}$ \\
\hline Schub & Verwendung dieses Begriffes nicht empfohlen \\
\hline Rezidiv & $\begin{array}{l}\text { Verwendung der Begriffe "schweres" und "leichtes" Rezidiv empfohlen } \\
\text { (s. unten) }\end{array}$ \\
\hline Schweres Rezidiv & $\begin{array}{l}\text { Wiederauftreten einer aktiven Erkrankung mit einem der Folgenden: } \\
\text { a. Klinische Zeichen einer Ischämie (einschließlich Kieferclaudicatio, visuel- } \\
\text { len Symptomen, der RZA zuschreibbarem Visusverlust, Kopfhautnekrose, } \\
\text { Insult, Claudicatio der Extremitäten) } \\
\text { b. Nachweis einer aktiven aortalen Entzündung, die zu fortschreitender } \\
\text { Großgefäßdilatation, -stenose oder -dissektion führt }\end{array}$ \\
\hline Leichtes Rezidiv & $\begin{array}{l}\text { Wiederauftreten einer aktiven Erkrankung, die nicht die Kriterien eines } \\
\text { schweren Rezidivs erfüllt }\end{array}$ \\
\hline Refraktär & $\begin{array}{l}\text { Unmöglichkeit, eine Remission zu induzieren (mit Nachweis einer Reak- } \\
\text { tivierung der Erkrankung, wie oben unter ",aktive Erkrankung" definiert) } \\
\text { trotz des Einsatzes der Standardtherapie }\end{array}$ \\
\hline Remission & $\begin{array}{l}\text { Abwesenheit aller klinischen Anzeichen und Symptome, die einer GGV zu- } \\
\text { zuordnen sind, und Normalisierung von BSG und CRP; zusätzlich sollte es } \\
\text { bei Patient(inn)en mit extrakranieller Erkrankung keinen Hinweis auf pro- } \\
\text { grediente Gefäßstenosen oder -dilatation geben (Frequenz wiederholter } \\
\text { Bildgebung sollte individuell entschieden werden) }\end{array}$ \\
\hline $\begin{array}{l}\text { Anhaltende Remis- } \\
\text { sion }\end{array}$ & $\begin{array}{l}\text { 1. Remission für mindestens } 6 \text { Monate } \\
\text { UND } \\
\text { 2. Erreichen der individuellen GC-Zieldosis }\end{array}$ \\
\hline GC-freie Remission & $\begin{array}{l}\text { 1. Anhaltende Remission } \\
\text { UND } \\
\text { 2. beendete GC-Therapie (immunsuppressive Therapie kann weiter erfol- } \\
\text { gen) }\end{array}$ \\
\hline
\end{tabular}

leichtes und schweres Rezidiv verwendet (- Tab. 4).

In der randomisiert kontrollierten doppelblinden GiACTA-Studie wurden 2 Gruppen mit RZA unter PrednisolonMonotherapie verglichen, die zusätzlich Placebo, jedoch keine Studienmedikation (TCZ) erhielten [253]. Diese Gruppen (GC-Monotherapie + Placebo) schlichen die GC binnen 26 bzw. 52 Wochen vollständig aus. In beiden Gruppen war die Rate anhaltender Remissionen in Woche 52 mit je 14,0 und 17,6\% (bzw. 20,0 und $33,3 \%$, wenn normalisiertes CRP nicht als Teil der Definition einer anhaltenden Remission verwendet wird) niedrig. Das Studienprotokoll war jedoch darauf ausgelegt, die Effektivität der Studienmedikation und nicht die optimale Dauer einer GC-Therapie zu demonstrieren. Die Empfehlung zur Reduktion einer GC-Monotherapie sieht schrittweise Reduktion. [141, 172]. duell niedrigste effektive GC-Dosierung erreicht wird, z. B. zunächst $\leq 5 \mathrm{mg}$ (RZA) bzw. $\leq 10 \mathrm{mg}$ (TAK) Prednisolonäquivalent täglich nach 1 Jahr. Der Versuch eines langsamen weiteren Ausschleichens bis zum Absetzen wird in der Regel nach einer längeren rezidivfreien Remission individuell erwogen.

Bei Patienten mit RZA, die mit GCeinsparender Medikation behandelt werden, ist evtl. eine schnellere GC-Reduktion möglich (s. Empfehlung 4).

Bei TAK kommt es bei bis zu $70 \%$ der Betroffenen im Verlauf zu Rezidiven mit vaskulären Komplikationen [50, 200]. Dazu trägt bei TAK offensichtlich eine rasche Prednisolon-Dosisreduktion deutlich bei [200]. Insbesondere eine rasche GC-Reduktion auf $<10 \mathrm{mg} / \mathrm{Tag}$ in den ersten 6 Monaten begünstigt wiederholte Rezidive. Deshalb wird bei TAK ab ca. dem dritten Monat die GC-Dosis langsamer reduziert als bei RZA: Die GC-Zieldosis bei TAK ist $\leq 10 \mathrm{mg}$ Prednisolonäquivalent täglich nach 1 Jahr. Die verfügbaren Daten geben nur Anhalte für die GC-Dosierung, da sie Kohortenanalysen und nicht aus prospektiven Studien entstammen. Im individuellen Verlauf hängt die GC-Reduktion von dem Ergebnis der klinischen und laborchemischen Untersuchung, ggf. ergänzt durch Bildgebung ab. Ziel ist immer die individuell niedrigste effektive Dosierung.

daher kein rasches und vollständiges Ausschleichen auf Basis der verfügbaren Daten vor, sondern eine langsame

Da eine GC-Therapie mit einem erheblichen Risiko unerwünschter Wirkungen und Komplikationen einhergeht [91, 234], wird im Verlauf eine Reduktion auf mit einem niedrigeren Komplikationsrisiko verbundene Dosierungen vorgenommen. Die Dosis wird (sofern die klinischen Symptome sistieren und die Entzündungsparameter normalisiert sind) schrittweise auf 10-15 mg (RZA) bzw. 15-20 mg (TAK) Prednisolonäquivalent täglich nach 3 Monaten reduziert

In der langfristigen Erhaltungstherapie wird die GC-Dosis in kleinen Schritten unter Kontrollen von klinischen Beschwerden und Entzündungswerten reduziert, bis die für die Betroffenen indivi-

\section{Empfehlung 3d (Konsens)}

Bei akutem Visusverlust oder einer Amaurosis fugax im Rahmen einer aktiven Riesenzellarteriitis (oder eines begründeten Riesenzellarteriitisverdachtes) sollte eine sofortige höher dosierte Glukokortikoidpulstherapie mit 500-1000 mg Methylprednisolon intravenös täglich über 3 bis 5 Tage erfolgen.

Gefäßverschlüsse im Rahmen einer aktiven RZA können zu ischämischen Komplikationen im Bereich der Augen (AION, Zentralarterienverschluss, Amaurosis fugax, Diplopie) und des zentralen Nervensystems (in der Regel Schlaganfall oder transitorische ischämische Attacke) führen [9, 88]. 
Okuläre Symptome werden in retrospektiven Arbeiten bei ca. einem Drittel der Fälle von RZA berichtet. Ein permanenter partieller und vollständiger Visusverlust tritt bei ca. 6-37\% der an RZA Erkrankten auf [78, 88, 110, 224, 276]. Eine transiente Amaurosis oder ein Flimmerskotom sind die wichtigsten Warnzeichen für den drohenden permanenten Sehverlust eines Auges, ebenso scheint die Kieferclaudicatio gehäuft einer RZA-assoziierten Sehstörung vorauszugehen [88]. Nach Eintreten eines einseitigen Sehverlustes droht binnen Stunden bis wenigen Wochen (in einer retrospektiven Studie Median 5 Tage) der Sehverlust auch des anderen Auges [88].

Die akute Sehstörung bei RZA beruht meist auf einer AION infolge eines Verschlusses der Aa. ciliares posteriores, welche die Papilla nervi optici und den posterioren Augenbereich mit Blut versorgen. Seltener liegt ein Verschluss der A. centralis retinae oder der A. ophthalmica zugrunde [100, 224].

Es gibt vereinzelt Hinweise aus retrospektiven Kohortenstudien mit hohem Biasrisiko, dass bei RZA-bedingtem Visusverlust die sofortige Gabe von hoch dosiertem (bis zu $1000 \mathrm{mg}$ ) Methylprednisolon für 2 bis 5 Tage zu einer Verbesserung der Sehfähigkeit führen kann [43]. Andere retrospektive Studien konnten eine Überlegenheit einer initialen intravenösen Hochdosis-GCPulstherapie verglichen mit der oralen Therapie zur Verbesserung der Sehfähigkeit nach initialem RZA-bedingtem Visusverlust aber nicht demonstrieren [88, 100]. Das Verbesserungspotenzial für die Sehfähigkeit nach bereits eingetretenem Sehverlust wird unterschiedlich eingeschätzt. Die Möglichkeit zur Verbesserung visueller Symptome hängt wohl auch von einem möglichst sofortigen Beginn (wenige Stunden bis evtl. $<24 \mathrm{~h}$ ) einer GC-Therapie nach Beginn der Sehstörung ab [88, 100]. Die sofortige hoch dosierte intravenöse GCPulstherapie soll insbesondere auch dem Schutz des kontralateralen Auges bzw. der Verhinderung des Fortschreitens eines partiellen Visusverlustes in eine vollständige Erblindung dienen, wobei diese Hypothese nicht mit hochwertiger Evidenz belegt werden kann. Das
Eintreten permanenter Sehstörungen bei RZA scheint nach retrospektiven Berichten v. a. vor Beginn einer GC-Therapie aufzutreten, jedoch nur selten danach [224]. Auch unter bereits begonnener GC-Therapie kann es in Einzelfällen (insbesondere in den ersten Tagen der Therapie) noch zu einer Amaurosis des anderen Auges kommen [88]. Der permanente Sehverlust durch RZA geht mit einer erhöhten Mortalität einher [91, 96].

Zerebrovaskuläre Komplikationen manifestieren sich bei ca. 3-7\% der Betroffenen, in der Regel als ischämischer Insult oder transitorische ischämische Attacke infolge einer Beteiligung der hirnversorgenden supraaortalen Gefäße [88, 227], wobei das vertebrobasiläre Stromgebiet im Gegensatz zu arteriosklerotisch bedingten Insulten häufiger betroffen erscheint [35]. Intrakraniell sind die V3- und V4-Abschnitte der Vertebralarterien bevorzugt betroffen $[35,88]$. Das Auftreten zerebrovaskulärer Ereignisse ist häufiger bei RZA mit okulären Symptomen und eine erhebliche Quelle von Morbidität und Mortalität [35]. Häufig wird bei schwerwiegenden ischämischen Komplikationen in anderen Organsystemen (z. B. kritische Extremitätenischämie) ebenfalls eine Methylprednisolon-Pulstherapie durchgeführt. Da akute zerebrovaskuläre Ereignisse bei RZA in der Mehrzahl trotz bereits begonnener hoch dosierter GC-Therapie eintreten [88], oftmals nur eine geringe Erhöhung der AkutePhase-Proteine vorliegt [35] und bis dato keine prospektiven Studiendaten vorliegen, die eine Verbesserung klinisch relevanter Endpunkte unter einer i.v.-GC-Pulstherapie zeigen, erfordert der Einsatz stets die Berücksichtigung möglicher Risiken (Infektgefährdung, Blutdruck- und Blutzuckerentgleisung etc.). Die Mortalität bei Patienten mit RZA und Schlaganfall scheint unter einer kombinierten Therapie mit Kortikoiden und Immunsuppressiva geringer zu sein [10].

\section{Glukokortikoid-einsparende Therapie bei Riesenzellarteriitis}

\section{Empfehlung 4a (Konsens)}

Bei bestimmten an Riesenzellarteriitis Erkrankten (insbesondere refraktäre oder rezidivierende Erkrankung, Vorhandensein von oder erhöhtes Risiko für Glukokortikoid-assoziierte Folgeschäden) sollte nach individueller Abwägung eine Glukokortikoid-einsparende Therapie mit Tocilizumab durchgeführt werden. Methotrexat kann als Alternative eingesetzt werden.

\section{Empfehlung 4b (Konsens)}

Unter einer Therapie mit Tocilizumab bei Riesenzellarteriitis sollte eine schnellere Reduktion der Glukokortikoiddosis verglichen mit der Glukokortikoidmonotherapie erfolgen. Auch unter Therapie mit Methotrexat bei Riesenzellarteriitis sollte eine raschere Glukokortikoiddosisreduktion angestrebt werden.

\section{Empfehlung 4c (Konsens)}

Bei anhaltender Remission bei der Riesenzellarteriitis sollte eine Deeskalation oder Beendigung der Glukokortikoideinsparenden Therapie erwogen werden.

GC-induzierte oder GC-aggravierte Komorbiditäten und Komplikationen sind ein häufiges Problem bei RZA [142]. $\mathrm{Zu}$ den GC-assoziierten Komorbiditäten zählen unter anderem arterielle $\mathrm{Hy}$ pertonie, Diabetes mellitus, Glaukom, Infektionen, Katarakt, Nebennierenrindeninsuffizienz und osteoporotische Frakturen [39, 44, 65, 121, 151, 209, 234, 270, 271]. Eine Task-Force der European League Against Rheumatism (EULAR) kam zu dem Ergebnis, dass Prednisolon-Dosierungen von $>10 \mathrm{mg}$ täglich (unabhängig von der behandelten Erkrankung) langfristig das Risiko von Komplikationen deutlich erhöhen, während Prednisolon-Dosierungen von $\leq 5 \mathrm{mg} /$ Tag mit einem niedrigen Komplikationsrisiko einhergehen (hiervon 
ausgenommen sind Fälle mit hohem kardiovaskulärem Risiko).

Bis zu $70 \%$ der an RZA Erkrankten entwickeln einen rezidivierenden Verlauf [9, 96, 105]. Einige Autoren beschrieben höhere Entzündungswerte bei Erstdiagnose als Risikofaktor für eine rezidivierende Erkrankung [110, 193], andere konnten dies nicht bestätigen [96]. Ein verlässlicher Parameter zur Abschätzung von GC-Bedarf, der notwendigen Dauer einer GC-Therapie und des Rezidivrisikos ist nicht verfügbar.

Abhängig vom Risikoprofil für GCaggravierte Komorbiditäten und von dem Vorliegen einer rezidivierenden Erkrankung oder eines hohen GC-Bedarfs wird bei Betroffenen mit RZA individuell die Indikation zur begleitenden GC-einsparenden Therapie gestellt.

In einer randomisiert kontrollierten doppelblinden Phase-3-Studie $(n=251$ RZA-Fälle) konnte nachgewiesen werden, dass der Interleukin-6-RezeptorAntagonist TCZ (in einer Dosis von $162 \mathrm{mg}$ s.c. wöchentlich) kombiniert mit einer GC-Therapie die Rate in Remission verbleibender Betroffener gegenüber denen mit einer GC-Monotherapie (+ Placebo) Behandelten signifikant erhöht, bei gleichzeitig deutlich reduziertem kumulativem GC-Bedarf und vergleichbaren Komplikationsraten [253]. Eine randomisiert kontrollierte doppelblinde Phase-2-Studie ( $n=30$ RZA-Fälle) zeigte ebenfalls eine höhere Rate von Remission nach 12 Wochen, ein erhöhtes rezidivfreies Überleben und einen verringerten GC-Bedarf in einer mit TCZ (8 mg/kg i.v. 4-wöchentlich) und Prednisolon behandelten Gruppe verglichen mit der Kontrollgruppe (Prednisolon und Placebo) [263].

TCZ wurde auf dem Boden dieser Studiendaten für die Behandlung der Riesenzellarteriitis in einer Dosis von $162 \mathrm{mg}$ s.c. wöchentlich zugelassen (und ist damit die bisher einzige in Europa zur Therapie der RZA zugelassene Substanz).

Die Therapie in beiden Studien ist über ca. 1 Jahr erfolgt, es liegen keine Daten oder verlässlichen Biomarker vor, aus denen eine notwendige Dauer der Fortführung einer Therapie mit TCZ sicher abgeleitet werden kann oder ob ein Reduktionsschema dem direkten Absetzen von
TCZ vorzuziehen ist. Langzeitdaten der oben erwähnten Phase-2-Studie zu TCZ bei RZA und der GiACTA-Studie zeigten, dass es nach Beendigung der Therapie mit TCZ bei einem Teil der Patienten im Verlauf zu einem Rezidiv kam [6, 252]. Weitere retrospektive oder Open-labelStudiendaten belegen die Wirksamkeit von TCZ bei der RZA [41, 156].

Es liegen 3 randomisiert kontrollierte doppelblinde Studien zur Effektivität von Methotrexat (MTX) bei RZA mit uneinheitlichen Ergebnissen vor. Jover et al. ( $n=42$ Fälle) beschrieben, dass die Kombination von MTX 10 mg p.o. wöchentlich mit Prednisolon (verglichen mit Placebo + Prednisolon) mit einer Reduktion des Rezidivrisikos und einer niedrigeren kumulativen GC-Dosis assoziiert war [125]. Zwei weitere Studien konnten keinen Nutzen einer MTX-Therapie kombiniert mit GC verglichen mit einer GC-Monotherapie (+ Placebo) belegen. Hoffman et al. ( $n=98$ Fälle) konnten unter einer MTX-Dosierung von $0,15 \mathrm{mg}$ MTX/kgKG p.o. (bei guter Verträglichkeit erhöht auf 0,25 mg/kgKG, maximal $15 \mathrm{mg}$ ) wöchentlich keine Reduktion von Rezidiven und keinen GC-einsparenden Effekt für MTX nachweisen (mit der Ausnahme von signifikant weniger Rezidiven mit isolierter Polymyalgie) [111]. Spiera et al. ( $n=21$ Fälle) verwendeten eine MTX-Startdosis von 7,5 mg p.o. wöchentlich (Beginn sobald GC auf $30 \mathrm{mg}$ reduziert worden waren), die bei Rezidiven jeweils um 2,5 mg wöchentlich erhöht wurde (Maximaldosis $20 \mathrm{mg}$ wöchentlich) [251]. Hierunter ließ sich kein GC-einsparender Effekt für MTX nachweisen.

Eine gemeinsame Analyse der Datensätze der 3 zuletzt genannten Studien in einer Metaanalyse ergab jedoch, dass MTX sowohl signifikant das Rezidivrisiko reduziert, als auch GC-einsparend wirkt [163]. Die Metaanalyse zeigte ein signifikant reduziertes Risiko für das erste und zweite Rezidiv, eine höhere Wahrscheinlichkeit für GC-freie Remission über 24 Wochen und eine niedrigere kumulative GC-Dosis zu Woche 48 bei mit MTX Behandelten im Vergleich zu Kontrollpersonen. Unter der Therapie mit MTX kam es nicht zu mehr unerwünschten Ereignissen als in den Place- bogruppen. Es ist zu beachten, dass MTX in den oben genannten Studien per os und teils in relativ niedrigen Dosierungen verabreicht wurde. Ob MTX in höheren Dosen oder durch subkutane Verabreichung effektiver sein könnte (wie dies bei anderen rheumatischen Erkrankungen, z. B. rheumatoider Arthritis, angenommen wird), ist nicht durch Studien bei der RZA belegt [101]. Weitere retrospektive Studien geben Hinweise auf eine Effektivität von MTX bei RZA [139, 150].

Infolgedessen stellt MTX eine alternative Option zur GC-einsparenden Therapie dar, ist in dieser Indikation aber formal nicht zugelassen.

In der GiACTA-Studie wurde die GCDosis in den TCZ-Behandlungsarmen innerhalb von 26 Wochen vollständig ausgeschlichen. Mehr als 50\% der an RZA Erkrankten blieben unter diesem Procedere auch nach 52 Wochen in Remission [253]. Daher sollte bei an RZA Erkrankten unter TCZ-Therapie eine raschere GC-Reduktion erwogen werden (unter entsprechenden Kontrollen, da unter dieser raschen GC-Reduktion auch in den TCZ-Behandlungsarmen Rezidive auftraten). Auch unter Therapie mit MTX könnte eine schnellere GCReduktion möglich sein, wobei mangels standardisierter Protokolle bzw. Studiendaten keine konkrete Empfehlung zu einem bestimmten Reduktionsschema abgegeben werden kann.

Es liegt keine Studie vor, in der MTX und TCZ direkt verglichen worden sind. Die unterschiedlichen Studiendesigns schließen belastbare Schlussfolgerungen über die mögliche Überlegenheit eines Wirkstoffs gegenüber dem anderen aus. Weitere Studien sind erforderlich, um die optimale Behandlungsdauer, das GC-Reduktionsregime und Strategien zur Reduktion oder Beendigung der GC-einsparenden Therapie, die Kosteneffizienz und die Überwachung einer Therapie einer RZA unter TCZ oder MTX zu definieren.

\section{Andere Immunsuppressiva bei Riesenzellarteriitis}

Für den Einsatz anderer Immunsuppressiva inklusive Biologika bei der RZA besteht keine oder eine nur sehr eingeschränkte Evidenz, da die wenigen kon- 
trollierten randomisierten Studien entweder keine Wirksamkeit zeigten oder aufgrund methodischer Mängel einen signifikanten Bias aufweisen [182] und somit keine generelle Therapieempfehlung begründen können.

\section{Weitere konventionelle Immun- suppressiva (außer Methotrexat)}

Eine randomisiert kontrollierte doppelblinde Studie berichtete einen GCeinsparenden Effekt für Azathioprin, jedoch wurden lediglich 31 Personen untersucht, diese litten teils an RZA, teils an PMR [61]. Aufgrund methodischer Mängel lässt sich aus diesen Daten keine überzeugende Evidenz für eine Wirksamkeit von Azathioprin bei der RZA ableiten [182].

Eine prospektive, nicht randomisierte Open-label-Studie und retrospektive Fallserien berichteten über einen möglichen Effekt von Leflunomid als GCeinsparende und das Rezidivrisiko reduzierende Substanz bei der RZA [5, 109, 257].

Retrospektive Fallserien berichten den erfolgreichen Einsatz von Cyclophosphamid (kontinuierlich p.o. oder i.v.-Pulstherapie) bei RZA mit hohem GC-Bedarf [31, 155, 213].

Keine der Studien zu Leflunomid oder Cyclophosphamid war randomisiert, sodass ein niedriges Evidenzniveau vorliegt.

Cyclosporin A zeigte in einer kontrollierten Studie keinen GC-einsparenden Effekt. Eine Therapie mit Dapson zeigte in einer Studie Wirksamkeitssignale, ging jedoch mit häufigen und teils schwerwiegenden Nebenwirkungen einher, sodass beide Medikamente zur Therapie der RZA keine günstige Datenlage haben $[160,230,231]$.

\section{Weitere Biologika (außer Tocilizumab)}

Es liegen 3 doppelblinde, randomisiert kontrollierte Studien zu Anti-TNF-Therapien bei RZA vor. In einer Studie wurde eine remissionserhaltende Therapie mit Infliximab $(n=29)$ oder Placebo $(n=16)$ jeweils zusammen mit GC bei Erkrankten mit der Neudiagnose einer RZA nach einer Remissionsinduktion mit GC verglichen. Die Studie wurde aufgrund der
Ergebnisse einer Interimsanalyse bereits nach 22 statt wie geplant nach 54 Wochen abgebrochen. Die Daten ergeben keinen Vorteil für Infliximab bezüglich einer Rezidivfreiheit oder Möglichkeit zur Reduktion von GC ohne Rezidiv [112]. Eine weitere Studie verglich eine Therapie mit Etanercept $(n=9)$ oder Placebo $(n=9)$ kombiniert mit GC. Obwohl in der Etanercept-Gruppe bei mehr Fällen als in der Placebogruppe (50 und $22 \%$, Unterschied nicht statistisch signifikant) nach 12 Monaten eine GC-freie Kontrolle der RZA möglich war und in der Etanercept-Gruppe eine signifikant niedrigere kumulative GC-Dosis nachweisbar war, lässt die Studie aufgrund der kleinen Fallzahl keine definitiven Schlüsse zu [169]. Eine weitere Studie verglich Adalimumab $(n=34)$ mit Placebo $(n=36)$ jeweils in Kombination mit GC bei neu diagnostizierter RZA. Es konnte kein Unterschied zwischen beiden Gruppen hinsichtlich des Erreichens einer Remission unter niedrig dosierten GC nachgewiesen werden [239]. Zusammenfassend hat keine dieser Studien zu Anti-TNF-Therapien eine Wirksamkeit bei RZA belegen können.

Eine doppelblinde, randomisiert kontrollierte Studie zeigte eine (statistisch gerade signifikante) Reduktion des Rezidivrisikos, wenn Prednisolon mit Abatacept kombiniert wurde (gegenüber Placebo). Die Studie war nicht zur Untersuchung der Reduktion GC-induzierter Morbidität ausgelegt [144].

Es liegen eingeschränkte Daten zum Einsatz von Ustekinumab bei RZA vor, das möglicherweise einen GC-einsparenden Effekt bei RZA haben könnte [52, 53].

Weitere Studien sind notwendig, um die Effektivität von weiteren Biologika bei der RZA zu definieren.

\section{Glukokortikoid-einsparende Therapie bei Takayasu-Arteriitis}

\section{Empfehlung 5 (Konsens)}

An einer Takayasu-Arteriitis Erkrankte sollten zusätzlich zu Glukokortikoiden mit konventionellen Immunsuppressiva behandelt werden. Bei refraktären, rezidivierenden oder Glukokortikoidabhängigen Verläufen sollten Tumornekrosefaktor-alpha-Inhibitoren oder Tocilizumab erwogen werden.

Bei der TAK besteht ein hohes Risiko für Rezidive (bis zu 70\%) und progrediente arterielle Läsionen [50, 200]. Retrospektive Kohortenstudien zeigen, dass immunsuppressive Medikamente zusätzlich zu GC bei TAK in den letzten Jahren zunehmend angewendet werden und dass analog zu dieser Entwicklung eine Besserung der Prognose belegt ist. Hierunter wird eine Reduktion des Auftretens neuer vaskulärer Läsionen und des Rezidivrisikos berichtet [94, 173, 200]. Die Empfehlung zum primären Einsatz einer konventionellen immunsuppressiven Therapie bei der TAK basiert daher auf Fallserien und Kohortenstudien, publizierte randomisiert kontrollierte Studien liegen nicht vor [7].

$\mathrm{Da}$ es keine Zulassung für eine medikamentöse Therapie bei TAK gibt, ist formal jeder Einsatz einer Therapie mit konventionellen Immunsuppressiva oder Biologika bei TAK „Off-Label“.

\section{Konventionelle Immunsuppressiva}

Drei kleine prospektive bzw. retrospektive Fallserien (insgesamt 61 Erkrankte) $[87,152,246]$ und eine Metaanalyse aus 2 dieser Fallserien [60] berichten bei insgesamt guter Verträglichkeit über eine Reduktion der Krankheitsaktivität und ein GC-einsparendes Potenzial unter Mycophenolat-Mofetil (MMF).

Hoffman et al. berichteten über eine Remissionsrate von $81 \%$ und eine deutliche Reduktion des Bedarfs an GC in einer Open-label-Studie zu MTX (in Kombination mit GC) bei 16 an TAK Erkrankten [113]. Im Rahmen einer kleinen, nicht kontrollierten Studie wurde der Einsatz einer Sequenz aus einer 3-monatigen oralen Cyclophosphamid-Therapie gefolgt von einer Erhaltungstherapie mit wöchentlichem MTX untersucht [80]; für die Auswertung konnten 8 Fälle herangezogen werden, davon hatten $4(50 \%)$ eine anhaltende Remission. Die Kurzund Langzeitdaten einer weiteren kleinen prospektiven Fallserie $(n=15$ Fälle) beschrieben eine hohe Remissionsrate $(93 \%)$, einen rezidivprophylaktischen 
und GC-einsparenden Effekt und eine akzeptable Verträglichkeit von Leflunomid $20 \mathrm{mg} /$ Tag bei etwa $50 \%$ der hiermit behandelten an TAK Erkrankten [248, 250].

Eine kleine, ebenfalls nicht kontrollierte Studie beschrieb eine Kontrolle der entzündlichen Krankheitsaktivität bei guter Verträglichkeit unter einer Kombinationstherapie von GC und Azathioprin bei TAK [262].

Eine aktuelle Sammlung von Fallserien und eine Metaanalyse fassen die bis dato publizierten Fallserien zusammen mit Hinweisen auf eine Effektivität der untersuchten Substanzen MTX, AZA, MMF, CYC, Tacrolimus und Leflunomid [20, 179].

\section{Biologika}

Innerhalb des Publikationszeitraumes der verwendeten Literatur liegen 2 randomisierte, placebokontrollierte Studien zum Einsatz von Biologika (TCZ und Abatacept) bei TAK vor. Beide Studien erreichten jedoch ihren primären Endpunkt nicht [145, 188]. Die Abatacept-Studie wurde an insgesamt 34 an TAK Erkrankten durchgeführt, es wurde - verglichen mit Placebo - kein therapeutischer Effekt nachgewiesen. In der Studie zu TCZ wurden insgesamt 36 Betroffene mit rezidivierender TAK eingeschlossen und erhielten entweder GC plus Placebo oder GC plus TCZ $162 \mathrm{mg} /$ Woche. Die zu Studienbeginn individuell unterschiedliche GC-Dosis wurde nach einem definierten Schema ab Woche 4 um $10 \%$ pro Woche bis auf minimal $0,1 \mathrm{mg} / \mathrm{kgKG}$ reduziert; der primäre Endpunkt war die Zeit bis zum ersten Rezidiv. Es zeigten sich in dieser Studie ein Trend zur Reduktion der Hazard Ratio (HR) für die Zeit bis zum ersten Rezidiv, der knapp nicht statistisch signifikant war, und ein ebenfalls nicht signifikanter Trend in der Verbesserung einiger sekundärer Endpunkte in der Intention-to-treat-Gruppe (eine als Sensitivitätsanalyse durchgeführte Auswertung der „Per Protocol“ behandelten Gruppe ergab dagegen eine statistisch gerade signifikante Reduktion der HR für die Zeit bis zum ersten Rezidiv). Zusätzliche Erfahrungen mit der TCZ-Behandlung bei TAK liegen aus prospektiven und retrospektiven, nicht kontrollierten Fallserien mit überwiegend zuvor therapierefraktärem Verlauf vor. In diesen Auswertungen wurde unter Einsatz von TCZ eine Reduktion der Krankheitsaktivität und/oder des GCBedarfs berichtet $[1,86,173,175,187$, 201, 259, 279].

Diverse Autoren berichten den erfolgreichen Einsatz der TNF-Inhibitoren Adalimumab, Etanercept und Infliximab zur Behandlung der TAK in offenen, nicht kontrollierten Studien und Fallserien, wobei die meisten Fallberichte zum Einsatz von Infliximab vorliegen [51, 94, 114, 173, 174, 181, 197, 199, 201, 214, 233, 240]. Kleine Fallserien berichten auch über den erfolgreichen Einsatz von Golimumab und Certolizumab [198, 256]. Eine Metaanalyse von Barra et al. und ein Review von Misra et al. bestätigen den anzunehmenden GC-einsparenden Effekt der Biologikatherapie aus den Fallserien [20, 179].

Zwei größere Fallserien deuten darauf hin, dass der rezidivprophylaktische Effekt durch eine Anti-IL-6R- oder AntiTNF-Therapie (bei einem Teil der Behandelten kombiniert mit konventionellen Immunsuppressiva) größer sein könnte als der durch konventionelle Immunsuppressiva [94, 173]. So war die Rate an anhaltenden Remissionen in einer norwegischen Kohortenstudie mit insgesamt 97 Fällen in der Gruppe, die einen TNFInhibitor erhielten, deutlich höher als in der Gruppe mit konventionellen Immunsuppressiva (42 vs. $20 \%$ ) [94].

Eine retrospektive Fallserie beschreibt den Einsatz von Rituximab bei einer geringen Zahl Betroffener mit TAK $(n=7)$ und uneinheitlichem Ansprechen auf die Therapie (Ansprechen bei $n=3$ ) [207].

In einer kleinen Serie von 3 Fällen und einem Einzelfallbericht wurde die Effektivität von Ustekinumab als GC-einsparende Medikation bei TAK beschrieben [258, 273].

Eine valide Evidenz aus kontrollierten Studien, die eine bessere Wirksamkeit von Biologika im Vergleich zu konventionellen Immunsuppressiva belegt, existiert bis dato noch nicht. Unter Berücksichtigung der bei dieser seltenen Erkrankung zur Verfügung stehenden eingeschränkten Evidenz stellen TNF-Inhi- bitoren und TCZ eine Reservetherapie bei therapierefraktärer TAK dar.

\section{Andere Therapieformen}

Zwei große doppelblinde randomisierte placebokontrollierte Studien beschreiben den Einsatz von Curcumin und Resveratrol bei TAK $[241,245]$. Aus den nur sehr eingeschränkt verfügbaren Informationen zu Diagnosestellung, Komedikation und Definition von Krankheitsaktivität und bei kurzer Nachbeobachtungsdauer lassen sich keine Therapieempfehlungen für die Praxis ableiten.

\section{Rezidivbehandlung}

\section{Empfehlung 6 (Starker Konsens)}

Bei einem schweren Rezidiv einer Großgefäßvaskulitis soll erneut eine Glukokortikoidtherapie begonnen bzw. eine bestehende Glukokortikoidtherapie intensiviert werden (Initialdosierung wie bei einer neu diagnostizierten Großgefäßvaskulitis). Bei einem leichten Rezidiv sollte die Glukokortikoiddosis auf mindestens die letzte wirksame Dosis erhöht werden. Eine Glukokortikoidsparende Therapie sollte bei rezidivierender Erkrankung begonnen oder angepasst werden.

Je nach Rezidivdefinition entwickeln bis zu $70 \%$ der an RZA und TAK Erkrankten unter einer GC-Monotherapie Rezidive $[50,96,105,142,154,167,200,209$, 219]. Im Sinne einer international einheitlichen Nomenklatur verwenden wir die Rezidivdefinition der aktuellen Empfehlungen der EULAR zu GGV (• Tab. 4; [102]).

Hinweise auf eine zunehmende Aktivität einer GGV können sein [142]:

- asymptomatischer Anstieg der Entzündungsparameter (ohne andere Erklärung),

- das (Wieder-)Auftreten krankheitsspezifischer Symptome (bis hin zum akuten Auftreten ischämischer Komplikationen) mit oder ohne gleichzeitigen Anstieg der Entzündungsparameter, 
- progrediente, auf eine fortbestehend aktive Entzündung hindeutende Befunde in der Bildgebung.

Kermani et al. beschrieben symptomatische Rezidive bei RZA auch ohne Anstieg von BSG oder CRP in $21 \%$ der Fälle [132]. Die Daten der GiACTA-Studie zeigen bei den mit Prednisolon (+ Placebo, also nicht mit TCZ) behandelten Gruppen, dass bei ca. einem Drittel der Rezidive normale Entzündungsparameter vorliegen. Parallel lagen bei über $50 \%$ der Betroffenen erhöhte Entzündungsparameter vor, ohne dass ein klinisches Rezidiv vorlag [254]. Einem asymptomatischen Anstieg der BSG auf $\geq 40 \mathrm{~mm} / \mathrm{h}$ folgte jedoch in $80 \%$ der Fälle ein klinisches Rezidiv in einer randomisierten, doppelblinden, placebokontrollierten Studie zum Effekt von MTX bei RZA [111]. Unter TCZ kommt es in der Regel nicht (bzw. nur sehr selten) zu einem Anstieg des CRP oder der BSG, dies gilt für GGVRezidive wie auch andere entzündliche Konstellationen, z.B. Infektionen [254]. Die Daten der GiACTA-Studie zeigten auch, dass ein größerer Teil der Rezidive unter noch nicht beendeter PrednisolonTherapie auftrat $(63 \%$ der Rezidive in den TCZ-Gruppen, $76 \%$ der Rezidive in den Placebogruppen) [254]. Autopsiestudien und Verlaufsstudien zur Bildgebung sowie TAB zeigen, dass sich bei zahlreichen Betroffenen mit GGV in klinischer Remission noch entzündete Gefäßwände in Histopathologie oder Bildgebung nachweisen lassen (ausführliche Diskussion dieser Daten im Abschnitt „Diagnostik“).

Nach einem Rezidiv einer GGV verlängert sich in der Regel die Dauer der GC-Therapie, woraus höhere kumulative GC-Dosen resultieren [167].

Bei Auftreten eines Rezidivs oder einer chronisch aktiven Erkrankung besteht stets das Risiko erneuter vaskulärer Komplikationen. Die Erhöhung der GC-Dosis (gefolgt von einer sukzessiven Reduktion nach Normalisierung von Symptomen und Entzündungsparametern) und die Prüfung einer Intensivierung der immunsuppressiven Medikation erfolgen daher bei jedem Rezidiv abhängig von dessen Schweregrad.

Es gibt keine Studien, die speziell die Therapie von Rezidiven bei GGV unter- suchten. Selbst bei größeren Kohortenstudien zu Rezidiven in der RZA fehlen häufig detaillierte Informationen zur Behandlung des Rezidivs bezüglich GC-Dosis und Reduktion, Beginn der Gabe von anderen Immunsuppressiva usw. [132, 142]. Die Protokolle zur Rezidivbehandlung unterscheiden sich zwischen den kontrollierten Studien, und die heterogenen Studiendesigns und Begleittherapien erlauben keine belastbare Schlussfolgerung, welche der verschiedenen Strategien die beste ist.

Bei rezidivierender GGV wird in der Regel eine GC-einsparende Therapie initiiert (falls nicht bereits bei Erstdiagnose begonnen) und/oder eine bereits bestehende GC-einsparende Therapie angepasst (z. B. Dosissteigerung oder Umstellung auf ein anderes Mittel).

Bisher gibt es keine randomisierten kontrollierten Studien zur Rezidivtherapie bei GGV. Die GiACTA-Studie umfasste 132 an RZA Erkrankte mit Krankheitsrezidiv, und TCZ war in dieser Situation der GC-Monotherapie überlegen [253]. Nach Absetzen von TCZ ließ sich im zweiten Abschnitt der GiACTA-Studie bei Rezidiven im Verlauf unter erneutem Beginn einer TCZ-Therapie in Kombination mit einer GC-Therapie wieder eine Remission erreichen [252].

Alle 3 randomisiert kontrollierten Studien zu MTX bei RZA umfassten nur neu diagnostizierte Erkrankungen. Eine Metaanalyse konnte zeigen, dass an RZA Erkrankte, die MTX erhielten, ein um $50 \%$ geringeres Risiko hatten, ein zweites Rezidiv zu entwickeln, was für eine Wirksamkeit von MTX auch nach Eintreten eines Rezidivs spricht. Andere Wirkstoffe wurden entweder nicht prospektiv untersucht oder zeigten keine Anzeichen für eine Wirksamkeit bei rezidivierender RZA.

Bei trotz GC-Therapie und Einsatz konventioneller Immunsuppressiva rezidivierender TAK besteht die Option (gemäß Empfehlung 5), einen Wechsel auf einen TNF-Inhibitor oder TCZ durchzuführen.
7. Thrombozytenaggregationshemmer, Antikoagulanzien und Statine

\section{Empfehlung 7 (Konsens)}

\section{Thrombozytenaggregationshemmer, Antikoagulanzien oder Statine sollten nicht routinemäßig zur Behandlung von Großgefäßvaskulitiden angewendet werden, sofern keine andere Indikation dafür besteht.}

Während 2 retrospektive Studien mit insgesamt nur wenigen Ereignissen einen protektiven Effekt vor ischämischen Komplikationen (ischämisch bedingte Sehstörungen, Insult) bei an RZA Erkrankten beschrieben, deren Medikation Acetylsalicylsäure (ASS), andere Thrombozytenaggregationshemmer [149, 192] oder orale Antikoagulanzien [149] enthielt, konnte dieser Zusammenhang in anderen retrospektiven Studien [22, $88,189,224]$ nicht gefunden werden. Randomisiert kontrollierte Studien zum Einsatz von ASS bei RZA sind nicht verfügbar [180]. Eine Metaanalyse von 6 retrospektiven Studien konnte keinen protektiven Effekt einer bereits vor Diagnose der RZA etablierten ASS-Therapie belegen. Bei Betroffenen mit bereits bestehender RZA hatte die Kombination von ASS und GC einen allenfalls marginalen protektiven Effekt ohne Erhöhung des Blutungsrisikos [168]. In einer retrospektiven Untersuchung hatten kardiovaskuläre Risikofaktoren und die Einnahme von Thrombozytenaggregationshemmern hingegen keinen Einfluss auf das Schlaganfallrisiko [93].

Aus den widersprüchlichen Daten ist eine generelle Empfehlung für den Einsatz von ASS bei RZA nicht ableitbar, es sei denn, hierfür besteht eine andere Indikation (z.B. KHK, signifikante Gefäßstenosen). Unter Wertung der eingangs diskutierten Evidenz hat die EULAR ihre frühere Empfehlung, ASS als medikamentöse Prophylaxe ischämischer Komplikationen bei RZA einzusetzen [183], in der Auflage von 2019 revidiert [102].

In einer retrospektiven Studie bei TAK wurde ein signifikanter prophylaktischer 
Effekt vor ischämischen Ereignissen für ASS beschrieben [249].

Signifikante Gefäßstenosen (auch infolge einer GGV), ischämische Komplikationen (oder ein hohes Risiko dafür) sowie kardiovaskuläre Komorbiditäten wie Zustand nach Insult oder Myokardinfarkt sind mögliche Konstellationen, in denen eine Indikation für eine Therapie mit Thrombozytenaggregationshemmern vorliegen kann. Die begrenzte Datenlage ist aber zur Festlegung einer Empfehlung zu einem routinemäßigen Einsatz bei allen an GGV Erkrankten nicht ausreichend.

Kwon et al. beschrieben in einer retrospektiven Auswertung von 74 an TAK Erkrankten eine Reduktion der Rezidivrate bei denjenigen, die mit Statinen behandelt wurden [140]. Derzeit existiert keine ausreichende Evidenz, die einen routinemäßigen Einsatz von Statinen bei GGV außerhalb der zugelassenen Indikationen rechtfertigt [82, 190, 210, 211].

Diese Empfehlung bezieht sich lediglich auf die routinemäßige Behandlung der GGV, schließt aber den Einsatz von Antikoagulanzien, Thrombozytenaggregationshemmern und Statinen bei GGV - wenn eine Indikation dafür besteht selbstverständlich nicht aus.

\section{Verlaufskontrollen}

\section{Empfehlung 8 (starker Konsens)}

\section{An Großgefäßvaskulitiden Erkrankte sollen regelmäßig klinisch und labor- chemisch überwacht werden.}

Es sind keine Daten verfügbar, auf deren Boden sich optimale Intervalle für Langzeitverlaufskontrollen bei RZA oder TAK festlegen lassen [7, 182]. In Anbetracht der hohen Rezidivrate und der möglichen Folgen von rezidivbedingten Gefäß- und Organschäden sind engmaschige Kontrollen, insbesondere zu Erkrankungsbeginn üblich (z. B. im ersten Jahr alle 1 bis 3 Monate und danach alle 3 bis 6 Monate, bei rezidivfreier Remission evtl. jährliche Nachsorge unter geteilter Betreuung zwischen fachärztlicher bzw. rheumatologischer und hausärztlicher Versorgung; konkrete Empfehlun- gen lassen sich hier nicht durch Literatur ausreichend belegen). Die Kontrollen beinhalten zumindest eine klinische Beurteilung und die Messung von BSG und CRP.

Da es zu späten Rezidiven (auch wenn bereits eine therapiefreie Remission erreicht werden konnte) kommen kann und die Inzidenz von Aortenaneurysmen bei der RZA nach 5 Jahren ab Diagnose zunimmt [161], wird die Langzeitbeobachtung von Betroffenen mit RZA, die asymptomatisch bleiben, auf individueller Basis geplant.

Der Stellenwert einer routinemäßigen Bildgebung zur Aktivitätsbewertung bei an GGV Erkrankten in klinischer und laborchemischer Remission ist aktuell aufgrund der lückenhaften und teilweise widersprüchlichen Datenlage nicht ausreichend beurteilbar und kann deshalb noch nicht in die Empfehlung einfließen. Wie in den Empfehlungen zur Bildgebung beschrieben, ist der individuelle Einsatz bildgebender Verfahren zur Langzeitüberwachung struktureller Schäden möglich (z. B. CT-Angiographie oder MR-Angiographie zur Detektion von Aneurysmen der Aorta). Insbesondere an RZA Erkrankte, bei denen zum Zeitpunkt der Diagnose bildgebend eine Beteiligung der extrakraniellen großen Gefäße nachgewiesen wurde, kommen für eine bildgebende Langzeitüberwachung der Aorta infrage [26, 32, 33]. Auf den nicht abschließend geklärten Stellenwert wiederholter Bildgebung zur Erfassung entzündlicher Aktivität wird in den Empfehlungen zur Bildgebung näher eingegangen. Um die Aussagekraft bildgebender Verfahren in der Verlaufsbeurteilung der entzündlichen Aktivität von GGV besser zu charakterisieren und ihre Wertigkeit in der Steuerung immunsuppressiver Therapien $\mathrm{zu}$ definieren, sind weitere prospektive Studien notwendig.

Die Intensität der Langzeitbeobachtung bei der TAK richtet sich maßgeblich nach den durch die Erkrankung entstandenen Gefäß- und Organschäden (z.B. aortale und kardiale Komplikationen, zerebrale Durchblutungsstörung, Nierenarterienstenose) und wird folglich auf individueller Basis festgelegt.

\section{Versorgung vaskulärer \\ Komplikationen}

\section{Empfehlung 9 (Konsens)}

An Großgefäßvaskulitiden Erkrankte mit Gefäßkomplikationen sollten von einem interdisziplinären Gefäßteam betreut werden. Erforderliche endovaskuläre und operative Gefäßeingriffe sollten, wann immer möglich, in Remission der Vaskulitis erfolgen. Die Entscheidung für spezifische Verfahren sollte individuell und nach interdisziplinärer Abstimmung getroffen werden. Bei gefäßchirurgischen Eingriffen sollte Gewebe zur histopathologischen Untersuchung gewonnen werden. Nach arteriellen Rekonstruktionen sollte eine lebenslange Nachsorge erfolgen.

An RZA Erkrankte mit Beteiligung der extrakraniellen Gefäße stellen eine klinisch bedeutsame Subgruppe dar. Im Vergleich zu an RZA mit rein kranieller Manifestation Erkrankten sind diejenigen mit Beteiligung der supraaortalen Arterien (insbesondere A. axillaris) jünger, seltener von anhaltenden Sehstörungen, jedoch häufiger von einer Polymyalgia rheumatica betroffen. Möglicherweise ist die Beteiligung der extrakraniellen Gefäße assoziiert mit häufigerem Auftreten von Rezidiven und vaskulären Komplikationen [57, 75, 182, 186]. Insgesamt sind die Berichte hierzu uneinheitlich, einige Autoren fanden keine Unterschiede bezüglich des Outcomes [34].

Bei RZA ist die Inzidenz von Aortenaneurysmen/-dissektionen erhöht [77, 131]. An RZA Erkrankte mit aortalen Manifestationen haben ein höheres Risiko einer Dilatation der Aorta und eine gesteigerte, insbesondere kardiovaskulär bedingte Mortalität $[26,131]$. Dies gilt nicht für die RZA ohne Beteiligung der Aorta oder mit isolierten Stenosen ihrer großen Abgänge [131].

Bei der TAK stellen die morphologischen Veränderungen der Aorta und ihrer großen Abgänge eine Hauptkomplikation dar [122, 242].

Rauchen scheint mit einem erhöhten Risiko für die Entwicklung von Steno- 
sen großer Gefäße bei RZA und TAK assoziiert zu sein [108, 131].

Bei der Behandlung ischämischer Komplikationen der GGV gilt, dass die Indikation für revaskularisierende Eingriffe zurückhaltend zu stellen ist, in der Regel beschränkt auf organ- oder extremitätenbedrohende oder die Lebensqualität stark einschränkende Durchblutungsstörungen [29, 170]. Für viele Gefäßterritorien sind prinzipiell sowohl endovaskuläre als auch offen-chirurgische Verfahren einsetzbar. Die Entscheidung für ein spezifisches Verfahren erfolgt optimalerweise unter Berücksichtigung der Präferenz der an GGV Erkrankten im interdisziplinären Konsens. Während das periprozedurale Komplikationsrisiko bei offen-chirurgischen Gefäßeingriffen höher ist, ist nach endovaskulären Interventionen eine deutlich höhere Rate von Rezidivstenosen zu beobachten [29, 69, 204].

Ein weiterer Grundsatz ist, dass sowohl endovaskuläre als auch offen-chirurgische Eingriffe, wann immer möglich, erst nach eingetretener Remission der Krankheitsaktivität der GGV vorgenommen werden [170]. Es wurde gezeigt, dass bei chirurgischen oder endovaskulären Interventionen bei TAK die Rate an Komplikationen (z. B. Restenose, Notwendigkeit einer Reintervention, Thrombose, Ausbildung neuer stenotischer Läsionen an anderer Stelle, Tod) erhöht ist, wenn diese bei aktiv entzündlicher Erkrankung durchgeführt werden [79, 95, 143, 222, 223]. Durch die Kombination mit einer immunsuppressiven Therapie lässt sich dielangfristige Durchgängigkeit der behandelten Gefäße verbessern [29, $69,134,148,158,177]$. Schwerwiegende akute Durchblutungsstörungen (Aortendissektion, Schlaganfall, akutes Koronarsyndrom) können jedoch Notfalleingriffe auch im floriden Stadium der GGV erforderlich machen [29, 108, 134, 148, 204].

Nach jeder arteriellen Revaskularisation im Kontext einer GGV ist dauerhaft eine regelmäßige, auch bildgebende Nachsorge erforderlich.

\section{Aortale Komplikationen}

Die Aorta ist in bildgebenden Untersuchungen in mehr als $50 \%$ der Fälle einer RZA beteiligt $[25,208]$. Als Folge der chronischen aortalen Inflammation besteht ein erhöhtes Risiko für dilatative Veränderungen bis hin zu Aneurysmen [26]. Aneurysmen der thorakalen Aorta betreffen sowohl bei der RZA wie auch bei TAK häufig die Aorta ascendens mit der Gefahr der Ausbildung einer Aortenklappeninsuffizienz und folglich einer Herzinsuffizienz. Bei an RZA Erkrankten mit aortalen Komplikationen ist das Mortalitätsrisiko erhöht (insbesondere bedingt durch Aneurysmarupturen und Aortendissektionen) [26, 77, 131]. Möglicherweise zeigen Aneurysmen bei RZA eine etwas raschere Wachstumstendenz (im Mittel 1,5 mm/Jahr) gegenüber degenerativen Aneurysmen und darüber hinaus ein relevantes Risiko einer Dissektion bereits bei Diametern unter $5,0 \mathrm{~cm}$.

Die TAK kann selten in Stenosen der Aorta resultieren, dann typischerweise im Bereich der Aorta thoracalis descendens bzw. im thorakoabdominellen Übergang oder im viszeralen Segment (Midaortic-Syndrom [MAS]). Im Langzeitverlauf nach Diagnose einer TAK können ebenfalls in bis zu $10 \%$ der Fälle Aneurysmen der Aorta auftreten, Aneurysmarupturen stellen eine bedeutsame Ursache der erhöhten Mortalität bei TAK dar $[50,178]$.

Bei Fehlen spezifischer Daten für das Management von Aneurysmen infolge GGV erfolgt die Therapie nach den Grundsätzen der Behandlung herkömmlicher, degenerativer Aneurysmen [74, 221]. Während Pathologien der Aorta descendens heute überwiegend endovaskulär behandelt werden, stellen Aneurysmen der Aorta ascendens und des Aortenbogens nach wie vor eine Domäne der offenen Herzchirurgie (Aortenersatz ggf. mit Aortenklappenersatz oder -rekonstruktion) dar [74, 221]. Eine aktiv entzündliche bzw. unzureichend kontrollierte Erkrankung kann im Verlauf zu einer progredienten Aortendilatation (im Anschlusssegment) bzw. zu einer Klappen- oder Prothesendislokation führen [11, 171]. Alle aortalen Eingriffe sollten daher, wann immer möglich, nach Erreichen einer Remission der entzündlichen Aktivität der GGV erfolgen [4, 81, 171].

\section{Stenosen aortaler Äste}

GGV können über die Ausbildung einer myointimalen Hyperplasie durch Stenosen und Verschlüsse der großen Gefäße mit ischämischen Komplikationen symptomatisch werden [108].

Sowohl bei RZA als auch TAK betreffen ischämische Symptome am häufigsten die oberen Extremitäten (Armclaudicatio, sekundäres Raynaud-Phänomen, Pulsverlust und Blutdruckseitendifferenz). Durch Kollateralisierung ist einerseits die kritische Ischämie der oberen Extremitäten sehr ungewöhnlich, andererseits kann häufig durch die alleinige medikamentöse Therapie eine suffiziente Symptomkontrolle oder gar Beschwerdefreiheit erzielt werden [56, 58, 235]. Die Restenoseraten nach Ballonangioplastie wie auch nach Bypasschirurgie im Bereich der typischen Stenoselokalisation bei RZA (Aa. axillares/brachiales) sind hingegen hoch [29]. Bei Reverschlüssen von arteriellen Rekonstruktionen im Bereich der oberen Extremitäten kann eine extremitätenbedrohende Ischämie auftreten. Endovaskuläre und offen chirurgische Gefäßeingriffe zur Verbesserung der Armdurchblutung werden daher in der Regel auf kurzstreckige ostiale Stenosen der A. subclavia, wie sie bei der TAK vorkommen, beschränkt [170].

Zerebrovaskuläre Symptome sind bei der RZA meist durch Schlaganfälle im Bereich dervertebrobasilären Strombahn bedingt ( $3 \%$ bis zu $7 \%$ der Fälle) [ 89 , 227]. Die Therapie erfolgt über die medikamentöse Behandlung der RZA hinaus nach den allgemeinen Grundsätzen der Therapie des ischämischen Schlaganfalls. Bei der TAK dominieren hingegen chronisch hämodynamisch bedingte Durchblutungsstörungen bei Obstruktion mehrerer hirnversorgender Arterien. Bei persistierender symptomatischer zerebrovaskulärer Insuffizienz trotz medikamentöser Therapie stellt die Revaskularisation eine Behandlungsoption dar. Aufgrund der häufig langstreckigen und stark fibrotischen Veränderungen ist der Einsatz endovaskulärer Therapieverfahren (Ballonangioplastie mit oder ohne Stentimplantation) nicht selten limitiert und bleibt Fällen mit kurzstreckigen Befunden (z.B. ostiale Stenosen) 
bzw. mit hohem Operationsrisiko vorbehalten [170]. Gemäß retrospektiver Studien weisen chirurgische Verfahren (typischerweise aortokarotidaler oder Subclavia-karotidaler Bypass) niedrigere Restenoseraten auf als endovaskuläre Therapieverfahren, wenn auch ein relevantes perioperatives Schlaganfallrisiko besteht [126, 136, 158, 272].

Relevante Nierenarterienstenosen gelten als ungewöhnliche Manifestation der RZA, sind hingegen häufig (20-30\% der Fälle) bei der TAK zu finden [50, 228]. Typischerweise sind sie am Abgang der Nierenarterie lokalisiert und treten nicht selten beidseitig auf. Bei einer Subgruppe der TAK bestehen sie im Rahmen eines MAS. Bilaterale Nierenarterienstenosen und eine konsekutive Niereninsuffizienz bei TAK sind mit einer schlechteren Prognose assoziiert [115]. Die Erkennung der sekundären Hypertonie und deren Management sind häufig erheblich durch begleitende Obstruktionen der Schulter-Arm-Arterien erschwert mit falsch niedrig gemessenen Blutdruckwerten an den oberen Extremitäten. Hier kann die Bestimmung der systolischen Knöchelarteriendruckwerte und des KnöchelArm-Index hilfreich sein. Bei trotz intensiver antihypertensiver Therapie refraktärer arterieller Hypertonie, hypertoniebedingten Organkomplikationen (z.B. Linksherzinsuffizienz) oder Ver- schlechterung der Nierenfunktion bzw. Abnahme der Nierengröße (ischämische Nephropathie) besteht die Therapieoption einer Revaskularisation hämodynamisch relevanter Nierenarterienstenosen bei TAK. Die Beurteilung der hämodynamischen Relevanz von Nierenarterienstenosen erfolgt duplexsonographisch. Die Evidenz für die Revaskularisation von Nierenarterienstenosen infolge einer TAK beruht ausschließlich auf retrospektiven Fallserien. Eine Metaanalyse zeigte ein erheblich höheres Risiko für Restenosen nach endovaskulären Interventionen gegenüber offen chirurgischer Revaskularisation von Nierenarterienstenosen bei TAK [126]. Aufgrund der geringeren Invasivität wird meistens primär eine endovaskuläre Therapie eingesetzt. Eine Metaanalyse von Studien zur endovaskulären Therapie zeigte keine signifikanten Unterschiede bezüglich des klinischen Outcomes bei Fällen, die bei residualer Stenose/Dissektion mittels Stentimplantation behandelt wurden, gegenüber Fällen, die nur mittels Ballonangioplastie behandelt wurden [123]. Wenn eine Stentimplantation erforderlich war, war im Verlauf die Restenoserate erhöht [123]. Der potenzielle Nutzen einer primären Stentangioplastie sowie des Einsatzes medikamentenbeschichteter Ballonkatheter bzw. Stents oder Stentprothesen in der Reduktion der Rezidivstenoserate bei Interventionen der Nierenarterien bei TAK ist auf Basis der verfügbaren Datenlage nicht abschließend $\mathrm{zu}$ beurteilen. Im Falle von klinisch relevanten Rezidivstenosen scheinen nach aortorenaler Bypasschirurgie hohe Langzeitoffenheitsraten $\mathrm{zu}$ bestehen [267]. Auch beim MAS ist die chirurgische Revaskularisation mit aortoaortalem/-biiliakalem Bypass bzw. Interponat das Standardverfahren.

Die symptomatische Beteiligung der Koronararterien und der Viszeralarterien ist bei RZA und TAK selten. Die Versorgung der koronaren Beteiligung bei der Revaskularisation der Koronararterien bei TAK wurde in kleineren retrospektiven Kohortenstudien untersucht. Die Rate schwerwiegender kardialer Komplikationen war bei perkutaner Koronarintervention (PCI) signifikant höher als bei operativer Bypassversorgung [264, 275]. Dieser Zusammenhang ließ sich insbesondere nur bei aktiver inflammatorischer Erkrankung nachweisen, bei nicht aktiv inflammatorischer Erkrankung zeigte sich jedoch kein Unterschied zwischen Bypassoperation und PCI [264].

Die symptomatische Ischämie der unteren Extremitäten ist bei den GGV selten, bei der TAK meist durch eine Aortenpathologie (z.B. MAS) bedingt, bei der RZA meist durch Obstruktionen der femorokruralen Arterien mit typischer-

Tab. 5 Tabellarische Darstellung der Einzelempfehlungen mit Konsensstärke. Starker Konsens: Zustimmung von $>95 \%$ der Stimmberechtigten auf der Leitlinienkonferenz; Konsens: Zustimmung von > $75 \%$ der Stimmberechtigten auf der Leitlinienkonferenz und Behandelnden unter Berücksichtigung von Wirksamkeit, Sicherheit und Wirtschaftlichkeit beruhen.

stärke

Starker Konsens

B An Großgefäßvaskulitiden Erkrankte sollten Zugang zu Informationen über ihre Erkrankung, insbesondere zu den Auswirkungen der Großgefäßvaskulitiden, ihren wichtigsten Warnsymptomen und ihrer Behandlung (einschließlich behandlungsbedingter Komplikationen) erhalten sowie auf die Möglichkeit zur Teilnahme an Selbsthilfegruppen aufmerksam gemacht werden.

C Z Ziele der Behandlung sind die Verhinderung akuter und später Komplikationen durch die Großgefäßvaskulitiden bzw. durch die Toxizität der medikamentösen Therapie, die Reduktion der Mortalität sowie der Erhalt und die Verbesserung der Lebensqualität an Großgefäßvaskulitiden Erkrankter.

D An Großgefäßvaskulitiden Erkrankte sollen auf durch die Behandlung beeinflusste (einschließlich kardiovaskulärer) Komorbiditäten untersucht werden. Um das kardiovaskuläre Risiko und behandlungsbedingte Komplikationen zu verringern, sollten Lebensstilberatung und Maßnahmen der Prävention und medikamentösen Prophylaxe angeboten werden.

1a Bei Verdacht auf eine Riesenzellarteriitis sollte umgehend eine Vorstellung bei einem auf die interdisziplinäre Diagnostik und Therapie von Großgefäßvaskulitiden spezialisierten Team erfolgen. Auch bei Verdacht auf eine Takayasu-Arteriitis sollten Diagnostik und Therapie durch ein spezialisiertes Team erfolgen, bei drohender ischämischer Komplikation ebenfalls umgehend.

1b Bei begründetem Verdacht auf eine Riesenzellarteriitis soll umgehend eine Glukokortikoidtherapie begonnen werden. Nicht sofort zur Verfügung stehende Diagnostik soll den Beginn einer Glukokortikoidtherapie bei Verdacht auf Riesenzellarteriitis nicht verzögern. Bestätigt sich der Verdacht auf das Vorliegen einer Riesenzellarteriitis nach abgeschlossener sorgfältiger Abklärung nicht, soll die begonnene Glukokortikoidtherapie unter Überwachung rasch beendet werden.
Starker

Konsens

Starker

Konsens

Starker Konsens

Starker Konsens

Starker Konsens 
2a Die Basisdiagnostik bei Verdacht auf eine Großgefäßvaskulitis soll eine gezielte Anamnese und eine gründliche klinische Untersuchung insbesondere der arteriellen Gefäße einschließen. Zudem soll eine Labordiagnostik einschließlich C-reaktiven Proteins und Blutsenkungsgeschwindigkeit erfolgen.

2b Die klinische Verdachtsdiagnose einer Großgefäßvaskulitis soll zeitnah durch bildgebende Verfahren oder histopathologisch gesichert werden. Insbesondere, wenn bereits eine Glukokortikoidtherapie begonnen wurde (z. B. bei begründetem Verdacht auf Riesenzellarteriitis), sollte die Diagnostik wegen unter Therapie abnehmender Sensitivität rasch vervollständigt werden.

2c Grundsätzlich sollten bei der Auswahl der diagnostischen Verfahren die klinische Fragestellung (z. B. zu untersuchendes Gefäßareal) sowie standortspezifische Faktoren wie Verfügbarkeit und Untersuchererfahrung berücksichtigt werden.

2d Bei unklaren oder negativen Befunden in Bildgebung oder Histologie, und fortbestehendem klinischem Verdacht sollte ein weiteres diagnostisches Verfahren eingesetzt werden.

2e Bei Verdacht auf eine prädominant kranielle Riesenzellarteriitis sollte die Ultraschalluntersuchung der Arteriae temporales und axillares die bildgebende Modalität der ersten Wahl darstellen. Alternativ kann die hochauflösende MRT eingesetzt werden. Be Verdacht auf eine prädominant extrakranielle Beteiligung sollte die MRT/MR-Angiographie, PET-CT oder CT eingesetzt werden.

2f Zur Beurteilung einer zusätzlichen aortalen Beteiligung bei prädominant kranieller Riesenzellarteriitis kann die MRT, CT oder PET-CT eingesetzt werden.

2g Bei Verdacht auf Takayasu-Arteriitis sollte die MR-Angiographie als Methode der ersten Wahl eingesetzt werden. Alternativ kann eine PET/PET-CT, Sonographie oder CT-Angiographie durchgeführt werden.

$2 \mathrm{~h} \quad$ Bei Verdacht auf eine kranielle Riesenzellarteriitis soll eine Temporalarterienbiopsie erfolgen, wenn eine aussagekräftige Bildgebung nicht zur Verfügung steht. Die Probenlänge einer Temporalarterienbiopsie sollte mindestens $1 \mathrm{~cm}$ betragen.

3a Bei Erstdiagnose einer aktiven Riesenzellarteriitis ohne Sehstörungen oder einer aktiven Takayasu-Arteriitis soll eine Glukokortikoidtherapie begonnen werden. Die Dosis sollte initial 40-60 mg Prednisolonäquivalent täglich betragen.

3b Nach Erreichen einer Remission soll die Glukokortikoiddosis bei einer Glukokortikoidmonotherapie schrittweise reduziert werden. Es sollten etwa 10-15 mg (Riesenzellarteriitis)/15-20 mg (Takayasu-Arteriitis) Prednisolonäquivalent täglich nach 3 Monaten sowie $\leq 5 \mathrm{mg}$ (Riesenzellarteriitis) $/ \leq 10 \mathrm{mg}$ (Takayasu-Arteriitis) täglich nach 1 Jahr erreicht werden.

3c Die Glukokortikoidreduktion sollte unter klinischen und laborchemischen Kontrollen individuell festgelegt werden. Als Ziel sollte die individuell niedrigste effektive Glukokortikoiddosierung angestrebt werden einschließlich eines individuell gesteuerten vollständigen Ausschleichens der Glukokortikoide bei nach 1 Jahr anhaltender Remission.

3d Bei akutem Visusverlust oder einer Amaurosis fugax im Rahmen einer aktiven Riesenzellarteriitis (oder eines begründeten Riesenzellarteriitisverdachtes) sollte eine sofortige höher dosierte Glukokortikoidpulstherapie mit 500-1000 mg Methylprednisolon intravenös täglich über 3 bis 5 Tage erfolgen.

4a Bei bestimmten an Riesenzellarteriitis Erkrankten (insbesondere refraktäre oder rezidivierende Erkrankung, Vorhandensein von oder erhöhtes Risiko für Glukokortikoid-assoziierte Folgeschäden) sollte nach individueller Abwägung eine Glukokortikoid-einsparende Therapie mit Tocilizumab durchgeführt werden. Methotrexat kann als Alternative eingesetzt werden.

Unter einer Therapie mit Tocilizumab bei Riesenzellarteriitis sollte eine schnellere Reduktion der Glukokortikoiddosis verglichen mit der Glukokortikoidmonotherapie erfolgen. Auch unter Therapie mit Methotrexat bei Riesenzellarteriitis sollte eine raschere Glukokortikoiddosisreduktion angestrebt werden.

4c Bei anhaltender Remission bei der Riesenzellarteriitis sollte eine Deeskalation oder Beendigung der Glukokortikoid-einsparenden Therapie erwogen werden.

5 An einer Takayasu-Arteriitis Erkrankte sollten zusätzlich zu Glukokortikoiden mit konventionellen Immunsuppressiva behandelt werden. Bei refraktären, rezidivierenden oder Glukokortikoid-abhängigen Verläufen sollten Tumornekrosefaktor-alpha-Inhibitoren oder Tocilizumab erwogen werden.

Bei einem schweren Rezidiv einer Großgefäßvaskulitis soll erneut eine Glukokortikoidtherapie begonnen bzw. eine bestehende Glukokortikoidtherapie intensiviert werden (Initialdosierung wie bei einer neu diagnostizierten Großgefäßvaskulitis). Bei einem leichten Rezidiv sollte die Glukokortikoiddosis auf mindestens die letzte wirksame Dosis erhöht werden. Eine Glukokortikoidsparende Therapie sollte bei rezidivierender Erkrankung begonnen oder angepasst werden.

7 Thrombozytenaggregationshemmer, Antikoagulanzien oder Statine sollten nicht routinemäßig zur Behandlung von Großgefäßvaskulitiden angewendet werden, sofern keine andere Indikation dafür besteht.

8 An Großgefäßvaskulitiden Erkrankte sollen regelmäßig klinisch und laborchemisch überwacht werden.

Starker

Konsens

Starker

Konsens

Starker

Konsens

Starker

Konsens

Starker

Konsens

Starker

Konsens

Starker

Konsens

Starker

Konsens

Konsens

Konsens

Konsens

Konsens

Konsens

Konsens

Konsens

Konsens

Starker Konsens

Konsens

Starker

Konsens

An Großgefäßvaskulitiden Erkrankte mit Gefäßkomplikationen sollten von einem interdisziplinären Gefäßteam betreut werden. Konsens Erforderliche endovaskuläre und operative Gefäßeingriffe sollten, wann immer möglich, in Remission der Vaskulitis erfolgen. Die Entscheidung für spezifische Verfahren sollte individuell und nach interdisziplinärer Abstimmung getroffen werden. Bei gefäßchirurgischen Eingriffen sollte Gewebe zur histopathologischen Untersuchung gewonnen werden. Nach arteriellen Rekonstruktionen sollte eine lebenslange Nachsorge erfolgen. 
weise beidseitiger, rasch progredienter Wadenclaudicatio. An RZA Erkrankte, bei denen die medikamentöse Therapie im Stadium der Claudicatio intermittens begonnen wird, werden häufig unter alleiniger medikamentöser Therapie und Gehtraining beschwerdefrei. Bei Diagnose im Stadium der kritischen Extremitätenischämie liegen häufig langstreckige femorokrurale Obstruktionen vor, die zusätzlich zur Immunsuppression eine operative Revaskularisation (kniegelenküberschreitende Bypasschirurgie) erfordern [58, 130].

\section{Tabellarische Darstellung der Einzelempfehlungen}

Tabellarische Darstellung der Einzelempfehlungen s. • Tab. 5.

\section{Korrespondenzadresse}

\section{Dr. J.H. Schirmer}

Klinik für Innere Medizin I, Sektion

Rheumatologie, Exzellenzzentrum

Entzündungsmedizin, Universitätsklinikum

Schleswig-Holstein, Campus Kiel

Arnold-Heller-Str. 3, 24105 Kiel, Deutschland

janhenrik.schirmer@uksh.de

\section{Prof. Dr. B. Hellmich}

Klinik für Innere Medizin, Rheumatologie und Immunologie, Vaskulitiszentrum Süd, Medius Klinik

Eugenstr. 3, 73230 Kirchheim unter Teck, Deutschland

b.hellmich@medius-kliniken.de

\section{Einhaltung ethischer Richtlinien}

Interessenkonflikt. Angaben zum Interessenkonflikt aller Leitlinienautoren sind im Leitlinienreport unter https://www.awmf.org/leitlinien/detail/ll/060-007. html einsehbar.

Für diesen Beitrag wurden von den Autoren keine Studien an Menschen oder Tieren durchgeführt. Für die aufgeführten Studien gelten die jeweils dort angegebenen ethischen Richtlinien.

\section{Literatur}

1. Abisror N, Mekinian A, Lavigne C et al (2013) Tocilizumab in refractory Takayasu arteritis: a case series and updated literature review. Autoimmun Rev 12:1143-1149. https://doi.org/10.1016/j. autrev.2013.06.019

2. Abularrage CJ, Slidell MB, Sidawy AN et al (2008) Quality of life of patients with Takayasu's arteritis.
J Vasc Surg 47:131-136. https://doi.org/10.1016/j. jvs.2007.09.044 (discussion 136-137)

3. Achkar AA, Lie JT, Hunder GG et al (1994) How does previous corticosteroid treatment affect the biopsy findings in giant cell (temporal) arteritis? Ann Intern Med 120:987-992

4. Adachi O, Saiki Y, Akasaka J et al (2007) Surgical management of aortic regurgitation associated with takayasu arteritis and other forms of aortitis. Ann Thorac Surg 84:1950-1953. https://doi.org/ 10.1016/j.athoracsur.2007.07.025

5. Adizie T, Christidis D, Dharmapaliah C et al (2012) Efficacy and tolerability of leflunomide in difficult to-treat polymyalgia rheumatica and giant cell arteritis: a case series. Int J Clin Pract 66:906-909. https://doi.org/10.1111/j.1742-1241.2012.02981. $x$

6. Adler S, Reichenbach S, Gloor A et al (2019) Risk of relapse after discontinuation of tocilizumab therapy in giant cell arteritis. Rheumatology (Oxford) 58:1639-1643. https://doi.org/10.1093/ rheumatology/kez091

7. Águeda AF, Monti S, Luqmani RA et al (2019) Management of Takayasu arteritis: a systematic literature review informing the 2018 update of the EULAR recommendation for the management of large vessel vasculitis. RMD Open 5:e1020. https:// doi.org/10.1136/rmdopen-2019-001020

8. Aiello PD, Trautmann JC, McPhee TJ et al (1993) Visual prognosis in giant cell arteritis Ophthalmology 100:550-555. https://doi.org/10. 1016/s0161-6420(93)31608-8

9. Alba MA, García-Martínez A, Prieto-GonzálezSetal (2014) Relapses in patients with giant cell arteritis: prevalence, characteristics, and associated clinical findings in a longitudinally followed cohort of 106 patients. Medicine (Baltimore) 93:194-201. https://doi.org/10.1097/MD.0000000000000033

10. Alsolaimani RS, Bhavsar SV, Khalidi NA et al (2016) Severe intracranial involvement in giant cell arteritis: 5 cases and literature review. JRheumatol43:648-656. https://doi.org/10.3899/ jrheum.150143

11. Ando M, Kosakai Y, Okita Y et al (1999) Surgical treatment for aortic regurgitation caused by nonspecific aortitis. Cardiovasc Surg 7:409-413

12. Arend WP, Michel BA, Bloch DA et al (1990) The American College of Rheumatology 1990 criteria for the classification of Takayasu arteritis. Arthritis Rheum 33:1129-1134

13. Armstrong AT, Tyler WB, Wood GC, Harrington TM (2008) Clinical importance of the presence of giant cells in temporal arteritis. J Clin Pathol 61:669-671. https://doi.org/10.1136/jcp.2007.049049

14. Aschwanden M, Daikeler T, Kesten F et al (2013) Temporal artery compression sign-A novel ultrasound finding for the diagnosis of giant cell arteritis. Ultraschall Med 34:47-50. https://doi. org/10.1055/s-0032-1312821

15. Aschwanden M, Imfeld S, Staub D et al (2015) The ultrasound compression sign to diagnose temporal giant cell arteritis shows an excellent interobserver agreement. Clin Exp Rheumatol 33:113-115

16. van Assen $\mathrm{S}$, Agmon-Levin $\mathrm{N}$, Elkayam $\mathrm{O}$ et al (2011) EULAR recommendations for vaccination in adult patients with autoimmune inflammatory rheumatic diseases. Ann Rheum Dis 70:414-422. https://doi.org/10.1136/ard.2010.137216

17. Bali HK, Jain S, Jain A, Sharma BK (1998) Stent supported angioplasty in Takayasu arteritis. Int J Cardiol 66(Suppl 1):S213-S217 (discussion S219-S220)
18. Ball EL, Walsh SR, Tang TY et al (2010) Role of ultrasonography in the diagnosis of temporal arteritis. Br J Surg 97:1765-1771. https://doi.org/ 10.1002/bjs.7252

19. Banerjee S, Grayson PC (2017) Vasculitis around the world: epidemiologic insights into causality and a need for global partnerships. J Rheumatol 44:136-139. https://doi.org/10.3899/jrheum. 161468

20. Barra L, Yang G, Pagnoux C (2018) Non-glucocorticoid drugs for the treatment of Takayasu's arteritis: a systematic review and meta-analysis. Autoimmun Rev 17:683-693. https://doi.org/10 1016/j.autrev.2018.01.019

21. Berger CT, Greiff V, John S et al (2015) Risk factors for pneumocystis pneumonia in giant cell arteritis: a single-centre cohort study. Clin Exp Rheumatol 33:122-125

22. Berger CT, Wolbers M, Meyer P et al (2009) High incidence of severe ischaemic complications in patients with giant cell arteritis irrespective of platelet count and size, and platelet inhibition. Rheumatology (Oxford) 48:258-261. https://doi org/10.1093/rheumatology/ken480

23. Berlit $P$, Krämer M et al (2018) Zerebrale Vaskulitis und zerebrale Beteiligung bei systemischen Vaskulitiden und rheumatischen Grunderkrankungen, S1-Leitlinie in: Deutsche Gesellschaft für Neurologie (Hrsg.), Leitlinien für Diagnostik und Therapie in der Neurologie. www.dgn.org/ leitlinien. Zugegriffen: 3. Juni 2019

24. Berthod PE, Aho-Glélé S, Ornetti $P$ et al (2018) CT analysis of the aorta in giant-cell arteritis: a casecontrol study. Eur Radiol 28:3676-3684. https:// doi.org/10.1007/s00330-018-5311-8

25. Blockmans D, de Ceuninck L, Vanderschueren $S$ et al (2006) Repetitive 18F-fluorodeoxyglucose positron emission tomography in giant cell arteritis: a prospective study of 35 patients. Arthritis Rheum 55:131-137. https://doi.org/10. 1002/art.21699

26. Blockmans D, Coudyzer W, Vanderschueren S et al (2008) Relationship between fluorodeoxyglucose uptake in the large vessels and late aortic diameter in giant cell arteritis. Rheumatology (Oxford) 47:1179-1184. https://doi.org/10.1093/ rheumatology/ken 119

27. Blockmans D, Stroobants S, Maes A, Mortelmans L (2000) Positron emission tomography in giant cell arteritis and polymyalgia rheumatica: evidence for inflammation of the aortic arch. Am J Med 108:246-249

28. ter Borg EJ, Haanen HCM, Seldenrijk CA (2007) Relationship between histological subtypes and clinical characteristics at presentation and outcome in biopsy-proven temporal arteritis. Identification of a relatively benign subgroup. Clin Rheumatol 26:529-532. https://doi.org/10.1007/ s10067-006-0332-0

29. Both M, Aries PM, Müller-Hülsbeck S et al (2006) Balloon angioplasty of arteries of the upper extremities in patients with extracranial giant-cell arteritis. Ann Rheum Dis 65:1124-1130. https:// doi.org/10.1136/ard.2005.048470

30. Boyev LR, Miller NR, Green WR (1999) Efficacy of unilateral versus bilateral temporal artery biopsies for the diagnosis of giant cell arteritis. Am J Ophthalmol 128:211-215. https://doi.org/ 10.1016/s0002-9394(99)00101-4

31. de Boysson H, Boutemy J, Creveuil C et al (2013) Is there a place for cyclophosphamide in the treatment of giant-cell arteritis? A case series and systematic review. Semin Arthritis Rheum 
43:105-112. https://doi.org/10.1016/j.semarthrit. 2012.12.023

32. de Boysson H, Daumas A, Vautier M et al (2018) Large-vessel involvement and aortic dilation in giant-cell arteritis. A multicenter study of 549 patients. Autoimmun Rev 17:391-398. https:// doi.org/10.1016/j.autrev.2017.11.029

33. de Boysson $\mathrm{H}$, Liozon E, Lambert Met al (2016) 18Ffluorodeoxyglucose positron emission tomography and the risk of subsequent aortic complications in giant-cell arteritis: a multicenter cohort of 130 patients. Medicine (Baltimore) 95:e3851. https://doi.org/10.1097/MD.0000000000003851

34. de Boysson $\mathrm{H}$, Liozon $\mathrm{E}$, Lambert $\mathrm{M}$ et al (2017) Giant-cell arteritis: do we treat patients with large-vessel involvement differently? Am J Med 130:992-995. https://doi.org/10.1016/j.amjmed. 2017.03.054

35. de Boysson H, Liozon $\mathrm{E}$, Larivière $\mathrm{D}$ et al (2017) Giant cell arteritis-related stroke: a retrospective multicenter case-control study. J Rheumatol 44:297-303. https://doi.org/10.3899/jrheum. 161033

36. de Boysson H, Liozon E, Ly KH et al (2019) The different clinical patterns of giant cell arteritis. Clin ExpRheumatol 37(Suppl 117):57-60

37. Breuer GS, Nesher R, Reinus K, Nesher G (2013) Association between histological features in temporal artery biopsies and clinical features of patients with giant cell arteritis. Isr Med Assoc J 15:271-274

38. Brito-Zerón P, Kostov B, Bosch X et al (2016) Therapeutic approach to lgG4-related disease: a systematic review. Medicine (Baltimore) 95:e4002. https://doi.org/10.1097/MD.0000000000004002

39. Broder MS, Sarsour K, Chang E et al (2016) Corticosteroid-related adverse events in patients with giant cell arteritis: a claims-based analysis. Semin Arthritis Rheum 46:246-252. https://doi. org/10.1016/j.semarthrit.2016.05.009

40. Buttgereit $F$, Brabant T et al (2018) S3 guidelines on treatment of polymyalgia rheumatica: evidencebased guidelines of the German Society of Rheumatology (DGRh), the Austrian Society of Rheumatology and Rehabilitation (ÖGR) and the Swiss Society of Rheumatology (SGT) and participating medical scientific specialist societies and other organizations. ZRheumatol 77:429-441. https://doi.org/10.1007/s00393-018-0476-8

41. Calderón-Goercke M, Loricera J, Aldasoro V et al (2019) Tocilizumab in giant cell arteritis. Observational, open-label multicenter study of 134 patients in clinical practice. Semin Arthritis Rheum 49:126-135. https://doi.org/10.1016/j. semarthrit.2019.01.003

42. Cavazza A, Muratore F, Boiardi L et al (2014) Inflamed temporal artery: histologic findings in 354 biopsies, with clinical correlations. Am J Surg Pathol 38:1360-1370. https://doi.org/10.1097/ PAS.0000000000000244

43. Chan CC, Paine M, O'Day J (2001) Steroid management in giant cell arteritis. Br JOphthalmol 85:1061-1064

44. Chandran A, Udayakumar PD, Kermani TA et al (2015) Glucocorticoid usage in giant cell arteritis over six decades (1950 to 2009). Clin Exp Rheumatol 33:98-102

45. Chatelain D, Duhaut P, Schmidt J et al (2009) Pathological features of temporal arteries in patients with giant cell arteritis presenting with permanent visual loss. Ann Rheum Dis 68:84-88. https://doi.org/10.1136/ard.2007.084947

46. Chauhan SK, Singh M, Nityanand S (2007) Reactivity of gamma/delta T cells to human $60-\mathrm{kd}$ heat-shock protein and their cytotoxicity to aortic endothelial cells in Takayasu arteritis. Arthritis Rheum 56:2798-2802. https://doi.org/10.1002/ art.22801

47. Chevalet $P$, Barrier JH, Pottier P et al (2000) A randomized, multicenter, controlled trial using intravenous pulses of methylprednisolone in the initial treatment of simple forms of giant cell arteritis: a one year followup study of 164 patients. JRheumatol 27:1484-1491

48. Chrysidis S, Duftner C, Dejaco C et al (2018) Definitions and reliability assessment of elementary ultrasound lesions in giant cell arteritis: a study from the OMERACT Large Vessel Vasculitis Ultrasound Working Group. RMD Open 4:e598. https:// doi.org/10.1136/rmdopen-2017-000598

49. Chung JB, Armstrong K, Schwartz JS, Albert D (2000) Cost-effectiveness of prophylaxis against pneumocystis carinii pneumonia in patients with Wegner's granulomatosis undergoing immunosuppressive therapy. Arthritis Rheum 43:1841-1848. https://doi.org/10.1002/15290131(200008)43:8<1841::AID-ANR21)3.0.CO;2-Q

50. Comarmond C, Biard L, Lambert M et al (2017) Long-term outcomes and prognostic factors of complications in Takayasu arteritis: a multicenter study of 318 patients. Circulation 136:1114-1122. https://doi.org/10.1161/CIRCULATIONAHA.116. 027094

51. Comarmond C, Plaisier E, Dahan K et al (2012) Anti TNF- $a$ in refractory Takayasu's arteritis: cases series and review of the literature. Autoimmun Rev 11:678-684. https://doi.org/10.1016/j.autrev. 2011.11.025

52. Conway R, O'Neill L, Gallagher P et al (2018) Ustekinumab for refractory giant cell arteritis: a prospective 52-week trial. Semin Arthritis Rheum 48:523-528. https://doi.org/10.1016/j.semarthrit 2018.04.004

53. Conway R, O'Neill L, O'Flynn E et al (2016) Ustekinumab for the treatment of refractory giant cell arteritis. Ann Rheum Dis 75:1578-1579. https:// doi.org/10.1136/annrheumdis-2016-209351

54. Conway R, Smyth AE, Kavanagh RG et al (2018) Diagnosticutility of computed tomographicangiography in giant-cell arteritis. Stroke 49:2233-2236. https://doi.org/10.1161/STROKEAHA.118.021995

55. Crowson CS, Matteson EL, Myasoedova E et al (2011) The lifetime risk of adult-onset rheumatoid arthritis and other inflammatory autoimmune rheumatic diseases. Arthritis Rheum 63:633-639. https://doi.org/10.1002/art.30155

56. Czihal M, Piller A, Schroettle A et al (2013) Outcome of giant cell arteritis of the arm arteries managed with medical treatment alone: cross-sectional follow-up study. Rheumatology (Oxford) 52:282-286. https://doi.org/10.1093/ rheumatology/kes239

57. Czihal M, Piller A, Schroettle A et al (2015) Impact of cranial and axillary/subclavian artery involvement by color duplex sonography on response to treatment in giant cell arteritis. J Vasc Surg 61:1285-1291. https://doi.org/10.1016/j.jvs.2014. 12.045

58. Czihal M, Tatò F, Rademacher A et al (2012) Involvement of the femoropopliteal arteries in giant cell arteritis: clinical and color duplex sonography. J Rheumatol 39:314-321. https://doi. org/10.3899/jrheum.110566

59. Dachverband Osteologie (2017) http://www dv-osteologie.org/uploads/Leitlinie\%202017/ Finale\%20Version\%20Leitlinie\%200steoporose \%202017_end.pdf.Zugegriffen:3.Juni 2019
60. Dai D, Wang $Y$, Jin $\mathrm{H}$ et al (2017) The efficacy of mycophenolate mofetil in treating Takayasu arteritis: a systematic review and meta-analysis. Rheumatol Int 37:1083-1088. https://doi.org/10. 1007/s00296-017-3704-7

61. De Silva M, Hazleman BL (1986) Azathioprine in giant cell arteritis/polymyalgia rheumatica: a double-blind study. Ann Rheum Dis 45:136-138

62. Dejaco C, Duftner C, Buttgereit F et al (2017) The spectrum of giant cell arteritis and polymyalgia rheumatica: revisiting the concept of the disease. Rheumatology (Oxford) 56:506-515. https://doi. org/10.1093/rheumatology/kew273

63. Dejaco C, Ramiro S, Duftner C et al (2018) EULAR recommendations for the use of imaging in large vessel vasculitis in clinical practice. Ann Rheum Dis 77:636-643. https://doi.org/10.1136/ annrheumdis-2017-212649

64. Dejaco C, Singh YP, Perel P et al (2015) 2015 Recommendations for the management of polymyalgia rheumatica: a European League Against Rheumatism/American College of Rheumatology collaborative initiative. Ann Rheum Dis 74:1799-1807. https://doi.org/10.1136/ annrheumdis-2015-207492

65. Delecoeuillerie G, Joly P, Cohen de Lara A, Paolaggi JB (1988) Polymyalgia rheumatica and temporal arteritis: a retrospective analysis of prognostic features and different corticosteroid regimens (11 year survey of 210 patients). Ann Rheum Dis 47:733-739

66. DGRh Website der Deutschen Gesellschaft für Rheumatologie. https://dgrh.de/Start/ Versorgung/Therapie\%C3\%BCberwachung/ Therapie\%C3\%BCberwachungsb\%C3\%B6gen. html.Zugegriffen: 11. Nov. 2019

67. Diamantopoulos AP, Haugeberg G, Hetland H et al (2014) Diagnostic value of color Doppler ultrasonography of temporal arteries and large vessels in giant cell arteritis: a consecutive case series. Arthritis Care Res 66:113-119. https://doi. org/10.1002/acr.22178

68. Diamantopoulos AP, Haugeberg G, Lindland A, Myklebust G (2016) The fast-trackultrasound clinic for early diagnosis of giant cell arteritis significantly reduces permanent visual impairment: towards a more effective strategy to improve clinical outcome in giant cell arteritis? Rheumatology (Oxford) 55:66-70. https://doi.org/10.1093/ rheumatology/kev289

69. Dong H, Che W, Jiang $X$ et al (2017) An unrecognised presentation of Takayasu arteritis: superficial femoral artery involvement. Clin Exp Rheumatol 35(Suppl 103):83-87

70. DuftnerC,Dejaco C, Sepriano Aetal(2018) Imaging in diagnosis, outcome prediction and monitoring of large vessel vasculitis: a systematic literature review and meta-analysis informing the EULAR recommendations. RMD Open 4:e612. https://doi. org/10.1136/rmdopen-2017-000612

71. Duru N, van der Goes MC, Jacobs JWG et al (2013) EULAR evidence-based and consensus-based recommendations on themanagement of medium to high-dose glucocorticoid therapy in rheumatic diseases. Ann Rheum Dis 72:1905-1913. https:// doi.org/10.1136/annrheumdis-2013-203249

72. Ehrenstein B (2018) Interpretation of tuberculosis and hepatitis screening before immunosuppressive treatment. Z Rheumatol 77:493-507. https:// doi.org/10.1007/s00393-018-0488-4

73. Einspieler I, Thürmel K, Pyka T et al (2015) Imaging large vessel vasculitis with fully integrated PET/MRI: a pilot study. Eur J Nucl Med Mol Imaging 
42:1012-1024. https://doi.org/10.1007/s00259015-3007-8

74. Erbel R, Aboyans V, Boileau C et al (2014) 2014 ESC Guidelines on the diagnosis and treatment of aortic diseases: document covering acute and chronic aortic diseases of the thoracic and abdominal aorta of the adult. The Task Force for the Diagnosis and Treatment of Aortic Diseases of the European Society of Cardiology (ESC). Eur Heart J 35:2873-2926. https://doi.org/10.1093/ eurheartj/ehu281

75. Espitia O, Néel A, Leux C et al (2012) Giant cell arteritis with or without aortitis at diagnosis. A retrospective study of 22 patients with longterm followup. J Rheumatol 39:2157-2162. https://doi. org/10.3899/jrheum.120511

76. Espitia O, Samson M, Le Gallou T et al (2016) Comparison of idiopathic (isolated) aortitis and giant cell arteritis-related aortitis. A French retrospective multicenter study of 117 patients. Autoimmun Rev 15:571-576. https://doi.org/10. 1016/j.autrev.2016.02.016

77. Evans JM, O'Fallon WM, Hunder GG (1995) Increased incidence of aortic aneurysm and dissection in giant cell (temporal) arteritis. A population-based study. Ann Intern Med 122:502-507

78. Ezeonyeji AN, Borg FA, Dasgupta B (2011) Delays in recognition and management of giant cell arteritis: results from a retrospective audit. Clin Rheumatol 30:259-262. https://doi.org/10.1007/ s10067-010-1616-y

79. Fields CE, Bower TC, Cooper LT et al (2006) Takayasu's arteritis: operative results and influence of disease activity. J Vasc Surg 43:64-71. https:// doi.org/10.1016/j.jvs.2005.10.010

80. de Franciscis S, Serra R, Luongo A et al (2007) The management of Takayasu's arteritis: personal experience. Ann Vasc Surg 21:754-760. https:// doi.org/10.1016/j.avsg.2007.03.021

81. Gagné-Loranger $M$, Dumont É, Voisine $P$ et al (2016) Giant cell aortitis: clinical presentation and outcomes in 40 patients consecutively operated on. Eur J Cardiothorac Surg 50:555-559. https:// doi.org/10.1093/ejcts/ezw041

82. García-Martínez A, Hernández-Rodríguez J, Grau JM, Cid MC (2004) Treatment with statins does not exhibit a clinically relevant corticosteroidsparing effect in patients with giant cell arteritis. Arthritis Rheum 51:674-678. https://doi.org/10. 1002/art.20541

83. Germanò G, Macchioni P, Possemato N et al (2017) Contrast-enhanced ultrasound of the carotid artery in patients with large vessel vasculitis: correlation with positron emission tomography findings. Arthritis Care Res 69:143-149. https:// doi.org/10.1002/acr.22906

84. Germanò G, Muratore F, Cimino L et al (2015) Is colour duplex sonography-guided temporal artery biopsy useful in the diagnosis of giant cell arteritis? A randomized study. Rheumatology (Oxford) 54:400-404. https://doi.org/10.1093/ rheumatology/keu241

85. Ghinoi A, Pipitone N, Nicolini A et al (2012) Largevessel involvement in recent-onset giant cell arteritis: a case-control colour-Doppler sonography study. Rheumatology (Oxford) 51:730-734. https://doi.org/10.1093/rheumatology/ker329

86. Goel R, Danda D, Kumar S, Joseph G (2013) Rapid control of disease activity by tocilizumab in 10 "difficult-to-treat" cases of Takayasu arteritis. Int J Rheum Dis 16:754-761. https://doi.org/10.1111/ 1756-185X.12220
87. Goel R, Danda D, Mathew J, Edwin N (2010) Mycophenolate mofetil in Takayasu's arteritis. Clin Rheumatol 29:329-332. https://doi.org/10.1007/ s10067-009-1333-6

88. González-Gay MA, Blanco R, Rodríguez-Valverde V et al (1998) Permanent visual loss and cerebrovascular accidents in giant cell arteritis: predictors and response to treatment. Arthritis Rheum 41:1497-1504. https://doi.org/10.1002/15290131(199808)41:8<1497::AID-ART22)3.0.CO;2-Z

89. Gonzalez-Gay MA, Vazquez-Rodriguez TR, GomezAcebo I et al (2009) Strokes at time of disease diagnosis in a series of 287 patients with biopsy-proven giant cell arteritis. Medicine (Baltimore) 88:227-235. https://doi.org/10.1097/ MD.0b013e3181af4518

90. Gonzalez-Gay MA, Vazquez-Rodriguez TR, Lopez Diaz MJ et al (2009) Epidemiology of giant cell arteritis and polymyalgia rheumatica. Arthritis Rheum 61:1454-1461. https://doi.org/10.1002/ art.24459

91. Graham E, Holland A, Avery A, Russell RW (1981) Prognosis in giant-cell arteritis. Br Med J 282:269-271

92. Grayson PC, Alehashemi S, Bagheri AA et al (2018) 18F-Fluorodeoxyglucose-positron emission tomography as an imaging Biomarker in a prospective, longitudinal cohort of patients with large vessel vasculitis. Arthritis Rheumatol 70:439-449. https://doi.org/10.1002/art.40379

93. Grossman C, Barshack I, Koren-Morag N et al (2017) Risk factors for severe cranial ischaemic events in patients with giant cell arteritis. Clin Exp Rheumatol 35(Suppl 103):88-93

94. Gudbrandsson B, Molberg $\emptyset$, Palm $\emptyset$ (2017) TNF inhibitors appear to inhibit disease progression and improve outcome in Takayasu arteritis; an observational, population-based time trend study. Arthritis Res Ther 19:99. https://doi.org/10.1186/ s13075-017-1316-y

95. Gülcü A, Gezer NS, Akar S et al (2017) Longterm follow-up of endovascular repair in the management of arterial stenosis caused by Takayasu's arteritis. Ann Vasc Surg 42:93-100. https://doi.org/10.1016/j.avsg.2016.10.066

96. Hachulla E, Boivin V, Pasturel-Michon U et al (2001) Prognostic factors and long-term evolution in a cohort of 133 patients with giant cell arteritis. Clin ExpRheumatol 19:171-176

97. Hatemi G, Christensen R, Bang D et al (2018) 2018 update of the EULAR recommendations for the management of Behçet's syndrome. Ann Rheum Dis 77:808-818. https://doi.org/10.1136/ annrheumdis-2018-213225

98. Hauenstein C, Reinhard M, Geiger J et al (2012) Effects of early corticosteroid treatment on magnetic resonance imaging and ultrasonography findings in giant cell arteritis. Arthritis Rheumatol 51:1999-2003. https://doi.org/10.1093/ rheumatology/kes153

99. Hayreh SS, Zimmerman B (2003) Visual deterioration in giant cell arteritis patients while on high doses of corticosteroid therapy. Ophthalmology 110:1204-1215. https://doi.org/10.1016/S01616420(03)00228-8

100. Hayreh SS, Zimmerman B, Kardon RH (2002) Visual improvement with corticosteroid therapy in giant cell arteritis. Report of a large study and review of literature. Acta Ophthalmol Scand 80:355-367

101. Hazlewood GS, Thorne JC, Pope JE et al (2016) The comparative effectiveness of oral versus subcutaneous methotrexate for the treatment of early rheumatoid arthritis. Ann Rhe- um Dis 75:1003-1008. https://doi.org/10.1136/ annrheumdis-2014-206504

102. Hellmich B, Agueda A, Monti S et al (2020) 2018 Update of the EULAR recommendations for the management of large vessel vasculitis. Ann Rheum Dis 79:19-30. https://doi.org/10.1136/ annrheumdis-2019-215672

103. Herlyn K, Buckert F, Gross WL, Reinhold-Keller E (2014) Doubled prevalence rates of ANCAassociated vasculitides and giant cell arteritis between 1994 and 2006 in northern Germany. Rheumatology (Oxford) 53:882-889. https://doi org/10.1093/rheumatology/ket440

104. Herlyn K, Gross WL, Reinhold-Keller E (2008) Longitudinal effects of structured patient education programs for vasculitis patients. Z Rheumatol 67:206-210. https://doi.org/10.1007/s00393008-0290-9

105. Hernández-Rodríguez J, García-Martínez A, Casademont J et al (2002) A strong initial systemic inflammatory response is associated with higher corticosteroid requirements and longer duration of therapy in patients with giant-cell arteritis. Arthritis Rheum 47:29-35

106. Hernández-Rodríguez J, Murgia G, Villar I et al (2016) Description and validation of histological patterns and proposal of a dynamic model of inflammatory infiltration in giant-cell arteritis. Medicine (Baltimore) 95:e2368. https://doi.org/ 10.1097/MD.0000000000002368

107. Hernández-Rodríguez J, Tan CD, Rodríguez ER, Hoffman GS (2009) Gynecologic vasculitis: an analysis of 163 patients. Medicine (Baltimore) 88:169-181. https://doi.org/10.1097/MD.0b013e3181a577f3

108. Hinojosa CA, Anaya-Ayala JE, Gomez-Arcive Z et al (2017) Factors associated with need for revascularisation in non-coronary arterial occlusive lesions secondary to Takayasu's arteritis. Eur J Vasc Endovasc Surg 54:397-404. https://doi. org/10.1016/j.ejvs.2017.05.020

109. Hočevar A, Ješe R, Rotar Ž, Tomšič M (2019) Does leflunomide have a role in giant cell arteritis? An open-label study. Clin Rheumatol 38:291-296. https://doi.org/10.1007/s10067-018-4232-x

110. Hocevar A, Rotar Z, Jese R et al (2016) Do early diagnosis and glucocorticoid treatment decrease the risk of permanent visual loss and early relapses in giant cell arteritis: a prospective longitudinal study. Medicine (Baltimore) 95:e3210. https://doi. org/10.1097/MD.0000000000003210

111. Hoffman GS, Cid MC, Hellmann DB et al (2002) A multicenter, randomized, double-blind, placebo-controlled trial of adjuvant methotrexate treatment for giant cell arteritis. Arthritis Rheum 46:1309-1318. https://doi.org/10.1002/art.10262

112. Hoffman GS, Cid MC, Rendt-Zagar KE et al (2007) Infliximab for maintenance of glucocorticosteroid-induced remission of giant cell arteritis: a randomized trial. Ann Intern Med 146:621-630

113. Hoffman GS, Leavitt RY, Kerr GS et al (1994) Treatment of glucocorticoid-resistant or relapsing Takayasu arteritis with methotrexate. Arthritis Rheum 37:578-582

114. Hoffman GS, Merkel PA, Brasington RD et al (2004) Anti-tumor necrosis factor therapy in patients with difficult to treat Takayasu arteritis. Arthritis Rheum 50:2296-2304. https://doi.org/10.1002/art.20300

115. Hong S, Ghang B, Kim Y-G et al (2017) Longterm outcomes of renal artery involvement in Takayasu arteritis. J Rheumatol 44:466-472. https://doi.org/ 10.3899/jrheum.160974

116. Huang Y, Ma X, Li M et al (2019) Carotid contrastenhanced ultrasonographic assessment of disease 
activity in Takayasu arteritis. Eur Heart J Cardiovasc Imaging 20:789-795. https://doi.org/10.1093/ ehjci/jey197

117. Hunder GG, Bloch DA, Michel BA et al (1990) The American College of Rheumatology 1990 criteria for the classification of giant cell arteritis. Arthritis Rheum 33:1122-1128

118. Hunder GG, Sheps SG, Allen GL, Joyce JW (1975) Daily and alternate-day corticosteroid regimens in treatment of giant cell arteritis: comparison in a prospective study. Ann Intern Med 82:613-618

119. Ishikawa K (1988) Diagnostic approach and proposed criteria for the clinical diagnosis of Takayasu's arteriopathy. J Am Coll Cardiol 12:964-972

120. Jakobsson K, Jacobsson L, Mohammad AJ et al (2016) The effect of clinical features and glucocorticoids on biopsy findings in giant cell arteritis. BMC Musculoskelet Disord 17:363. https://doi.org/10.1186/s12891-016-1225-2

121. Jamilloux Y, Liozon E, Pugnet $G$ et al (2013) Recovery of adrenal function after long-term glucocorticoid therapy for giant cell arteritis: a cohort study. PLoS One 8:e68713. https://doi. org/10.1371/journal.pone.0068713

122. Jennette JC, Falk RJ, Bacon PA et al (2013) 2012 revised International Chapel Hill Consensus Conference Nomenclature of Vasculitides. Arthritis Rheum 65:1-11. https://doi.org/10.1002/art. 37715

123. Jeong HS, Jung JH, Song GG et al (2017) Endovascular balloon angioplasty versus stenting in patients with Takayasu arteritis: a meta-analysis. Medicine (Baltimore) 96:e7558. https://doi.org/ 10.1097/MD.0000000000007558

124. Jobard S, Magnant J, Blasco Het al (2017) Quality of life of patients treated for giant cell arteritis: a casecontrol study. Clin Rheumatol 36:2055-2062. https://doi.org/10.1007/s10067-017-3619-4

125. Jover JA, Hernández-García C, Morado IC et al (2001) Combined treatment of giant-cell arteritis with methotrexate and prednisone. A randomized, double-blind, placebo-controlled trial. Ann Intern Med 134:106-114

126. Jung JH, Lee YH, Song GG et al (2018) Endovascular versus open surgical intervention in patients with Takayasu's arteritis: a meta-analysis. Eur J Vasc Endovasc Surg 55:888-899. https://doi.org/10. 1016/j.ejvs.2018.02.030

127. Kaiser M, Weyand CM, Björnsson J, Goronzy JJ (1998) Platelet-derived growth factor, intimal hyperplasia, and ischemic complications in giant cell arteritis. Arthritis Rheum 41:623-633. https://doi.org//10.1002/15290131(199804)41:4/623::AID-ART9>3.0.CO;2-6

128. Karahaliou M, Vaiopoulos G, Papaspyrou S et al (2006) Colour duplex sonography of temporal arteries before decision for biopsy: a prospective study in 55 patients with suspected giant cell arteritis. Arthritis Res Ther 8:R116. https://doi.org/ 10.1186/ar2003

129. Kermani TA, Schmidt J, Crowson CS et al (2012) Utility of erythrocyte sedimentation rate and C-reactive protein for the diagnosis of giant cell arteritis. Semin Arthritis Rheum 41:866-871. https://doi.org/10.1016/j.semarthrit.2011.10.005

130. Kermani TA, Warrington KJ (2011) Lower extremity vasculitis in polymyalgia rheumatica and giant cell arteritis. Curr Opin Rheumatol 23:38-42. https:// doi.org/10.1097/BOR.0b013e3283410072

131. Kermani TA, Warrington KJ, Crowson CS et al (2013) Large-vessel involvement in giant cell arteritis: a population-based cohort study of the incidence-trends and prognosis. Ann
Rheum Dis 72:1989-1994. https://doi.org/10 1136/annrheumdis-2012-202408

132. Kermani TA, Warrington KJ, Cuthbertson D et al (2015) Disease relapses among patients with giant cell arteritis: a prospective, longitudinal cohort study.JRheumatol 42:1213-1217.https://doi.org/ 10.3899/jrheum.141347

133. Kermani TA, Ytterberg SR, Warrington KJ (2011) Pneumocystis jiroveci pneumonia in giant cell arteritis: a case series. Arthritis Care Res 63:761-765. https://doi.org/10.1002/acr.20435

134. Kim HJ, Lee C-S, Kim JS et al (2011) Outcomes after endovascular treatment of symptomatic patients with Takayasu's arteritis. Interv Neuroradiol 17:252-260. https://doi.org/10.1177/ 159101991101700219

135. Kim IY, Eun YH, Jeong $\mathrm{H}$ et al (2017) Clinical characteristics and outcomes of 61 patients with chronic periaortitis including lgG4-related and non-lgG4-related cases. Int J Rheum Dis 20:1751-1762. https://doi.org/10.1111/1756$185 X .13194$

136. Kim Y-W, Kim D-I, Park YJ et al (2012) Surgical bypass vs endovascular treatment for patients with supra-aortic arterial occlusive disease due to Takayasu arteritis. J Vasc Surg 55:693-700. https:// doi.org/10.1016/j.jvs.2011.09.051

137. Klink T, Geiger J, Both M et al (2014) Giant cell arteritis: diagnostic accuracy of MR imaging of su perficial cranial arteries in initial diagnosis-results from a multicenter trial. Radiology 273:844-852. https://doi.org/10.1148/radiol.14140056

138. Kobayashi Y, Ishii T, Harigae H (2014) Takayasu's arteritis. In: Ball GV, Fessler BJ, Bridges SL (Hrsg) Oxf. Textb.Vasc., 3. Aufl. Oxford University Press, Oxford, S319-329

139. Koster MJ, Yeruva K, Crowson CSetal (2019) Efficacy of methotrexate in real-world management of giant cell arteritis: a case-control study. JRheumatol 46:501-508. https://doi.org/10.3899/ jrheum.180429

140. Kwon OC, Oh JS, Park M-C et al (2019) Statins reduce relapse rate in Takayasu arteritis. Int J Cardiol 287:111-115. https://doi.org/10.1016/j. ijcard.2019.02.046

141. Kyle V, Hazleman BL (1989) Treatment of polymyalgia rheumatica and giant cell arteritis. I. Steroid regimens in the first two months. Ann Rheum Dis 48:658-661

142. Labarca C, Koster MJ, Crowson CS et al (2016) Predictors of relapse and treatment outcomes in biopsy-proven giant cell arteritis: a retrospective cohort study. Rheumatology (Oxford) 55:347-356 https://doi.org/10.1093/rheumatology/kev348

143. Labarca C, Makol A, Crowson CS et al (2016) Retrospective comparison of open versus endovascular procedures for Takayasu arteritis. JRheumatol 43:427-432.https://doi.org/10.3899/ jrheum. 150447

144. Langford CA, Cuthbertson D, Ytterberg SR et al (2017) A randomized, double-blind trial of abatacept (CTLA-4lg) for the treatment of giant cell arteritis. Arthritis Rheumatol 69:837-845. https:// doi.org/10.1002/art.40044

145. Langford CA, Cuthbertson D, Ytterberg SR et al (2017) A randomized, double-blind trial of abatacept (CTLA-4lg) for the treatment of Takayasu arteritis. Arthritis Rheumatol 69:846-853. https:// doi.org/10.1002/art.40037

146. Lariviere D, Benali K, Coustet B et al (2016) Positron emission tomography and computed tomography angiography for the diagnosis of giant cell arteritis: a real-life prospective study.
Medicine (Baltimore) 95:e4146. https://doi.org/ 10.1097/MD.0000000000004146

147. Laurent C, Ricard L, Fain $O$ et al (2019) PET/MRI in large-vessel vasculitis: clinical value for diagnosis and assessment of diseaseactivity. SciRep 9:12388. https://doi.org/10.1038/s41598-019-48709-w

148. Lee B-B, Laredo J, Neville R, Villavicencio JL (2009) Endovascular management of takayasu arteritis: is it a durable option? Vascular 17:138-146. https:// doi.org/10.2310/6670.2009.00012

149. Lee MS, Smith SD, Galor A, Hoffman GS (2006) Antiplateletand anticoagulant therapy in patients with giant cell arteritis. Arthritis Rheum 54:3306-3309. https://doi.org/10.1002/art.22141

150. Leon L, Rodriguez-Rodriguez L, Morado I et al (2018) Treatment with methotrexate and risk of relapses in patients with giant cell arteritis in clinical practice. Clin Exp Rheumatol 36(Suppl 111):121-128

151. Les I, Pijoán Jl, Rodríguez-Álvarez R et al (2015) Effectiveness and safety of medium-dose prednisone in giant cell arteritis: a retrospective cohort study of 103 patients. Clin ExpRheumatol 33:90-97

152. Li J, Yang Y, Zhao J et al (2016) The efficacy of mycophenolate mofetil for the treatment of Chinese Takayasu's arteritis. Sci Rep 6:38687. https://doi.org/10.1038/srep38687

153. Lie JT (1990) Illustrated histopathologic classification criteria for selected vasculitis syndromes. American College of Rheumatology Subcommittee on Classification of Vasculitis. Arthritis Rheum 33:1074-1087. https://doi.org/10.1002/ art.1780330804

154. Liozon E, Roblot P, Paire D et al (2000) Anticardiolipin antibody levels predict flares and relapses in patients with giant-cell (temporal) arteritis. A longitudinal study of 58 biopsy-proven cases. Rheumatology (Oxford) 39:1089-1094

155. Loock J, Henes J, Kötter l et al (2012) Treatment of refractory giant cell arteritis with cyclophosphamide: a retrospective analysis of 35 patients from three centres. Clin Exp Rheumatol 30:S70-S76

156. Loricera J, Blanco R, Hernández JL et al (2015) Tocilizumab in giant cell arteritis: multicenter open-label study of 22 patients. Semin Arthritis Rheum 44:717-723. https://doi.org/10.1016/j. semarthrit.2014.12.005

157. Lottspeich C, Dechant C, Köhler A et al (2019) Assessment of disease activity in Takayasu arteritis: potential role of contrast-enhanced ultrasound. Ultraschall Med 40:638-645. https://doi.org/10. 1055/a-0817-5423

158. Luo XY, Wu QH, Zhang FX (2017) Open and endovascular management of severe cerebral ischemia in Takayasu's arteritis. Ann Vasc Surg 42:101-110. https://doi.org/10.1016/j.avsg.2017. 01.001

159. Luqmani R, Lee E, Singh S et al (2016) The role of ultrasound compared to biopsy of temporal arteries in the diagnosis and treatment of giant cell Arteritis (TABUL): a diagnostic accuracy and cost-effectiveness study. Health Technol Assess 20:1-238. https://doi.org/10.3310/hta20900

160. Ly KH, Dalmay F, Gondran G et al (2016) Steroid-sparing effect and toxicity of dapsone treatment in giant cell arteritis: a single-center, retrospective study of 70 patients. Medicine (Baltimore) 95:e4974. https://doi.org/10.1097/ MD.0000000000004974

161. Mackie SL, Hensor EMA, Morgan AW, Pease CT (2014) Should I send my patient with previous giant cell arteritis for imaging of the thoracic aorta? A systematic literature review and meta-analysis. 
Ann Rheum Dis 73:143-148. https://doi.org/10. 1136/annrheumdis-2012-202145

162. Maeda H, Handa N, Matsumoto Met al (1991) Carotid lesions detected by B-mode ultrasonography in Takayasu's arteritis: „macaroni sign“ as an indicator of the disease. Ultrasound Med Biol 17:695-701. https://doi.org/10.1016/0301-5629(91)90101-2

163. Mahr AD, Jover JA, Spiera RF et al (2007) Adjunctive methotrexate for treatment of giant cell arteritis: an individual patient data meta-analysis. Arthritis Rheum 56:2789-2797. https://doi.org/10.1002/ art.22754

164. Makkuni D, Bharadwaj A, Wolfe K et al (2008) Is intimal hyperplasia a marker of neuro-ophthalmic complications of giant cell arteritis? Rheumatology (Oxford) 47:488-490. https://doi.org/10.1093/ rheumatology/ken 012

165. Ma-Krupa W, Jeon M-S, Spoerl S et al (2004) Activation of arterial wall dendritic cells and breakdown of self-tolerance in giant cell arteritis. J Exp Med 199:173-183. https://doi.org/10.1084/ jem.20030850

166. Maleszewski JJ, Younge BR, Fritzlen JT et al (2017) Clinical and pathological evolution of giant cell arteritis: a prospective study of follow-up temporal artery biopsies in 40 treated patients. Mod Pathol 30:788-796. https://doi.org/10.1038/modpathol. 2017.10

167. Martinez-Lado L, Calviño-Díaz C, Piñeiro A et al (2011) Relapses and recurrences in giant cell arteritis: a population-based study of patients with biopsy-proven disease from northwestern Spain. Medicine (Baltimore) 90:186-193. https://doi.org/ 10.1097/MD.0b013e31821c4fad

168. Martínez-Taboada VM, López-Hoyos M, Narvaez J, Muñoz-Cacho P (2014) Effect of antiplatelet/ anticoagulant therapy on severe ischemic complications in patients with giant cell arteritis: a cumulative meta-analysis. Autoimmun Rev 13:788-794. https://doi.org/10.1016/j.autrev. 2014.02.006

169. Martínez-Taboada VM, Rodríguez-Valverde V, Carreño $L$ et al (2008) A double-blind placebo controlled trial of etanercept in patients with giant cell arteritis and corticosteroid side effects. Ann Rheum Dis 67:625-630. https://doi.org/10.1136/ ard.2007.082115

170. Mason JC (2018) Surgical intervention and its role in Takayasu arteritis. Best Pract Res Clin Rheumatol 32:112-124. https://doi.org/10.1016/j.berh.2018. 07.008

171. Matsuura K, Ogino $\mathrm{H}$, Kobayashi J et al (2005) Surgical treatment of aortic regurgitation due to Takayasu arteritis: long-term morbidity and mortality. Circulation 112:3707-3712. https://doi. org/10.1161/CIRCULATIONAHA.105.535724

172. Mazlumzadeh M, Hunder GG, Easley KA et al (2006) Treatment of giant cell arteritis using induction therapy with high-dose glucocorticoids: a doubleblind, placebo-controlled, randomized prospective clinical trial. Arthritis Rheum 54:3310-3318. https://doi.org/10.1002/art.22163

173. Mekinian A, Comarmond C, Resche-Rigon M et al (2015)Efficacy ofbiological-targeted treatmentsin Takayasu arteritis: multicenter, retrospective study of 49 patients. Circulation 132:1693-1700. https:// doi.org/10.1161/CIRCULATIONAHA.114.014321

174. Mekinian A, Néel A, Sibilia J et al (2012) Efficacy and tolerance of infliximab in refractory Takayasu arteritis: French multicentre study. Rheumatology (Oxford) 51:882-886. https://doi.org/10.1093/ rheumatology/ker380

175. Mekinian A, Resche-Rigon M, Comarmond C et al (2018) Efficacy of tocilizumab in Takayasu arteritis: multicenter retrospective study of 46 patients. J Autoimmun 91:55-60. https://doi.org/10.1016/j. jaut.2018.04.002

176. Miller DV, Maleszewski JJ (2011) The pathology of large-vessel vasculitides. Clin Exp Rheumatol 29:S92-98

177. Min P-K, Park S, Jung J-H et al (2005) Endovascular therapy combined with immunosuppressive treatment for occlusive arterial disease in patients with Takayasu's arteritis. J Endovasc Ther 12:28-34. https://doi.org/10.1583/12-01-04-1329.1

178. Mirouse A, Biard L, Comarmond C et al (2019) Overall survival and mortality risk factors in Takayasu's arteritis: a multicenter study of 318 patients. J Autoimmun 96:35-39. https://doi org/10.1016/j.jaut.2018.08.001

179. Misra DP, Wakhlu A, Agarwal V, Danda D (2019) Recent advances in the management of Takayasu arteritis. Int J Rheum Dis 22(Suppl 1):60-68 https://doi.org/10.1111/1756-185X.13285

180. Mollan SP, Sharrack N, Burdon MA, Denniston AK (2014) Aspirin as adjunctive treatment for giant cell arteritis. Cochrane Database Syst Rev. https://doi. org/10.1002/14651858.CD010453.pub2

181. Molloy ES, Langford CA, Clark TM et al (2008) Antitumour necrosis factor therapy in patients with refractory Takayasu arteritis: long-term follow-up. Ann Rheum Dis 67:1567-1569. https://doi.org/10. 1136/ard.2008.093260

182. Monti S, Águeda AF, Luqmani RA et al (2019) Systematic literature review informing the 2018 update of the EULAR recommendation for the management of large vessel vasculitis: focus on giant cell arteritis. RMD Open 5:e1003. https://doi. org/10.1136/rmdopen-2019-001003

183. Mukhtyar C, Guillevin L, Cid MC et al (2009) EULAR recommendations for the management of large vessel vasculitis. Ann Rheum Dis 68:318-323. https://doi.org/10.1136/ard.2008.088351

184. Muratore F, Boiardi L, Cavazza A et al (2016) Correlations between histopathological findings and clinical manifestations in biopsy-proven giant cell arteritis. J Autoimmun 69:94-101. https://doi. org/10.1016/j.jaut.2016.03.005

185. Muratore F, Cavazza A, Boiardi L et al (2016) Histopathologic findings of patients with biopsynegative giant cell arteritis compared to those without arteritis: a population-based study. Arthritis Care Res 68:865-870. https://doi.org/10. 1002/acr.22736

186. Muratore F, Kermani TA, Crowson CS et al (2015) Large-vessel giant cell arteritis: a cohort study. Rheumatology (Oxford) 54:463-470. https://doi. org/10.1093/rheumatology/keu329

187. Nakaoka Y, Higuchi K, Arita Y et al (2013) Tocilizumab for the treatment of patients with refractoryTakayasuarteritis. IntHeartJ54:405-411

188. Nakaoka Y, Isobe M, Takei S et al (2018) Efficacy and safety of tocilizumab in patients with refractory Takayasu arteritis: results from a randomised, double-blind, placebo-controlled, phase 3 trial in Japan (the TA)KT study). Ann Rheum Dis 77:348-354. https://doi.org/10.1136/ annrheumdis-2017-211878

189. Narváez J, Bernad B, Gómez-Vaquero C et al (2008) Impact of antiplatelet therapy in the development of severe ischemic complications and in the outcome of patients with giant cell arteritis. Clin Exp Rheumatol 26:S57-S62

190. Narváez J, Bernad B, Nolla JM, Valverde J (2007) Statin therapy does not seem to benefit giant cell arteritis. Semin Arthritis Rheum 36:322-327. https://doi.org/10.1016/j.semarthrit.2006.10.001
191. Narváez J, Bernad B, Roig-Vilaseca D et al (2007) Influence of previous corticosteroid therapy on temporal artery biopsy yield in giant cell arteritis. Semin Arthritis Rheum 37:13-19. https://doi.org/ 10.1016/j.semarthrit.2006.12.005

192. Nesher G, Berkun Y, Mates M et al (2004) Lowdose aspirin and prevention of cranial ischemic complications in giant cell arteritis. Arthritis Rheum 50:1332-1337. https://doi.org/10.1002/ art.20171

193. Nesher G, Nesher R, Mates M et al (2008) Giant cell arteritis: intensity of the initial systemic inflammatory response and the course of the disease. Clin Exp Rheumatol 26:S30-S34

194. Niederkohr RD, Levin LA (2007) A Bayesian analysis of the true sensitivity of a temporal artery biopsy. Invest Ophthalmol Vis Sci 48:675-680. https://doi. org/10.1167/iovs.06-1106

195. Nielsen BD, Gormsen LC, Hansen IT et al (2018) Three days of high-dose glucocorticoid treatment attenuates large-vessel 18F-FDG uptake in largevessel giant cell arteritis but with a limited impact on diagnostic accuracy. Eur J Nucl Med Mol Imaging 45:1119-1128. https://doi.org/10.1007/ s00259-018-4021-4

196. Nielsen BD, Hansen IT, Kramer S et al (2019) Simple dichotomous assessment of cranial artery inflammation by conventional 18F-FDG PET/CT shows high accuracy for the diagnosis of giant cell arteritis: a case-control study. Eur J Nucl Med Mol Imaging 46:184-193. https://doi.org/10.1007/ s00259-018-4106-0

197. Novikov PI, Smitienko IO, Moiseev SV (2013) Tumor necrosis factor alpha inhibitors in patients with Takayasu's arteritis refractory to standard immunosuppressive treatment: cases series and review of the literature. Clin Rheumatol 32:1827-1832. https://doi.org/10.1007/s10067013-2380-6

198. Novikov PI, Smitienko IO, Sokolova MV et al (2018) Certolizumab pegol in the treatment of Takayasu arteritis. Rheumatology (Oxford) 57:2101-2105. https://doi.org/10.1093/rheumatology/key197

199. Nunes G, NevesFS, Melo FM et al (2010) Takayasu arteritis:anti-TNF therapy in a Brazilian setting. Rev Bras Reumatol 50:291-298

200. Ohigashi H, Haraguchi G, Konishi M et al (2012) Improved prognosis of Takayasu arteritis over the past decade-comprehensive analysis of 106 patients. Circ J 76:1004-1011

201. Ohigashi H, Tamura N, Ebana Y et al (2017) Effects of immunosuppressive and biological agents on refractory Takayasu arteritis patients unresponsive to glucocorticoid treatment. J Cardiol 69:774-778. https://doi.org/10.1016/j.jjcc.2016.07.009

202. Omma A, Erer B, Karadag O etal (2017) Remarkable damage along with poor quality of life in Takayasu arteritis: cross-sectional results of a longterm followed-up multicentre cohort. Clin Exp Rheumatol 35(Suppl 103):77-82

203. Onen F, Akkoc N (2017) Epidemiology of Takayasu arteritis. Presse Med 46:e197-e203. https://doi. org/10.1016/j.lpm.2017.05.034

204. ParkHS, DoYS, ParkKB etal(2013) Long term results of endovascular treatment in renal arterial stenosi from Takayasu arteritis: angioplasty versus stent placement. Eur J Radiol 82:1913-1918. https://doi. org/10.1016/j.ejrad.2013.06.019

205. Park JW, Curtis JR, Moon J et al (2018) Prophylactic effect of trimethoprim-sulfamethoxazole forpneumocystis pneumonia in patients with rheumatic diseases exposed to prolonged high-dose glucocorticoids. Ann Rheum Dis 77:644-649. https:// doi.org/10.1136/annrheumdis-2017-211796 
206. Patil P, Williams M, Maw WW et al (2015) Fast track pathway reduces sight loss in giant cell arteritis: results of a longitudinal observational cohort study. Clin Exp Rheumatol 33:103-106

207. Pazzola G, Muratore F, Pipitone $\mathrm{N}$ et al (2017) Rituximab therapy for Takayasu arteritis: a seven patients experience and a review of the literature. Rheumatology (Oxford). https://doi.org/10.1093/ rheumatology/kex249

208. Prieto-González S, Arguis P, García-Martínez A et al (2012) Large vessel involvement in biopsyproven giant cell arteritis: prospective study in 40 newly diagnosed patients using $\mathrm{CT}$ angiography. Ann Rheum Dis 71:1170-1176. https://doi.org/10. 1136/annrheumdis-2011-200865

209. Proven A, Gabriel SE, Orces C et al (2003) Glucocorticoid therapy in giant cell arteritis: duration and adverse outcomes. Arthritis Rheum 49:703-708. https://doi.org/10.1002/art.11388

210. Pugnet G, Sailler L, Bourrel R et al (2015) Is statin exposure associated with occurrence or better outcome in giant cell arteritis? Results from a French population-based study. J Rheumatol 42:316-322. https://doi.org/10.3899/jrheum. 140906

211. Pugnet G, Sailler L, Fournier J-P et al (2016) Predictors of cardiovascular hospitalization in giant cell arteritis: effect of Statin exposure. A French population-based study. J Rheumatol 43:2162-2170. https://doi.org/10.3899/jrheum. 151500

212. Puppo C, Massollo M, Paparo F et al (2014) Giant cell arteritis: a systematic review of the qualitative and semiquantitative methods to assess vasculitis with $18 \mathrm{~F}$-fluorodeoxyglucose positron emission tomography. Biomed Res Int 2014:574248. https:// doi.org/10.1155/2014/574248

213. Quartuccio L, Maset M, De Maglio $G$ et al (2012) Role of oral cyclophosphamide in the treatment of giant cell arteritis. Rheumatology (Oxford) 51:1677-1686. https://doi.org/10.1093/ rheumatology/kes127

214. Quartuccio L, Schiavon F, Zuliani Fetal (2012) Longterm efficacy and improvement of health-related quality of life in patients with Takayasu's arteritis treated with infliximab. Clin Exp Rheumatol 30:922-928

215. Quinn EM, Kearney DE, Kelly J et al (2012) Temporal artery biopsy is not required in all cases of suspected giant cell arteritis. Ann Vasc Surg 26:649-654. https://doi.org/10.1016/j.avsg.2011. 10.009

216. Quinn KA, Ahlman MA, Malayeri AA et al (2018) Comparison of magnetic resonance angiography and $18 \mathrm{~F}$-fluorodeoxyglucose positron emission tomography in large-vessel vasculitis. Ann Rheum Dis 77:1165-1171. https://doi.org/10.1136/ annrheumdis-2018-213102

217. Raine C, Stapleton PP, Merinopoulos D et al (2018) A 26-week feasibility study comparing the efficacy and safety of modified-release prednisone with immediate-release prednisolone in newly diagnosed cases of giant cell arteritis. Int J Rheum Dis 21:285-291. https://doi.org/10.1111/1756185X.13149

218. Raninen RO, Kupari MM, Pamilo MS et al (1996) Arterial wall thickness measurements by B mode ultrasonography in patients with Takayasu's arteritis. Ann Rheum Dis 55:461-465. https://doi. org/10.1136/ard.55.7.461

219. Restuccia G, Boiardi L, Cavazza A et al (2016) Flares in biopsy-proven giant cell arteritis in northern Italy: characteristics and predictors in a long-term follow-up study. Medicine (Baltimore) 95:e3524. https://doi.org/10.1097/MD.0000000000003524

220. Restuccia G, Cavazza A, Boiardi L et al (2012) Small-vessel vasculitis surrounding an uninflamed temporal artery and isolated vasa vasorum vasculitis of the temporal artery: two subsets of giant cell arteritis. Arthritis Rheum 64:549-556. https://doi.org/10.1002/art.33362

221. Riambau V, Böckler D, Brunkwall J et al (2017) Editor's choice-management of descending thoracic aorta diseases: clinical practice guidelines of the European Society for Vascular Surgery (ESVS). Eur J Vasc Endovasc Surg 53:4-52. https:// doi.org/10.1016/j.ejvs.2016.06.005

222. Rosa Neto NS, Shinjo SK, Levy-Neto M, Pereira RMR (2017) Vascular surgery: the main risk factor for mortality in 146 Takayasu arteritis patients. Rheumatol Int 37:1065-1073. https://doi.org/10 1007/s00296-017-3656-y

223. Saadoun D, Lambert M, Mirault Tet al (2012) Retrospective analysis of surgery versus endovascular intervention in Takayasu arteritis: a multicenter experience. Circulation 125:813-819. https://doi. org/10.1161/CIRCULATIONAHA.111.058032

224. Salvarani C, Cimino L, Macchioni P et al (2005) Risk factors for visual loss in an Italian populationbased cohort of patients with giant cell arteritis. Arthritis Rheum 53:293-297. https://doi.org/10. 1002/art.21075

225. Salvarani C, Silingardi M, Ghirarduzzi A et al (2002) Is duplex ultrasonography useful for the diagnosis of giant-cell arteritis? Ann Intern Med 137:232-238. https://doi.org/10.7326/00034819-137-4-200208200-00006

226. Sammel AM, Hsiao E, Schembri G et al (2019) Diagnostic accuracy of positron emission tomography/ computed tomography of the head, neck, and chest for giant cell arteritis: a prospective, doubleblind, cross-sectional study. Arthritis Rheumatol 71:1319-1328. https://doi.org/10.1002/art.40864

227. Samson M, Jacquin A, Audia S et al (2015) Stroke associated with giant cell arteritis: a populationbased study. J Neurol Neurosurg Psychiatry 86:216-221. https://doi.org/10.1136/jnnp-2014307614

228. Sanchez-Alvarez C, Mertz LE, Thomas CS et al (2019) Demographic, clinical, and radiologic characteristics of a cohort of patients with Takayasu arteritis. Am J Med 132:647-651. https://doi.org/ 10.1016/j.amjmed.2018.12.017

229. Schäfer VS, Chrysidis S, Dejaco C et al (2018) Assessing vasculitis in giant cell arteritis by ultrasound: results of OMERACT patient-based reliability exercises. J Rheumatol 45:1289-1295. https://doi.org/10.3899/jrheum.171428

230. Schaufelberger C, Andersson R, Nordborg E (1998) No additive effect of cyclosporin a compared with glucocorticoid treatment alone in giant cell arteritis: results of an open, controlled, randomized study. Br J Rheumatol 37:464-465

231. Schaufelberger $C$, Möllby $H$, Uddhammar A et al (2006) No additional steroid-sparing effect of cyclosporine a in giant cell arteritis. Scand J Rheumatol 35:327-329. https://doi.org/10.1080/ 03009740500474537

232. Schmidt D, Löffler KU (1994) Temporal arteritis. Comparison of histological and clinical findings. Acta Ophthalmol (Copenh) 72:319-325

233. Schmidt J, Kermani TA, Bacani AK et al (2012) Tumor necrosis factor inhibitors in patients with Takayasu arteritis: experience from a referral center with long-term followup. Arthritis Care Res 64:1079-1083. https://doi.org/10.1002/acr.21636
234. Schmidt J, Smail A, Roche B et al (2016) Incidence of severe infections and infection-related mortality during the course of giant cell arteritis: a multicenter, prospective, double-cohort study. Arthritis Rheumatol 68:1477-1482. https://doi. org/10.1002/art.39596

235. Schmidt WA, Moll A, Seifert A et al (2008) Prognosis of large-vessel giant cell arteritis. Rheumatology (Oxford) 47:1406-1408. https://doi.org/10.1093/ rheumatology/ken258

236. Schmidt WA, Seifert A, Gromnica-Ihle Eet al (2008) Ultrasound of proximal upper extremity arteries to increase the diagnostic yield in large-vessel giant cell arteritis. Rheumatology (Oxford) 47:96-101. https://doi.org/10.1093/rheumatology/kem322

237. Seeliger B, Sznajd J, Robson JC et al (2017) Are the 1990 American College of Rheumatology vasculitis classification criteria still valid? Rheumatology (Oxford) 56:1154-1161. https://doi.org/10.1093/ rheumatology/kex075

238. Seko Y, Minota S, Kawasaki A et al (1994) Perforinsecreting killer cell infiltration and expression of a $65-\mathrm{kD}$ heat-shock protein in aortic tissue of patients with Takayasu's arteritis. J Clin Invest 93:750-758. https://doi.org/10.1172/JCl117029

239. Seror R, Baron G, Hachulla E et al (2014) Adalimumab for steroid sparing in patients with giant-cell arteritis: results of a multicentre randomised controlled trial. Ann Rheum Dis 73:2074-2081. https:// doi.org/10.1136/annrheumdis-2013-203586

240. Serra R, Grande R, Buffone G et al (2014) Effects of glucocorticoids and tumor necrosis factoralpha inhibitors on both clinical and molecular parameters in patients with Takayasu arteritis. JPharmacol Pharmacother 5:193-196. https://doi. org/10.4103/0976-500X.136101

241. Shao N, Jia H, Li Y, Li J (2017) Curcumin improves treatment outcome of Takayasu arteritis patients by reducing TNF-a: a randomized placebocontrolled double-blind clinical trial. Immunol Res 65:969-974. https://doi.org/10.1007/s12026017-8917-z

242. Sharma BK, Jain S, Suri S, Numano F (1996) Diagnostic criteria for Takayasu arteritis. Int J Cardiol 54(Suppl):S141-S147

243. Sharma BK, Siveski-lliskovic N, Singal PK (1995) Takayasu arteritis may be underdiagnosed in North America. Can J Cardiol 11:311-316

244. Sharma S, Sharma S, Taneja K et al (1998) Morphological mural changes in the aorta in non-specific aortoarteritis (Takayasu's arteritis): assessment by intravascular ultrasound imaging. Clin Radiol 53:37-43

245. Shi G, Hua M, Xu Q, Ren T (2017) Resveratrol improves treatment outcome and laboratory parameters in patients with Takayasu arteritis: a randomized double-blind and placebo-controlled trial. Immunobiology 222:164-168. https://doi org/10.1016/j.imbio.2016.10.008

246. Shinjo SK, Pereira RMR, Tizziani VAP et al (2007) Mycophenolate mofetil reduces disease activity and steroid dosage in Takayasu arteritis. Clin Rheumatol 26:1871-1875. https://doi.org/10. 1007/s10067-007-0596-z

247. Slart RHJA et al (2018) FDG-PET/CT(A) imaging in large vessel vasculitis and polymyalgia rheumatica: joint procedural recommendation of the EANM, SNMMI, and the PET Interest Group (PIG), and endorsed by the ASNC. Eur J Nucl Med Mol Imaging 45:1250-1269. https://doi.org/10.1007/s00259018-3973-8

248. de Souza AWS, de Almeida Agustinelli $R$, de Cinque Almeida $\mathrm{H}$ et al (2016) Leflunomide in Takayasu arteritis-A long term observational study. Rev 
Bras Reumatol. https://doi.org/10.1016/j.rbr.2015. 09.007

249. de Souza AWS, Machado NP, Pereira VM et al (2010) Antiplatelet therapy for the prevention of arterial ischemic events in Takayasu arteritis. Circ J 74:1236-1241

250. de Souza AWS, da Silva MD, Machado LSG et al (2012) Short-term effect of leflunomide in patients with Takayasu arteritis: an observational study. Scand J Rheumatol 41:227-230. https://doi.org/ 10.3109/03009742.2011.633553

251. Spiera RF, Mitnick HJ, Kupersmith M et al (2001) A prospective, double-blind, randomized, placebo controlled trial of methotrexate in the treatment of giant cell arteritis (GCA). Clin Exp Rheumatol 19:495-501

252. Stone JH, Bao M, Han J et al (2019) Long-term outcome of Tocilizumab for patients with giant cell arteritis: results from part 2 of the GiACTA trial. Ann Rheum Dis 78(Suppl 2):A145

253. Stone JH, Tuckwell K, Dimonaco S et al (2017) Trial of tocilizumab in giant-cell arteritis. N Engl J Med 377:317-328. https://doi.org/10.1056/ NEJMoa1613849

254. Stone JH, Tuckwell K, Dimonaco S et al (2019) Glucocorticoid dosages and acute-phase reactant levels at giantcellarteritis flare in a randomized trial of Tocilizumab. Arthritis Rheumatol 71:1329-1338. https://doi.org/10.1002/art.40876

255. Strehl C, Bijlsma JWJ, de Wit M et al (2016) Defining conditions where long-term glucocorticoid treatment has an acceptably low level of harm to facilitate implementation of existing recommendations: viewpoints from an EULAR task force. Ann Rheum Dis 75:952-957. https://doi.org/10.1136/ annrheumdis-2015-208916

256. Suematsu R, TashiroS, Ono N etal (2018) Successful golimumab therapy in four patients with refractory Takayasu's arteritis. Mod Rheumatol 28:712-715. https://doi.org/10.3109/14397595.2015.1134393

257. Tengesdal S, Diamantopoulos AP, Myklebust G (2019) Leflunomide versus methotrexate in treatment of giant cell arteritis: comparison of efficacy, safety, and drug survival. Scand J Rheumatol 48:333-335. https://doi.org/10.1080/ 03009742.2019 .1575980

258. Terao C, Yoshifuji H, Nakajima T et al (2016) Ustekinumab as a therapeutic option for Takayasu arteritis: from genetic findings to clinical application.Scand J Rheumatol 45:80-82. https://doi.org/ 10.3109/03009742.2015.1060521

259. Tombetti E, Franchini S, Papa M et al (2013) Treatment of refractory Takayasu arteritis with tocilizumab: 7 Italian patients from a single referral center. J Rheumatol 40:2047-2051. https://doi. org/10.3899/jrheum.130536

260. Treitl KM, Maurus S, Sommer NN et al (2017) 3Dblack-blood 3T-MRI for the diagnosis of thoracic large vessel vasculitis: a feasibility study. Eur Radiol 27:2119-2128. https://doi.org/10.1007/s00330016-4525-x

261. Uddhammar A, Eriksson A-L, Nyström L et al (2002) Increased mortality due to cardiovascular disease in patients with giant cell arteritis in northern Sweden. JRheumatol 29:737-742

262. Valsakumar AK, Valappil UC, Jorapur V et al (2003) Role of immunosuppressive therapy on clinical, immunological, and angiographic outcome in active Takayasu's arteritis. JRheumatol 30:1793-1798

263. Villiger PM, Adler S, Kuchen S et al (2016) Tocilizumab for induction and maintenance of remission in giant cell arteritis: a phase 2, randomised, double-blind, placebo-controlled trial. Lancet 387:1921-1927. https://doi.org/10. 1016/S0140-6736(16)00560-2

264. Wang X, Dang A, Lv N et al (2017) Long-term outcomes of coronary artery bypass grafting versus percutaneous coronary intervention for Takayasu arteritis patients with coronary artery involvement. Semin Arthritis Rheum 47:247-252. https://doi.org/10.1016/j.semarthrit.2017.03.009

265. Warrington KJ, Weyand CM (2014) Giant cell arteritis and polymyalgia rheumatica. In: Ball GV, Fessler BJ, Bridges SL (Hrsg) Oxf. Textb. Vasc., 3. Aufl. Oxford University Press, Oxford, S307-318

266. Watts R, Al-Taiar A, Mooney J et al (2009) The epidemiology of Takayasu arteritis in the UK. Rheumatology (Oxford) 48:1008-1011. https:// doi.org/10.1093/rheumatology/kep153

267. Weaver FA, Kumar SR, Yellin AE et al (2004) Renal revascularization in Takayasu arteritis-induced renal artery stenosis. J Vasc Surg 39:749-757. https://doi.org/10.1016/j.jvs.2003.12.022

268. Weiner SM, Bergner R (2015) Dosage and toxicity of antirheumatic drugs in renal insufficiency. Z Rheumatol 74:300-309. https://doi.org/10. 1007/s00393-014-1480-2

269. Weyand CM, Goronzy JJ (2003) Medium- and large-vessel vasculitis. N Engl J Med 349:160-169. https://doi.org/10.1056/NEJMra022694

270. Wilson JC, SarsourK, Collinson Netal (2017) Serious adverse effects associated with glucocorticoid therapy in patients with giant cell arteritis (GCA): a nested case-control analysis. Semin Arthritis Rheum 46:819-827. https://doi.org/10.1016/j. semarthrit.2016.11.006

271. Wilson JC, Sarsour K, Collinson N et al (2017) Incidence of outcomes potentially associated with corticosteroid therapy in patients with giant cell arteritis. Semin Arthritis Rheum 46:650-656. https://doi.org/10.1016/j.semarthrit.2016.10.001

272. Xiao Y, Zhou J, Wei X et al (2016) Outcomes of different treatments on Takayasu's arteritis. J Thorac Dis 8:2495-2503. https://doi.org/10. 21037/jtd.2016.08.12

273. Yachoui R, Kreidy M, Siorek M, Sehgal R (2018) Successful treatment with ustekinumab for corticosteroid- and immunosuppressant-resistant Takayasu's arteritis. Scand J Rheumatol 47:246-247. https://doi.org/10.1080/03009742. 2017.1278788

274. Yamada I, Nakagawa T, Himeno Y et al (2000) Takayasu arteritis: diagnosis with breath-hold contrastenhanced three-dimensional MR angiography. J Magn Reson Imaging 11:481-487

275. Yang Y, Tian T, Yang K et al (2017) Outcomes of percutaneous coronary intervention and coronary artery bypass grafting in patients with Takayasu arteritis. Int J Cardiol 241:64-69. https://doi.org/ 10.1016/j.ijcard.2017.02.041

276. Yates M, MacGregor AJ, Robson J et al (2017) The association of vascular risk factors with visual loss in giant cell arteritis. Rheumatology (Oxford) 56:524-528. https://doi.org/10.1093/ rheumatology/kew397

277. Yilmaz N, Can M, Oner FA et al (2013) Impaired quality of life, disability and mental health in Takayasu's arteritis. Rheumatology (Oxford) 52:1898-1904. https://doi.org/10.1093/rheumatology/ket238

278. Ypsilantis E, Courtney ED, Chopra N et al (2011) Importance of specimen length during temporal artery biopsy. Br J Surg 98:1556-1560. https://doi. org/10.1002/bjs.7595

279. Zhou J, Chen Z, Li J et al (2017) The efficacy of tocilizumab for the treatment of Chinese Takayasu's arteritis. Clin Exp Rheumatol 35(Suppl 103):171-175 